(Aus der König1. Universitäts-Frauenklinik München. Director: Geheimrath Prof. Dr. Ritter Franz v. Winckel.)

\title{
Ueber die Histologie der Adenocarcinome im Uterusfundus.
}

Von

\section{Dr. Offergeld,}

(Hierzu Tafel V.)

Für die malignen, epithelialen Neubildungen im Uteruskörper hat sich die nachfolgende, dem Lehrbuche von Kaufmann ${ }^{1}$ ) entnommene Eintheilung gut bewährt, hauptsächlich deshalb, weil sie auf den histologischen Unterschieden der Geschwülste aufgebaut ist. Hiernach unterscheidet man Tumoren:

I. ausgehend vom Drüsenepithel:

a) Adenoma malignum

a) einschichtige Epithellage

B) uniformes Epithel (meist nur in der Cervix vorkommend),

b) Adenocarcinom,

c) papilläres Adenocarcinom,

d) Carcinoma solidum,

e) verhorntes Plattenepithelcarcinom (selten entstanden durch Metaplasie);

II. ausgehend vom Oberflächenepithel und Hornkrebs (meist entstanden durch Metaplasie).

So häufig das Carcinom die mehr distalen Partien des Uterus befällt, so selten wird man es im Corpus finden; nur $5-6 \mathrm{pCt}$. aller Uteruscarcinome sind im Fundus localisirt. Klinisch ist es das am meisten gutartige Carcinom der weiblichen Geschlechts-

1) Kaufmann, Lehrbuch der spec. path. Anatomie. Berlin. 1896. 
organe, soweit natürlich sich der Begriff der Benignität mit einem Carcinom vertragen lässt; das geht am besten wohl daraus hervor, dass es eine ausgesprochene Erkrankung des Greisenalters hinsichtlich der physiologischen Function der Genitalien des Weibes ist; während nach Krukenberg's ${ }^{1}$ ) Statistik das Durchschnittsalter ə3,7 betrïgt, hat gar Hofmeier ${ }^{2}$ ) als Mittel 54,5 Jahre herausgerechnet; man sieht also, dass gewöhnlich die Erkrankung ein schon der senilen Atrophie anheimgefallenes Organ ergreift, in welchem natürlich yon einem regen Stoffwechsel keine Rede mebr sein kann. In Folge dessen ist sein Wachsen auch nur ein sehr langsames und es wird meist noch dadurch beeinträchtigt, dass sich das Endo- und auch das Myometrium im Zustande der chronisch-interstitiellen Entzündung befindet, wodurch eine Vergrösserung und Verdickung des ganzen Organes bedingt wird.

Nur langsam schieben die Corpuscarcinome sich gegen die Muscularis vor und erst in den Endstadien buchten sie die Serosa vor oder brechen in die Peritonealhöhle durch; makroskopisch ist die Grenze gegen das Gesunde stets scharf. Da aber die jungen, sprossenden Zellen sehr leicht durch die Flora der vaginalen Bakterien irritirt werden, so kommt es bald zur Verjauchung and Vereiterung der Geschwulst, und da meist durch eine Stenose am inneren Yuttermund der Abfluss des Sekretes gehemmt wird, zur Retention im Cavum selbst - Pyometra genannt -, der dann meist schnell das Epithel des Uterus erliegt. Die weitere Verbreitung geschieht central- und peripherwärts. Zunächst machen sie Metastasen in der Cervix, an der Portio und der Vagina. Hier soll nach Pfannenstiel ${ }^{3}$ ) es sich um Spontanimpfung versehleppter Zellen im Sekret der Pyometra handeln, wogegen Hofmeient) an echte Impfmotastasen im Sinne von Winter glaubt. Während Lebensbaum ${ }^{5}$ ), Fischer ${ }^{6}$ ) und Hesse ${ }^{7}$ ) ihre distalen Metastasen beim Corpuscarcinom durch die Pfannenstiel'sche Hypothese erklären, will

1) Krukenberg, Citirt naoh Gobhard, Path. Anatomie der weiblichen Sexualorgane. Leipzig. 1899.

2) Hofmeier, Ebendaselbst.

3) Pfannonstiel, Centralblatt f. Gynäk. 1893.

4) Hofmeier, Münchener med. Woohenschr. 1890.

5) Lebensbaum, Centralbl. f. Gynäk. 1893.

6) Fischer, Zeitschr. f. Geburtsh. u. Gynäk. Bd. 21.

7) Hesse, Dissert. Jena. 1896. 
Offergeld, Ueber die Histologie der Adenocarcinome im Uterusfundus. 291

Kaufmann ${ }^{1}$ ) auch einen anderen Modus der Metastasirung gelten lassen.

Selten sind auch die regionären Tochtergeschwülste in der Mucosa des Corpus selbst. Ueber die Verbreitung in den Lymphbahnen sei verwiesen auf die treffliche Arbeit von Seelig²) and die jüngere Publication von Kroemera ${ }^{3}$. Besonders aber sind die Bahnen zu erwähnen, welche entlang der Spermatica zur Wirbelsäule laufen und sich dort am unteren Pol der Niere in die Drüsen an den grossen Gefässen einsenken (untere, lumbale Drüsen), und die, welche vom Collum herstammend nach Aufnahme der Lymphwege des Fundus im oberen Theil des Ligament. latum verlaufend zum Ovarium hinziehen. Diese Bahnen scheinen gelegentlich mit Vorliebe beim Corpuscarcinom befallen zu werden, berichtet doch Littauer ${ }^{4}$ ) über 14 Fälle von Carcinom des Uterus, wo im Ovarium sich Metastasen fanden; $12 \mathrm{mal}$ lag ein Funduscarcinom, nur 2 mal ein Collumcarcinom ror; im Uebrigen sind auch diese Fälle sehr selten.

Erst nach Durchbruch des serösen Ueberzuges in den letzten Stadien kann die carcinomatöse Infiltration längs der Bahnen der Ligamenta rotunda bis zu den Inguinaldrüsen fortschreiten. Interessant ist auch der von Gebhards) mitgetheilte Fall, wo sich eine Metastase im subperitonealen Fettgewebe der vorderen Batchwand vorfand; weiterhin die von $\mathrm{Blau}^{6}$ ) und Dybowsky ${ }^{7}$ publieirten Metastasen in Nabel und Blase. Dass aber Blau's Statistik sicher falseh ist, habe ich unlängst erst hervorgehoben (ef. Monatsschrift f. Geburtsh. a. Gynäk. Bd. 22. Heft 4).

Die Matrix der Corpuscarcinome ist entweder das Epithel der Drüsen oder der Oberfläche; im ersteren Falle kommt es zur Bildung von Drüsenimitationen (Adenocarcinom) oder. solider Zellhaufen (Carcinoma solidum und simplex); im letzteren geschieht zuerst eine Metaplasie von Cylinderepithel in Plattenepithel, welches verhornt; erst das Plattenepithel wächst in soliden Strängen in die Muscularis hinein.

1) Kaufmann, Lehrbuch der spec. path. Anat. Wiesbaden. 1896.

2) Seelig, Preisschrift Strassburg a. M. Virchow's Arch. Bd. 140.

3) Kroemer, Monatsschr. f. Geburtsh. u. Gynäk, Bd. 1.

4) Littauer, Centralbl. f. Gynäk. 1895.

5) Gebhard, Path. Anatomie der weibl. Sexualorgane. Leipzig. 1899.

6) Blau, Dissertat. Berlin. 1870. Charité-Annalen. 1890.

7) Dybowsky, Dissertat. Berlin. 1880. 
292 Offergeld, Ueber die Histologie der Adenocarcinome im Uterusfundus.

Was das Deckepithelaarcinom angeht, nur so viel, als zum Verständniss der Adenocarcinome nöthig ist. In wie weit die Metaplasie von Cylinder-zu. Plattenepithel möglich ist, steht noch dahin; schon die blosse Transformation des ersteren zu mehrschichtigem Plattenepithel wird von verschiedenen Autoren direct als ein Forstadium des Hornkrebses angesprochen. Im Uebrigen sind die Oberflächencarcinome sehr selten; Pseudocarcinome finden sich zwar häufiger durch Umwandlung beider Epithelgattungen, jedoch ist hierbei der Process nur auf die Oberfläche beschränkt, er ähnelt der von einzelnen Pathologen behaupteten Metaplasie von Cylinderzu Plattenepithel bei der bronchiektatischen Caverne und der Urethralstrictur nach Gonorrhoe; Veit und ZelIner nennen diesen Vorgang Ichthyosis uterina oder Epidermisirung. Anders bei den echten Oberflächencarcinomen. Die neugebildeten Plattenepithelien dringen in Form solider Zapfen in die Tiefe weit über die Mucosa in die Musculatur hinein; sie haben ein grosses Proliferations- und Theilungsvermögen, wie an ihren zahlreichen Mitosen, besonders an den Riesenmitosen, die Riesenzellen mit vielen Kernen liefern, unschwer zu erkennen ist. Diese Zapfen sind meist diffus in und über die ganze Mucosa des. Fundus vertheilt; Gebhardy) hat hierfür passender Weise die Bezeichnung , Znckerguss ${ }^{\text {th }}$ vorgeschlagen. Andererseits kann auch von einer in Plattenepithel übergegangenen Stelle sich ein Oberflächencarcinom entwickeln; dieser Fälle sind nur sehr wenige publicirt [Piering $\left.{ }^{2}\right)$, Flaischlen ${ }^{3}$ ), Emmanuel4), Gellkorn ${ }^{5}$, Hofmeier ${ }^{6}$, Kaufmann 7 , Gebhard ${ }^{1}$, Eekardt ${ }^{8}$ ), Zabulotzky $\mathrm{y}^{\mathrm{g}}$ ]; der directe Ausgangspunkt war in keinem dieser

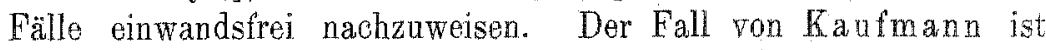
gerade deshalb besonders interessant, weil neben dem verhornten Carcinom des. Deckepithels ein Adenocarcinom im Corpus bestand, also bei der gleichen Patientín beide Epithelarten des Corpus sich

1) Gebhard, Zeitschr. f. Geburtsh. u. Gyn. Bd. 24.

2) Piering, Zeitschr. f. Heilkunde. Bd. VIII. Wien. 1887.

3) Flaischlen, Zeitschr. f. Geburtsh. u. Gynäk. Bd. 32.

4) Emmanuel, Ebendas. Bd. 32.

5) Gellkorn, Ebendas. Bd. 36.

6) Hofmeier, Ebendas. Bd. 32.

7) Ka ufmann, Gesellschaft f. vaterländische Kultur. Breslau. Sitzuny vom 5. Mai 1894.

8) Eckardt, Dieses Archiv. Bd. 55.

9) Zabulotzky, Nouv. arch. d'obstr. et de gynéls. Tom. Vol. K. 
in pathologischer Proliferation befanden. Gebhard lässt es offen, ob eine Epidermoidalisation der Cancroidbildung vorausging; Friedländer ${ }^{1}$ ) ist geneigt, diese Frage zu bejahen in seinem Falle; als Ursache der Metaplasie bei dem kindlichen Uterus glaubt er die Infectionskrankheit ansprechen zu müssen. Flaischlen ${ }^{2}$ ) und Fränkelª) erklären die Pyometra als das Agens, welches die Metaplasirung des Epithels bedinge, oder mindest hierzu sehr geeignet mache. Während die von v. Rosthorn ${ }^{4}$ ) u. Flaischlen ${ }^{2}$ ) publicirten Fälle direct durch Metaplasie von Oberflächen- zu Plattenepithel entstanden sind, und letzteres erst atypisch gewuchert ist, soll es sich in dem von Pfannenstiel ${ }^{5}$ ) veröffentlichten Falle nur um ein secundäres Corpuscarcinom gehandelt haben, indem ein primärer Cervixknoten durch Ueberwuchern des inneren Muttermundes in das Corpus uteri gelangte. Nun ist es ganz interessant, dass Fränkelia) solche Stellen auch bei Drüsencarcinomen gefunden hat; an solchen Partien traf er Zellen an, welche Plattenepithelien sehr ähnelten, diese wucherten in die Tiefe als solide Stränge.

Ungemein selten, von vielen Autoren sogar direct geleugnet ist die Metaplasie bei den Drüsencarcinomen im Fundus; diese entstehen vielmehr durch directe Umwandlung des normalen Drüsenepithels in das Carcinom, sei es nun mit oder ohne adenomatöses Vorstadium. Da in der Regel dieses vorhanden ist, so ist das Erste der Beginn einer excessiven Drüsenwucherung unter Beibehaltung des Drüsentypus, so dass lange Zeit die Mehrschichtigkeit des Epithels ausbleibt. Nur selten beginnt sofort das wilde, mehrschichtige Epithellagen erzeugende Wachsthum, so dass das Stadium des Adenoms in Wegfall kommt. Es nimmt seinen Ursprung stets von einer eng umgrenzten Stelle der Mucosa, in deren Umgebung sich dann eine beträchtliche entzündliche Reaction mit kleinzelliger Infiltration einstellt. Sein Wachsen ist in der Hauptsache ein flächenhaftes, daher mitunter die ganze Corpusschleimhaut mit disseminirten Knötchen besetzt ist, ohne jedoch an der Muscularis Halt zu machen, sondern, wenn auch nur langsam, geht es auch in diese hinein. Das primäre Corpuscarcinom überschreitet nie

1) Friedländer, Zeitschr. f. Geburtsh. u. Gynäkol. Bd. 38.

2) Flaischlen, Zeitschr. f. Geburtsh. u. Gynäkol. Bd. 32.

3) Fränkel, Hegar's Beiträge zur Geburtsh. u. Gynäkol. Bd. II. H. 3.

4) v. Rosthorn, Festschr. z. 50jährigen Jubiläum der Berliner gynähoIogischen Gesellschaft.

5) Pfannenstiel, Centralbl. f. Gynäkol. 1893. 
294 Offergeld, Ueber die Histologie der Adenocarcinome im Uterusfundus.

das Orificium internum (anderes Epithel nach der Ansicht mancher Autoren), wenn es auch die ganze Fundushöhle ausfüllen kann, erst ganz spät wird secundär, vielleicht auf dem Blutwege, vielleicht auch durch die Lymphbahnen die Cervix und die Portio ergriffen. Wenn man von den seltenen Fällen absieht, wo das Funduscarcinom als gestielter carcinomatöser Polyp auftritt, dessen Stiel aus der Submucosa besteht, und wo die maligne Epithelproliferation nur an der Spitze Platz gegriffen hat, also an der Stelle, welche frei in das Cavum nteri hineinragt, während die ubrige Mucosa und besonders das Myometrium intact ist, und wo man therapeutisch blos mit der Curette oder der Abtragung des Polypen unter Zurücklassung des Stieles und des ganzen Uterus definitive Heilung erzielt, so bilden die circumscripten Carcinome entweder kraterartige Ulcera mit infiltrirten Rändern, oder lassen sich, mag ihre Grösse eine auch noch so wechselnde sein, in folgende 3 Unterabtheilungen einbringen. Entweder hat dio Gewebsneubildung in mehr gleichmässiger Weise stattgefunden, so dass ein Knollen in das Cayum hineinragt (Ca. tuberosum), oder an mehreren Stellen gleichzeitig unter Production kleiner Knötchen mit Rundzelleninflitration im benachbarten Stroma (Ca. papillare), oder man trifft bleine, derbe, in Wasser flottirende Zotten an (Ca. villosum). Ihre Entstehung ist eine doppelte: einmal durch eine ausgiebige Drüsenwucherung im Verein mit reicher Neubildung gefässhaltigen Bindegewebes und sodanm durch ein usurirendes Eindringen von Drüsengewebe in das Myometrium hinein; diese Möglichkeit ist hente durchaus zuzulassen, da man bisweilen in den carcinomatösen Zotten noch intacte glatte Muskeln aus der Wand findet.

Die hauptsächlichste Eigenthümlichkeit der Drüsencarcinome ist die Bildung gesehlossener Epithelverbände unter Beibehaltung eines centralen Lumens und der Sekretionsfähigkeit der Zellen, deren Producte im Verein mit Transsudationsvorgängen in der Nachbarschaft und Degeneration in den Zellen selbst im Gewebe liegen bleiben und dadurch Oysten erzengen, während das Bindegewebe sich gleichzeitig vermehrt (Cystadenocarcinome). Gleich wie die Drüsencarcinome anderer Organe (Haut, Schleimhäute, Intestinaltractus) aus den drüsigen Anhängen und Einstülpungen entstehen, so anch die des Uterus; die Zellformation ist cylindrisch, cubisch oder so variabel, dass man sie in keine Rubrik unterbringen kann, also polymorph.

Was nun die Histogenese der Drüsenearcinome angeht, 
so ist diese gerade so wenig geklärt, wie die der Carcinome überhaupt; nachdem für letatere die alten Anschaungen von Virchow ${ }^{1}$, der eine echte Metaplasie aus Bindegewebe annahm, und Koester ${ }^{2}$, der sie von den Endothelien der Gefässe und Lymphbahnen herzuleiten versuchte, sich längst als falsch er-wiesen haben, neigt man ja heute bekanntlich immer mehr der Ansicht zu, dass der Mutterboden eines Carcinoms sich meist unverändert erhalten hat, dass besonders eine vom embryonalen Leben herrührende Störung fehlt. Während Thiersch ${ }^{3}$ ) die primäre Schädigung in einer Schwächung des Bindegewebes erblickt, während Hauser ${ }^{4}$ ) und Hansemann ${ }^{5}$ ) nur eine Aenderung seines fibrillären Charakters annehmen, ohne aber hierfür einen Beweis zu erbringen, ist ja sicherlich die interessanteste Theorie die, welche Ribbert6) für die fibro-epithelialen Tumoren, also auch für die Carcinome, aufgestellt hat. Sie gehen hervor aus einem dem normalen Wachsthum entsprechenden, gleichzeitigen Wuchern von Bindegewebe and Epithel; letzteres wird nicht einfach abgehoben von den mesodermalen Derivaten, sondern zeigt selbst lebhafte Wachsthumserscheinungen, wie wohl es für sich allein nicht in das Bindegewebe vordringen kann, sondern das Primäre soll die Wucherung des Bindegewebes selbst sein durch Aufhebung der normalen Spannung der Gewebe. In diesem Stroma bleiben Lücken frei, in welchen sich Epithelien einlegen, so, dass entweder die Maschen ganz angefüllt werden, oder sie sich um ein central gelegenes Lumen gruppiren, also den drüsigen Bau imitiren. Die Ausscheidung der Epithelien aus dem normalen Verbande geschieht durch embryonale Keimausschaltung - früher Aberration genannt -, Traumen oder Entzündungen; diese dislocirten Zellen bewahren ein enormes Proliferationsvermögen, dringen in die erweiterten Bindegewebslücken und Lymphbahnen vor, so dass entweder anastomosirende Zellstränge oder unregelmässig gestaltete Räume im Bindegewebe entstehen, welche als Alveolen imponiren. Dies gilt für den Typus der fibro-epithelialen Geschwulst, das Adenom; obschon

1) Virchow, Virch. Archiv. Bd. 3.

2) Koester, Entwicking der Carcinome. Würzburg 1869.

3) Thiersch, Der Epithelkrebs der Haut, Leipzig 1873.

4) Hauser, Virch. Archiv. Bd. 138, 141.

5) Hansemann, Virch. Arch. Bd. 119.

6) Ribbert, Virch. Arch. Bd. 135, 141. Das pathologische Wachsthum. Bonn 1896. 
296 Offergeld, Ueber die Histologie der Adenocarcinome im Uterusfundus.

nach Ribberi'1) die Carcinome häufig aus ihnen entstehen sollen, unterscheiden sie sich von ihnen durch ein selbständiges Epithelwachsthum, welches zum Bindegewebe nur durch das Hineinwachsen in die Lymphspalten Beziehung hat, sonst aber, abgesehen ron den Anfangsstadien, vollkommen unabhängig ist; es fehlt bei ihm der organische Zusammenhang, Ribbert2) spricht als primären Vorgang an eine Bindegewebsneubildung mit jungen Gefässen, welche sich gegen das Epithel vorschiebt; letzteres nimmt an Dicke sehr zu, so dass ein Bild wie bei der chronischen Entzündung der Cutis und Subcutis entsteht; aber diese Stufe wird sehr bald über. schritten, das wuchernde Epithel geht in die Tiefe vor und erst jetzt werden durch das wachsende Bindegewebe einzelne Epithelzellen abgesprengt und wachsen im Zusammenhang mit dem Oberfächenepithel weiter; das schrankenlose Wachsthum wird dem Epithel erst aufgezwungen durch eine Abtrennung einzelner Zellen oder Zapfen aus dem continuirlichen, organisirten Zusammenhange. Da also zuerst eine entzündliche Wucherung des Bindegewebes auftritt, so folgt, dass lang bestehende Entzündungen sehr zu Carcinom prädisponiren ( $\mathrm{z}$. B. mechanische, chemische, thermische, bakterielle Einflüsse). Bei rasch veriaufenden Entzïndungen dagegen gehen einmal die Epithelien selbst zu Grunde and die abgesprengten Epithelgellen verschwinden aus dem Bindegewebe. Während also die anderen Geschwülste ihren Ursprung aus der embryonalen Periode nehmen, sich auf Blastomere zurückführen lassen, sollen die Carcinome erst im extrauterinen Leben erworben werden.

Uebertragen wir Ribbert's Theorie auf die Drüsencarcinome, so mässte also zuerst eine chronisch-interstitielle Entzündung in der Mucosa irgend eines Organes Platz greifen, in deren Verlauf es zur Absprengung von Epithelien der Drüsen käme. Diese dislocirten, vom Matterboden getrenten Zelien würden sich dann in pathologischer Weise weiter entwickeln. Darin herseht vollkommene Uebereinstimmung, dass gerade die Histogenese dieser Carcinome eine besonders schwierige ist, weil man so selten die ersten Anfänge der atypischen Epithelwacherung zu Gesicht bekommt. Alle Autoren, sowohl die, welche Ribbert's Theorio annehmen, wie ihre Gegner fanden an den Grenzen von gesunder Schleimhant und Carcinom eine allmähliche oder plötzliche Umwandlung der nor-

1) Ribbert, Lehrbuch der pathol. Histologie. Bonn 1896.

2) Ribbert, Lehrbuch der allgemeinen Pathologie. Leipzig 1901. 
malen Epithelien und einen Uebergang der normalen Tubuli, Alveolen und Follikel in die analogen Gebilde oder in solide Stränge des Carcinomparenchyms. Auch findet sich mitunter eine Vergrösserung der Zellen durch Verdichtung und Zunahme des Plasma, Aenderung in ihrer äusseren Gestalt und Schwund der specifischen Function; Vergrösserung und Hyperchromatie der Kerne und zahlreiche pathologische Mitosen. Die Zellen theilen sich und durch Anhäufung ihres Produktes innerhalb der Drüse entsteht Mehrschichtigkeit des Epithels, während das Lumen von soliden Zellen angefüllt wird; endlich wird die bindegewebige Membrana propria der Drüse perforirt und es erfolgt der Ausbruch der soliden Zellwucherung nach aussen. In der Umgebung findet man reactiv entzündlich-hyperplastische Wucherung am Epithel der präexistirenden Drüsen, bestehend in Vermehrung und Doppelschichtung der Epithelien, chromatinreichen Kernen, Abhebung des Epithels von der Basalmembran und Anfüllung des Lumens mit Zellen, unter Umständen auch direkte Zellneubildung. Oft bricht aber auch das Carcinom in dem nur spärlich entwickelten Bindegewebe in die Drüsen ein und wuchert in ihnen weiter, da es im Zwischengewebe sich nur schlecht weiter zu entwickeln vermag.

Auf einen Punkt ist hier noch einzugehen, nämlich auf die Theilungsvorgänge der Carcinomzellen; man hat früher versucht, die Vorgänge bei der Mitose zur Erklärung der Histogenese zu verwerthen. Zum Studium der Kerntheilung ist es nöthig, als Vergleich absolut gesunde Schleimhaut der betreffenden Partie heranzuziehen. Nachdem schon Hansemann ${ }^{1}$ ) und Gebhard ${ }^{2}$ ) eine vom Normalen abweichende Kerntheilung festgestellt hatten, hat A mann jr. ${ }^{3}$ ) die Sache näher verfolgt und gezeigt, wie charakteristiseh die Mitose, aber auch besonders ihre Degeneration ist. Während beim normalen Cylinderepithel die Theilungsaxe der Mitosen parallel zur Zellbasis steht, ist sie beim Carcinom des Cylinderepithels senkrecht zu ihr gestellt; hier werden also die jungen Tochterzellen übereinander liegen, während sie bei gesundem Epithel nebeneinander liegen; daneben findet man aber aucb

1) Hansemann, Specifität, Altruismus und Anaplasie der Zellen. Berlin 1893.

2) Gebhard, Pathologische Anatomie der weiblichen Sexualorgane. Jieipzig 1899.

3) Amann, Kernstructur im Uteruscarcinom. Verhandl. d. deutschen Gesellsch. f. Gynäk. Bd. 6. 
Riesenmitosen von meist multipolarem Typus, welche später Riesenzellen liefern, dann Aberration der Chromosomen, asymmetrische Anordnung derselben, so dass unregelmässige Figuren, hauptsächlich Triaster entstehen; weiterhin können die Centrosomen und Aequa-
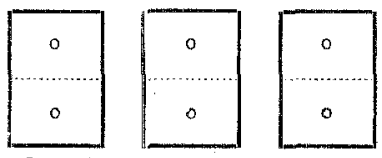

Schema der Theilung beim Drüsencarcinom.
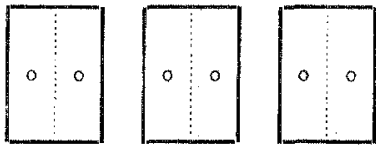

Schema der Theilung im normalen Cylinderepithel.

torialplatten vermehrt sein. Wenn man diese Erscheinungen auch künstlich durch Ligatur der zuführenden Arterien hervorrufen kann, so sind sie doch sehr für die Diagnose eines Carcinoms zu verwerthen, in noch böherem Grade aber die ron Amann'1) beschriebenen degenerativen Vorgängen am Kern. Man kann hierbei unterscheiden zunächst die Pyknose, wobei der Kern unter Erhaltung des Tinctionsvermögens kleiner wird, oder in Fragmente zerfällt; sodann die Sprossung und Vacuolenbildung, die hyaline Degeneration, wo an der Peripherie des Kerns sich hyaline Schollen anlagern, und endlich die Umlagerung des Gerüstes oder der Wand mit Chromatin, welches dann in die Zelle selbst übertritt. Auch die Zelleinschlüsse, besonders die eingewanderten Leukocyten, können in ihren Kernen die gleichen Veränderungen aufweisen. Natürlich kann auch die Zelle selbst degeneriren; durch regressive Veränderungen sollen nach Fränkel ${ }^{2}$ ) solche Abweichungen bedingt werden, dass die Zelle ihren epithelialen Charakter verliert und einer Sarkomzelle sehr ähnelt, also sich dem Bindegewebe nähert. Im Centrum, hier am ehesten durch mangelhafte Osmose bedingt, kann man hyaline, fettige, myxomatöse Degeneration oder Verkalkung antreffen, oder die Zelle hat als solche zu existiren überhaupt aufgehört und man findet nur noch Plasmatrümmer. Mit Recht hat Amann ${ }^{1}$ ) darauf aufmerksam gemacht, dass der höehste Grad der Degeneration dann erreicht wird, wenn es nicht mehr zur Kariokinese kommt, sondern wenn auf amitotischem

1) Amann, Lehrbuch d. gynäkol. Diagnostik. Wiesbaden 1897 .

2) Fränkel, Ueber Drüsenkrebse des Uterus. Hegar's Beitr. Bd.II. H. 3. 
Offergeld, Ueber die Histologie der Adenocarcinome im Uterusfundus. 299

Wege durch einfache Sprossurg die Erzeugung der Tochterzellen geschieht. Da aber die Kerntheilungsvorgänge durchaus nichts für ein Carcinom Charakteristisches besitzen, so sind sie zur Erklärung der Histogenese nicht zu verwerthen.

Folgen wir nun jetzt der im Anfang dieser Abhandlung aufgestellten Eintheilung, so wäre zuerst kurz eine Geschwulst zu beschreiben, welche von vielen Autoren als "Adenoma malignum" bezeichnet wird. Ruge ${ }^{1}$ ) hat hierfür folgende Definition abgegeben: Das maligne Adenom ist ein Drüsencarcinom mit bestimmten Zellen und eigenthümlichem Bau; es stellt dar ein unentwirrbares Convolut von dicht aneinander. liegenden Epithelschichten, vergleichbar einem Irrgarten oder Haufen Regenwürmer; es liegt Drüse dicht an. Drüse; ihre Form ist atypisch; die Membrana propria fehlt; der grosse Kern der stets uniformen cubischen oder cylindrischen Epithelien liegt central. Es ist also der Adenomeharakter gewahrt, aber die neugebildeten Drüsenschläuche gehen destruirend in das Gewebe hinein; stets findet man Stellen mit atypischer Epithelwucherung; die Metastasen haben Drüsenform. Im Allgemeinen sind diese Geschwülste sobr selten und werden wohl stets seltener werden mit dem Fortschritt unserer Diagnostik; so kann man heute schon die beiden von Gessner ${ }^{2}$ ) und Sänger ${ }^{3}$ ) publicirten Fälle nicht mehr zu dieser Gruppe gehörig bezeichnen.

Histologisch unterscheidet sich das Adenoma malignum nur graduell von der glandulären Endometritis. Vermehren sich bei dieser nur die Drüsen (Endometritis glandularis hyperplastica) in excessiver Weise, so hat man ein malignes Adenom; von einem schmalen Reste Stromagewebes getrennt, senken sich von der Oberfläche her nebeneinander Drüsen in die Tiefe; gestaltet sich bei der Endometritis nur der Verlauf der Drüsen unregelmässig (Endometritis glandularis hypertrophica), so. gehen, nur dureh sehr wenig Zwischengewebe getrennt, von einem Hauptaste sich bald wieder dichotomisch theilende Nebenäste ab, entweder als gerade, schlanke, oder kurze, plumpe Gänge. In ersterem Falle geschieht das Wachsthum in axifugalem (centripetalem) Sinne, es giebt Drüsenausstülpungen, man findet eine Menge gerade verlaufender Drüsen neben-

1) Ruge, Zeitschr. f. Geburtsh. u. Gynäk. Bd. 31.

2) Gessner, Zeitschr. f. Geburtsh. u. Gynäk. Bd. 34.

3) Sänger, Centralbl. f. Gynäk. 1896. 
300 Offergeld, Ueber die Histologie der Adenocarcinome im Uterusfundus.

einander, nur durch eine Spur Zwischengewebe getrennt; im letzteren erfolgt durch axipetales (centrifugales) Wachsthum eine Binstülpung von Drüsen, es liegen bier die zusammengehörigen Zellcomplexe dicht nebeneinander; jenes sind extraglanduläre, evertirende, dieses intraglanduläre, invertirende Formen; zwischen beiden giebt es viele Uebergänge. Eine sehr seltene Form ist die, wo nur Unregelmässigkeiten im Verlauf der Drüsen entstehen. Die Zellen des reinen malignen Adenoms weichen nur sehr wenig ron denen der Drüsen ab; sie haben ein mehrzeiliges Epithel, sind hocheylindrisch, prismatisch oder haben die Form einer sechsseitigen Pyramide.

Vereinzelt findet man Zellen mit schmalem Kern und vielem Chromatingehalt; die Mitosen sind zwar zahlreich, aber stehen in ihrer Axe parallel zu der Zellbasis. Solche Tumoren findet man ausser im Uterus, wo sie durch Livius-Fürst ${ }^{1}$ ), Veit'2), Kaufmann ${ }^{3}$ ), Eckkard ${ }^{4}$ ), Krukenberg ${ }^{5}$ ), Eberth ${ }^{6}$ ), Olshausen ${ }^{7}$ ) und Selberga beschrieben wurden, auch im Intestinaltractus [Selberg $\left.{ }^{8}\right)$, in der Leber, entstanden rom Parenchym und vom Epithel der Gallengänge, and in den Drüsen der Bronchialschleimhaut wie in den Schweiss- und Speicheldrüsen. Eine heillose Verwirrung ist nun dadurch entstanden, dass verschiedene Autoren [Bröse ${ }^{9}$ ), Knauss-Camerer ${ }^{10}$ ) u. A.], seitdem Kaufmann ${ }^{11}$ ) Polymorphie des Epithels und solide Zellhaufen gefunden hat bei diesen Tumoren, auch die mehrschichtigen Neoplasmen so benennen, wenn sie eine ziemliche Regelmässigkeit im adenomatösen Bau aufweisen. Zur Diagnostik im mikroskopischen Bilde hat Gebhard ${ }^{12}$ ) einigo Merkmale aufgestellt. Darnach spricht ein excessives Drüsenwachsthum mit dichotomischer Verzweigung schon in den obersten Schichten der Mucosa, unregelmässiger, meist spitzwinkliger $\mathrm{Ab}$ -

1) Livius-Fürst, Zeitsohr. f. Geburtsh. u. Gynäk. Bd. 14.

2) Voit, Ebendas. Bd. 7.

3) Ka ufmann, Festschrift für Ponfick. Deutsohe Ztschr. f. Chir. Bd.14.

4) Eckhard, Dieses Archiv, Bd. 55.

5) Krulienberg, Monatsschr. f. Geburtsh. u. Gynäk. Bd. 5.

6) Eberth, Virchow's Arch. Bd. 43. 158.

7) Olshausen, Handbuch der Frauenkrankheiten. Berlin. 1886.

8) Selberg, Virchow's Arch. Bd. 160.

9) Bröse, Zeitschx. f. Geburtsh. u. Gynäk. Bd. 3.

10) Knauss-Camerer, Ebendas. Bd. 34.

11) Kaufmann, Festschrift f. Ponfick.

12) Gebhard, Path. Anatomie der weibl. Sexualorgane. Leipzig. 1899. 
gang der neugebildeten Drüsen und Verschlingung untereinander sehr für malignes Adenom, während Amann') ganz besonders auf die grosse Hyperplasie der Drüsen mit Schwund des interglandulären Gewebes aufmerksam gemacht hat. Aber so einfach ist diese histologische Diagnose nicht; klinisch ist der Tumor absolut maligne, und man wird wohl Orth beipflichten dürfen darin, "dass es wegen der eigenthümlichen normalen Verhältnisse an dieser Stelle (bei der Mucosa des Uterus) schwierig sei, ein Criterium zu finden, um das einfache Auseinandergedrängtwerden der Muskeln, wie es ja auch bei der chronischen, productiven Endometritis beobachtet wird, von dem Zerstörtwerden durch ein malignes Adenom sicher zu unterscheiden." Seit dieser Zeit geht das Bestreben der meisten Autoren dahin, das destruirend in das Gewebe, besonders die Uterusmusculatur hineinwachsende maligne Adenom mit dem Carcinom zu identificiren [Fraenkel2)]; Schmaus ${ }^{3}$ ) betont, dass, wenn der Drüsentypus noch ganz erhalten ist, nur der Nachweis des schrankenlosen Weiterwucherns in die Tiefe zum Ziele führen wird; ja Winter ${ }^{4}$ ) sieht diesen Tumor höchstens als ein seltenes Frühstadium der folgenden Gruppe, des Adenocarcinoms, an, und dem Vorschlage von Krukenberg ${ }^{5}$ ), den Namen des "Adenoma malignum destruens" als eigene Species fallen zu lassen, sind viele Pathologen und Gynäkologen gefolgt [Borst ${ }^{6}$ ), Kauf$\left.\operatorname{man} n^{7}\right)$ ]. Sie sind nicht etwa degenerirte Tumoren, sondern haben schon von Haus aus die Eigenschaften eines echten Careinoms mitgebracht, wenn sie auch nur ganz geringe Abweichungen vom Drüsentypus zeigen;- sie können einem unschuldigen Adenom aufs Erste so ähnlich sehen, dass Hansemann ${ }^{8}$ ) jeden Unterschjed im histologischen Bilde leugnet und Kaufmann ${ }^{7}$ ) auf die enormen diagnostischen Schwierigkeiten mit Nachdruck hinweist; ja im Verein mit Borst6) tritt er dafür ein, das maligne Adenom dem Carcinom gleich zu setzen, „da es nur den Charakter des Mutter-

1) Amann, Lehrbuch der mikroskopisch-gynäkologischen Diagnostik. Wiesbaden. 1897.

2) Fraenkel, Hegar's Beiträge. Bd. 2. H. 3,

3) Schmaus, Grundriss der Path. Anatomie. Wiesbaden. 1899.

4) Winter, In Veit's Eandbuch der Gynäk. Bd. III.

5) Krukenberg; Monatsschr. f. Geburtsh. u. Gynäk. Bd. 5.

6) Borst, Die Lehre von den Geschwülsten. Wiesbaden. 1902.

7) Kaufmann, Festschrift f. Ponfick.

8) Hansemann, Die mikroskopische Diagnostik der kösartigen Geschwulste. Wiesbaden. 1897/1902. 
302 Offergeld, Ueber die Histologie der Adenocarcinome im Vterusfundus.

bodens in ziemlicher Treue bewahre"; es ist also wahrscheinlich ein Carcinom mit geringster Anaplasie der Epithelien [Han semann 1)] oder, wie Kaufmann²) sich ausdrückt, ein höchst organisirtes Carcinom; dafür spricht aueh der klinische Verlauf und die Fähigkeit der Metastasirung. Unter diesen Verhältnissen ist uns ja unser therapentisches Handeln direct bestimmt; man wird $\mathrm{Orth}^{3}$ ) vollständig beipflichten, wenn er am Ende des Kapitels über diese Tumoren schreibt: Ohne den klinischen Verlauf zu kennen, lässt sich trotz der Schwierigkeit in der Deutung des histologischen Bildes bei einem Befund von dicht zusammenliegenden Drüsenschläuchen, besonders wenn sie der normalen Umgrenzung durch die Tunica propria und Muskelfasern entbehren, eine maligne Neubildung des Uterus diagnosticiren, welche die Totalexstirpation indicirt."

Diese Tumoren sind also mit einer grossen Wahrscheinlichkeit schon der Gruppe der Adenocarcinome zuzuweisen; letztere findet man ja ausser im Cterus auch noch in den Ovarien (hier meist metastatisch) und in der Mamma; daneben körnen auch die männliehen Geschlechtsorgane befallen werden, so besonders die Hoden und Prostata; nur der Vollständigkeit wegen sei ihres Vorkommens im Intestinaltractus und der Thyreoidea gedacht. Während beim reinen Adenom - also dem benignen Tumor im klinischen Sinne - die neugebildeten Acini und Tubuli hinsichtlich der Bẹsehaffenheit des Epithels und bindegewebigen Stromas die grösste Aehnlichkeit mit den Drüsen des Mutterbodens bewahren, weist beim Adenocarcinom das Parenchym zwar drüsige Formation auf, diese aber mit grösster Willkür des epithelialen Wachsthums. Das Epithel wächst selbstständig, sodass in der Form der Zellen die grösste Willkür herrscht, selbst wenn der drüsige Bar noch deutlich zu erkennen ist. Während beim Adenom das Verhältniss der ectound mesodermalen Derivate ungestört ist, hat beim Carcinom durch das Verhalten des Epithels der Grenzstreit zwischen den Abkömmlingen der beiden Keimblätter wie im embryonalen Leben wieder begonnen [Ball4)], nur wird kein fertiges Product geliefert, sondern es geht schrankenlos weiter; die neugebildeten Drüsenschläuche

1) Hanseman, Specificiftät, Altroismus und Specifität der Zellen. Berlin. 1893.

2) Kanfmann, Festschrift für Ponfick.

3) Orth, Lehrbuch der Pathologie. 1887/1093.

4) Ball, Princip des Wachsthums. Berin 1876. 
Offergeld, Ueber die Histologie der Adenocarcinome im Uterusfundus. 303

kommen in beliebigen Räumen des alten oder neugebildeten Bindegewebes zu liegen, indem sie in dasselbe hineinwuchern. Lässt man die Annahme zu Recht bestehen, dass das maligne Adenom ein Vorstadium des Adenocarcinoms ist, so wird nach verschieden langer Zeit ersteres mehrschichtig; klinisch sind sich beide gleich: beide sind als absolut maligne Neubildungen aufzufassen, da sie ein progredientes Wachsthum zeigen und Metastasen sowie Kachexie bedingen.

Die das Lumen begrenzenden Epithelien legen sich so nebeneinander wie es der Raum gestattet; daher entsteht die Polymorphie; man findet Zellen von rundlicher, ovaler oder cubischer Gestalt, solche mit Ausläufern (geschwänzte) oder mit concaven Eindrücken; die normalerweise vorhandenen Brücken zwischen den Zellen fehlen. Auch die Kerne sind gewöhnlich abnorm gross. Die Tunica propria ist zerstört, die Membrana limitans perforirt, die einzelnen Drüsen stehen unter einander in zahlreicher Communication; ganz besonders aber ist die Wucherung gegen und in die Muscularis vorgedrungen. Oft ist auch schon der Drüsentypus vernichtet, man findet ein wirres System verschieden weiter Lumina, welche nur Spalten in den Epithelmassen darstellen. Diese selbst bilden nur einen Saum um das Lumen, ohne Belag. Die Grenze zwischen gesunder und erkrankter Mucosa ist sehr scharf, oder man findet gewisse, blasse, polymorphe Zellen mit verschiedener Grösse und Lage des Kernes. Amann ${ }^{1}$ ) hat die Mehrschichtung des Epithels direct beobachtet; unter pathologischer Mitosenbildung stellen sich die Theilungsaxen der Kernspindeln senkreeht zur Zellbasis, sodass also die Tochterzellen übereinander liegen; hierdurch werden die
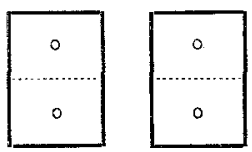

jüngeren Zellen sich untereinander sofort differenziren; die obere wird secerniren, die untere nicht. Die durch Theilung entstandenen Zellen schliessen sich peripheriewärts an, es findet daher unter Erhaltung des Drüsencharakters eine Verschiebung der Zellbasis nach dem Stroma, also peripherwärts statt. Der Schluss ist eine vollständige Ausfüllung des Lumens durch Epithelstränge, also die Bildung solider Epithelmassen in alveolären Hohlräumen des StromaBand 6.

1) Amann, Verhandlungen der Deutschen Gesellschaft f. Gynäkologie. 
304 Offergeld, Ueber die Histologie der Adenocarcinome im Uterusfundus.

gewebes; dieses selbst hat den Character des lymphadenoiden Gewebes der Mucosa; zwischen den Fasern sind zahlreiche Rundzellen, zumal wenn Ulceration da war. Diese Sekretionsfähigkeit - neben der Verhornung der beste Beweis für die epitheliale Herkunft -- ist analog der physiologischen Sekretion und kommt besonders den gereilten, in allen Strukturen höher entwickelten Carcinomen zu, also den Adenocarcinomen; diese Eigenschaft hat Hansemann ${ }^{1}$ ) als den geringsten Grad der Anaplasie der Carcinomzellen vom Matterboden gedeutet. Im Uebrigen deckt sich der Befund ganz mit dem des malignen Adenoms, mit Ausnahme der Mehrschichtigkeit des Epithels, welches der, wichtigste, nach Gebhard $^{2}$ ) der einzigste Punkt für die histologische Differentialdiagnose abgiebt.

Nur zum Unterschiede sei mit ein paar Worten der benignen epithelialen Neubildung im Fundus uteri gedacht; die reinen Adenome sind sehr selten und werden bei Lebzeiten kaum diagnosticirt, weil sie keine Beschwerden verursachen. Wichtig ist, dass die Geschwulst durch eine derbe, bindegewebige Kapsel abgegrenzt ist; dass ferner um jede Drüse die Membrana propria erhalten ist and die Zellen typische Cylinderform haben mit basaler Cylinder- und freier Sekretionsfläche; die spärlichen Mitosen sind nicht pathologisch und stehen parallel zur. Zellbasis, sodass die Tochterzellen nebeneinander liegen; es fehit also die Mehrschichtigkeit vollständig.

Das Adenocarcinom ist rom Carcinoma glandulare simplex unterschieden durch seinen lang erkennbaren adenomatösen Bau; da bei diesem die excessive Drüsenneubildung fehlt, so wird das histologische Bild einfacher; es ist ein gross-alveoläres Oarcinom, wobei die erweiterten Uterusdrüsen entweder mehrschichtiges Epithel haben oder mit Epithelmassen angefüllt sind. Wie aber schon kurz erwähnt, neigt man jetzt der Ansicht $z u$, dass alle Drüsencarcinome mit der Zeit in solide übergehen werden, wobei die Zwischenstufe mit dem lang erkennbaren adenomatösen Typus mitunter fehlen kann.

Der bisweilen klinisch protrahirte Verlauf einer Geschwulst im L'undus uteri, im Verein mit dem wechselvollen histologiscnen Befunde, aber ganz besonders der Umstand, dass der schon längst

1) Hansemann, Berl, Hin. Wochenschr. 1896.

2) Path. Anatomie der weibl. Sexualorgane. Leipzig 1899. 
diagnosticirte Tumor plötzlich sein Verhalten ändert und Symptome macht, welche wir nur bei malignen Uterustumoren finden, dass er unter Anderem plötzlich sich bedeutend vergrössert und die durrh das diagnostische Curettement zu Tage geförderten Mucosastücke auf einmal mindestens als "höchst verdächtig " gedeutet werden müssen, hat Veranlassung gegeben eine "maligne Degeneration" eines bisher benignen Tumors anzunehmen. So ist von verschiedenen Autoren z. B. dieser Vorgang bei Papillom und Adenom behauptet worden; diese führen an, dass das Epithel sowohl über die Oberfläche hinwegziehe, als ganz besonders sich in die Tiefe senke; wie Babes') glaubt durch Verminderung der Widerstände. Kaufmann ${ }^{2}$ ) giebt dieses auch den Epithelien der Adenome zu. Nach Ribbert³) können alle fibro-epitheliale Tumoren, auch wenn sie ganz langsam wachsen oder gar stationär bleiben, plötzlich durch irgend einen Anlass zur Proliferation gebracht werden und durch Perforation in ein Blut- oder Lymphgebiet direct mit ihren Zellen Metastasen erzeugen. Histologisch findet man selbst hier mitunter noch eine Zellformation, welche den unveränderten Epithelien dieser Stelle durchaus ähnlich sieht; Der Unterschied ist nur zu erheben durch Anordnung, Grösse und Färbung der Epithelien. Diese Vorgänge hat Schmauss ${ }^{4}$ ) ausführlich beschrieben: die Drüsen nehmen die verschiedenste Form an, haben unregelmässige Verzweigungen und nach aussen Ausbuchtungen, papilläre Vorsprünge bisweilen nach innen; der Epithelbelag wird mehrschichtig, die Epithelien füllen das Lumen aus; ihre Gestalt ist unregelmässig. Das Charakteristische ist die Perforation der Membrana propria und somit das Vorhandensein der Tumorzellen im Bindegewebe um die Drüse, besonders in den Jymphspalten. Dort bilden sie ein Netzwerk, welches die Mucosa perforirt und in die tiefen Schichten hineinwächst. Obschon es seinen Charakter als Cylinderepithel bewahrt, bildet es theils solide Stränge, theils hohle Gebilde, deren Lumen von Epithelien angefüllt ist, sodass ein drüsiges Aussehen entsteht (Adenocarcinom). Ich glaube, dass man im Allgemeinen daran wird festhalten dürfen, dass echte Uebergänge nicht vorkommen, und dass sich die Bilder auch anders in ungezwungener Weise erklären lassen, etwa so,

1) Babes, Rom. med. 1900. Münchener med. Wochenschr. 1901.

2) Kaufmann, Virchow's Arch. Bd. 154.

3) Ribbert, Lebrbuch der allg. Pathol. Leipzig. 1901.

4) Schmauss, Grundriss der path. Anatomie. Wiesbaden. 1899. 
306 Offergeld, Ueber die Histologie der Adenocarcinome im Uterusfundus.

dass ein schnell wachsendes Carcinom ein Adenom mit durchsetzt, so wie die von Borst ${ }^{1}$ ) und Morris Wolf ${ }^{2}$ ) beschriebenen Fälle. Gerade ersterer tritt mit Nachdruck dafür ein, die Annahme von Uebergängen oder Entartung preiszugeben. Nan wird ihm beipflichten müssen, dass ein Carcinom, welches im interglandulären Gewebe wuchert, einmal die Drüsenkapsel perforiren kann und dann in die Schläuche selbst gelangt; sodann kann aber auch selbstständig in einem fibro-epithelialen Gewebe ein Carcinom entstehen, welches secundär in die vorhandenen Drüsen hineinwuchert.

Es wird sich hierbei handeln um Einschlïsse unentwickelter, aber noch entwickelungsfähiger Epithelkeime, die entweder aus der fötalen Lebensperiode her bestanden, oder im Verlaufe der Geschwulst sich aus unverbrauchtem Material bildeten; aus den mannigfachsten Ursachen erleiden sie eine Abnahme ihrer Wachsthumsenergie. Borst ${ }^{3}$ ) und Jubarsch ${ }^{4}$ ) sehen das Epithel im Carcinom als ein schon primär ganz anders gestaltetes an; daher besitzt es schon von Hause seine malignen Eigenschaften und hat nicht nöthig, diese erst zu erwerben. Weiter besteht auch die Möglichkeit, dass es sich einfach um hyperplastische Zustände der Art handelt, dass durch den primär vorhandenen Reiz des Carcinoms erst secundär das Adenom entstanden ist. Gerade so wenig sich ein Uebergang von der einfachen Hyperplasie zum Adenom construiren lässt, da bei ersterem eine vollständige Uebereinstimmung in anatomischem und physiologischem Sinue zwischen den Drüsen der Hyperplasie und des Matterbodens vorhanden sein muss [Rindfleisch 5)], so wenig lässt sich auch eirie Diffusion vom Adenom zum Carcinom nachweisen, als es vielmehr sicher anzunehmen ist, dass ein Carcinom aus sich herauswächst ohne Vitbetheiligung der angrenzenden Epithelien gleicher oder verschiedener Art an der Proliferation. Hs ist höchst unwahrscheinlich, dass von einem Adenocareinom an der Peripherie ein inficirender Reiz zum Wachsthum so ausgen̈bt wird, dass stets vorher

1) Borst, Verhandl. d. pkysikal, medic. Gesellschaft. Würzburg. 31. 32. 33.34 .

2) Morris Wolf, Dissert. Rostock. 1899.

3) Borst, Die Lehre von den Geschwülsten. Wiesbaden 1902.

4) Lubarsch, Ergebnisso der allgem. Pathol. Bd. I-VI.

5) Rindfleisch, Sitzungsbericht der physikal.-medicin. Gesellschaft Würzburg 1902. 
normales Epithel carcinomatös werde; die grösste Masse des Carcinoms wächst aus sich heraus, da es eine Metaplasie von Bindegewebe zum Epithel nicht giebt und eine solche der Epithelien unter einander auch nicht in grossem Maassstabe stattfindet, weil man ja sonst bei den Drüsencarcinomen eine flächenhafte Ausbreitung finden müsste, während dessen sie ja bekanntlich in die Tiefe wuchern. Man wird daher wohl auch nicht. fehl gehen, hinsichtlich der sogenannten malignen Degeneration mit Borst ${ }^{1}$ ) daran festzuhalten, dass das Carcinom "in die Umgebung mit eigenen Truppen vorschreitet, ohne sich aus vorher gefundenem Gewebe stets neue Söldner für sein destruirendes Wachsthum zu werben".

Wie man aus dem Vorliegenden ersieht, giebt es in der Histologie der malignen epithelialen Tumoren im Uterusfundus, welche ihren Ausgangspunkt von den Drüsen der Mucosa herleiten, noch manche Streitfragen, die unendlich weit von einer allgemein befriedigenden Lösung entfernt sind. In der Absicht, zur Klärung dieser Verhältnisse einen ganz bescheidenen Beitrag zu liefern, wurde diese Arbeit unternommen, welche sich auf das Sammlungsmaterial theilweise der $\mathrm{Kgl}$. gynäkologischen Klinik in München, sowie auf die während meiner Assistentenzeit operirten, also frischen Fälle, stützt. Erstere waren in Kayserling'scher Flüssigkeit conservit, letztere, auch die Stücke aus den einzelnen Probeausschabungen, wurden in 4 proc. Formalinlösung gehärtet. Nachdem in allen Fällen die Fixirungs- oder Conservirungsflüssigkeit durch Abspülen in fliessendem Wasser beseitigt war, wurde die Entwässerung durch Einlegen in Alkohol von steigender Concentration besorgt. Die weitere Behandlung richtete sich nach der Grösse der aus dem Tumor excidirten Stücke. Grössere, welche Uebersichtsbilder liefern sollten, wurden in Celloidin eingebettet. (Aus dem absoluten Alkohol kamen sie zuerst in die AlkoholAethermischung ana, dann in Celloidin III, II, I, und wurden in diesem nach dem bekannten Verfahren gegossen; die Aufbewahrung der auf Holzblöckchen aufgeklebten Stücke, sowie das spätere Schneiden auf dem Mikrotom geschah mit der Triaslösung [A]kohol absolut, Aether und Glycerin ana]; diese Mischung liefert sehr brauchbare und helle Schnitte, man kann die Stücke monatelang aufheben, ohne dass sie an ihrer Güte verlieren.) Die kleinen

1) Borst, Die Lehre von den Geschwülsten. Wiesbaden. 1902. 
wurden in der bekannten Weise für die Paraffineinbettung vorbereitet und in diesem gegossen; hierbei kann man viel dünnere Schnitte erzielen, die man zom Studium der histologischen Einzelheiten benutzt. Die mit dem Mikrotom angefertigten und getrockneten Schnitte wurden mit Hämatoxylin-Eosin gefärbt; bei den ganz frischen Objecten konrte mit Erfolg die Apalty'sche Drüsenfärbemethode angewandt werden, wodureh wunderbar klare und schöne Bilder erzieit wurden, welche die mikroskopischen Feinheiten in nie geahnter Deutlichkeit zu Tage treten liessen; besonders scharf wurden bei dieser Methode die Zellgrenzen und Umrisse der Kerne; die Dauereinbettung der vollkommen fertigen Präparate erfolgte in Canadabalsam.

Folgendes war das Ergebniss der mikroskopischen Untersuchung:

\section{Fall I.}

Das Präparat entstammt einer 07 jährigen Patientin, welche im Juli 1899 mit den typischen Erscheinungen einer malignen Neubildung im Fundus aur Klinik kam; die diagnostische Ausschabung ergab ein Adenocarcinom.

Der mit den Adinexen exstirpirte Uterus ist stark vergrössert und seine Wandung verdickt. Das ganze Corpus ist von einer harten, weisslichen Masse angefüllt, welche sich bis in die Cervix erstreckt. Trotz der Dicke der Wandung ist die Muscularis kaum $0,5 \mathrm{~cm}$ stark, sondern der Hauptantheil an der Verdickung fällt dem Tumor za; das Carcinom selbst zeigt körnigen Zerfall. Der Ausgangspunkt befindet sich an der hinteren Wand etwas näher dem Abgang der linken Adnexe.

Histologisch ist auf den Schnitten Muscularis und Mucosa getroffen. Erstere ist durch das wuchernde Carcinom auseinandergedrängt, so dass Nester entstehen und weist durchweg interstitiell entzuindliche Prozesse auf; die Mehrzahl der Nester enthält nur Detritus; hier findet man grosse, zerfallene Zellen und Kerntrümmer, sowie Reste einzelner glatster Maskelfasem und spürliche Leukozyten. Die Zellgrenzen sind sehr stark verwischt, so dass die einzelnen Individuen ineinander überzufliessen scheinen (syncytiale Umwandlung?).

Innerhalb dieses Detritus, welcher sich besonders stark im Cavum uteri vorfindet, liegen einzelne mehr oder minder intacte Drüsenimitationen verschiedener Grösse und Form; ihr Epithel ist theils schon mehr oder weniger verändert, so z. B. schlecht tingirt oder granulirt, zum Theil ist es aber auch noch ganz intact. Hier findet man eine grosse Polynorphie der Zellen und Mehrschichtung, sowie Variabilitäten der Kerne, ferner sieht man wie an einzelnen Stellen eine ganz unregelmässige Wucherung beginnt, indem die Zellen sich regellos theilen und statt boher Cylinderzellen kleine, mehr platte Zellen hervorbringen. Der Jebergang ist theils ein ganz plötzlicher, theils ein langsamer, indem schon ganz vereinzel te Carcinomzellen zwischen den typischen Cylinderzellen zu finden sind. Besonders in den gegen die Muscularis vorgeschobenen Partien ist auch der Versuch der Irüsenimitation gemacht, d. h. man findet Lumina, um welche in concentrischer Anord- 
nung oder auch mehr länglich in verschiedenen Schichten Epithelien liegen, die jedoch ibre längliche Form eiligebüsst haben; es handelt sich vielmehr um mehr quadratische, helle, schlecht gefärbte und tingirbare Zellen mit einem unverhältuissmässig grossen, zackigen Kern. Sodann ist an einer auderen Stelle auch eine Gruppirung von Zellen um ein centrales Lumen zu erkennen, welche leicht zur Annahme führen könnte, dass es sich um den gleichen Vorgang handelte. Zwar wird hier auch das Rohr von zahlreichen kleiuen Zellen begrenzt, jedoch eine genaue Untersuchung lässt feststellen einmal das Fehlen des centralen Begrenzungssaumes und sodann finden sich Risse und Sprünge in der Nachbarschaft dieser Gebilde, daher wird man wohl nicht fehlgehen in der Annahme, dass hier keine Imitation von Drüsen vorliegt, sondern es sich handelt um Kunstproducte oder Zerfall im Carcinom.

Im Uebrigen zeigen gerade diese Zellen, besonders deutlich, wo sie an die Muskulatur anstossen, die bekannten Degenerationserscheinungen, die hauptsächlich in fettiger und hyaliner Degeneration der Zellen bestehen, während der Kern noch unberührt geblieben ist. Diese Verhältnisse sieht man am klarsten, wo die scheinbare Drüsenneubildung in das Myometrium hineindringt. Daneben giebt es aber auch echte Drüsenimitationen. Hier liegt Drüse an Drüse, das interglanduläre Gewebe ist bis auf die letzten Spuren hin geschwunden, und nur ganz vereinzelte Biudegewebsfasern und Capillaren sind aufzuweisen, in deren, Umgebung sich eine spärliche, kleinzeilige Infiltration zeigt. Die Membrana propria um die einzelnen Drüsen ist ganz geschwunden; das Epithel ist ein zwei- oder mehrschichtiges, ziemlich niedriges Cylinderepithel, zwischen welchen einzelue grössere, blasse, runde Zellen mit scharfen Kernen eingelagert sind. Manche dieser Drüsen sind durch Muskelfibrillen eingeschlossen, so dass ein Bild ähnlich wie Nester im Carcinom entsteht. Wo die Drüsen aneinanderstossen, ist der Uebergang von einer Drüse zur andern zu beobachten; gerade hier zeigt sich in besonderem Maasse die Polymorphie des Epithels.

In einigen anderen Schnitten sind mehr längliche Schläuche getroffen, welche durchgehends ein niederes, mehr cubisches Epithel mit grossem Kern zeigen; dieses ist zwar nur einschichtig, neigt aber sehr zum Zerfall; ganz plötzlich kommt dann eine Stelle, wo die Mehrschichtung angeht und die Zellen hinsichtlich ihres Tinktionsvermögens einen carcinomatösen Charakter annehmen. Im Uebrigen ist in diesen Schnitten die Drüsenimitation reichlicher, aber auch freier, da mehrfach aus zwar polymorphem aber einschichtigem Epithel ganz plötzlich kleine, platte Zellen zu mehrschichtigen, carcinomatösen sich vereinigen. Diese Drüsenneubildung ist am reinsten gewahnt im Bereiche der ursprünglichen Mucosa, etwas weniger schon in der Muscularis, wo, zwar neben neugebildeten Drüsen, eher der Charakter des Carc. glandul. simplex vorhanden ist, während nach der Seite des Uteruscarcinoms nur Detritus anzutreffen ist.

Eine Schnittreihe, einer anderen Stelle des gleichen Tumors entnommen, lässt eine nur spärliche Neubildung von Drüsen erkennen, welche im Allgemeinen auf den ersten Blick den Charakter der glandulären Endometritis haben. Daneben giebt es auch solche, welche nur durch ein eben angedeutetes, interglanduläres Bindegewebe mit spärlicher Leukocyteninfiltration getrennt sind, welche sofort durch die Mehrschichtigkeit des Epithels auffallen. Diese jedoch weisen einen ganz anderen Zellcharakter auf: während bei ersteren die hohe Form des 
Cylinderepithels vorherrscht, sind die Zellen hier mehr quadratisch und abereinandergeschichtet, so zwar, dass in der Regel die untere Schicht die kleineren Zellen aufweist und viel heller tingirt ist als die obere. Die Anordnung ist aber nicht concentrisch, sondern die Zellen liegen regellos neben- und übereinander. Zumal in der unteren Schicht sind die Kerne unverhältnissmässig gross und schlecht tingirt. An den neugebildeten Drüsen ist die Membrana propria ganz geschwunden und auch ungefärbt nicht mehr zu erkennen. An ganz vereinzelten Stellen haben sich an die oben beschriebene untere Schicht der zweischichtigen Zellage eine Menge kleinster, fast quadratischer Zellen mit grossem Kern angelegt, welche keine Intercellularsubstanz besitzen. Wir baben es hier mit dem Tebergang zum Carc. glandul. simplex zu thun.

Wo aber eine Druse diesen Uebergang aufweist, da findet er sich meist an verschiedenen Stellen der Peripherie. Sonst ist in diesen Präparaten neben spärlichen neugebildeten Drüsen in der Muscularis nur Detritus vorhanden. In wenigen dieser Drüsen findet sich im Centrum eine Nenge kleiner, schlecht tingirter Zellen, welche ohne Intercellularsubstanz neben einander liegen und einen gut gefärbten, ziemlich grossen Kern besitzen.

Bei Längsschnitten Iässt sich das Verhalten von Bindegewebe zu. den neugebildeten Drüsen feststellen. Schon bei Lupenvergrosserung fâllt die excessive Drüsenvermelnung anf, welche eine ungehenre Ver$z$ weigung aufweisen und theils durch Confluenz benachbarter Drüsen entstanden ist. Sehr interessant sind die Vorsprïnge des Bindegewebes in die Drüsenwand (Figur 1), sowie bei starker Vergrösserung die kleinzellige Infiltration im Stroma. Die Fasern des Bindegewebes sind auseinandergedrängt und entzalten neben Leukocyten auch vereinzelte kleine, cubische Zellen, welche als Carcinomzellen anausprechen sind. Die fibrilläre Structar ist hauptsächlich um die Gefasse herum yerwischt, wo auch die Infiltration der Capcinomzellen und dex Lenkocyten am stäksten ist.

Das Verhältniss des scheinbaren Ueberganges eines Adenocarcinoms in das alveoläre ist besser als in diesem Falle beim folgenden zu erkennen.

\section{Fall II.}

Das Prapparat stellt den durch abdominale Totalexstirpation gewonnenen Uterus einer 52 jährigen Magd dar, welche hereditär nicht belastet war; sie acquirirte vor 20 Jahren eine Gonorhoe und machte in 8 Jahren 3 Partixs spontan durch. Periode seit dem 16. Lebensjahr ziemlich stark, aber unregelmässig; vor 7 Jahren letate Periode, Seit 2 Jahren atypisehe Blutungen, sehr stark, in der Zwischenzeit stinkenden Fluss; seit den letzten 4 Yonaten starke Abmagerung. Im 20 . Lebens. jahre zweimal Gelenkrheumatismus.

Stat. praes.: Patientin zeigt die typischen Erscheinungen einer compensirten Aorteninsufficienz mit allen Folgezustanden.

Portio steht in der Sp.-linie etwas nach rechts von der Medianlinie abgewichen, ist kurz und dick. Mr. für Finger durchgängig; Uterus selbst gross, hart, schmerzlos, füblt sich als Tumor an, gut beweglich.

Therapie: Zuerst wurde die vaginale Totalexstirpation versucht; als es aus der arrodirten Cervix sehr stark blutete, wurde tamponirt und durch Laparotomie die Totalexstirpation vollendet. Nach Resection 
der Adnexe wurde beiderseits im Lig. latum die Art. uterina gefasst und ligirt, darauf die Ureteren mit der Blase zur Seite geschoben und der Uterus in typischer Weise exstirpirt. Drainage mit Jodoformgaze durch die Vagina; Schluss der Bauchwunde.

Reactionsloser Verlauf; Exitus nach 20 Monaten aus unbekannter Ursache.

Uterus mässig vergrössert; Myometrium im Mittel $3,5 \mathrm{~cm}$ dick; Serosa intact. Im Corpus ausgehend von der hinteren Wand ein kleinapfelgrosser, stark ulcerirter Tumor, der sich gegen die Ungebung nach oben hin scharf abgrenzt, peripherwärts dagegen bis bart an das Orificium interuum reicht. Das ganze Uteruscavum ist angefüllt mit zerbröckelten Tumormassen.

Histologische Untersuchung: Auf den Schnitten ist Muscularis und Mucosa getroffen; in ersterer sind die unverkennbaren Zeichen einer lang bestehenden interstitiellen Entzündung, welche sich hauptsächlich im Bereiche der Gefässe ausgebildet hat; diese sind strotzend mit Blut gefült und die ihre Wand mitbildenden elastischen Elemente zeigen die typischen Veränderungen, während die gleichen Gewebe im Nyometrium selbst viel weniger eingreifend geschädigt sind. Obschon die Grenze zwischen Muscularis und Mucosa ziemlich scharf ist, giebt es doch zahlreiche Vorsprünge letzterer in die Musculatur hinein, gebildet durch ein neugewuchertes, kernreiches Bindegewebe; in der Mucosa zerstreut liegen Drüsen, durchaus ähnlich denen der glandulären Endometritis; in dem neugewucherten Bindegewebe sind diese sehr viel spärlicher. Das interstitielle Gewebe ist gewuchert, lässt jedoch keine kleinzellige Infiltration um die Drüsen herum erkennen. An den Partien, wo durch den Härtungsprozess das Epithel abgehoben ist, sieht man um die Drüsen eine scharf gefärbte mit Kemen versehene Membran, welche da, wo zwei Drüsen aneinanderstossen in einander übergeht; diese Membran ist glashell. Die Epithelien sind einschichtig und haben die Form von hohen Cylindern mit gut tingirtem, länglich-rundem Kerı; es ist im Grossen und Ganzen das Bild der sogenannten "gemischten Endometritis". Bei scharfer Einstellung gewahrt man mit der starken Vergrösserung, dass unter diesen Zellen sich einzelne finden, welche in Grösse, Form und Farbe des Zellleibes, als auch besonders in Form und Lage des Kernes von ihren Nachbarn abweichen; wohl das Bemerkenswertheste ist, dass die scharfe Trennung in die basale und secernirende Fläche geschwunden ist. An diesen Stellen ist auch die Tunica propria perforirt und in der Nachbarschaft sind reichlich Leukocyten. Schon hier findet man vereinzelt asymmetrische Mitosen; dicht daneben ist der Process weiter gegangen: das Epithel weist eine sehr grosse Variabilität in der Zellformation auf, besonders aber schon ausgesprochene Mehrschichtigkeit, während auf der gegenüberliegenden Seite der Drüsen sicb ein ausgesprochenes Carcinom mit kleinen, polyedrischen Zellen breit macht und schon Ausläufer in die Drüse selbst bineinschickt. An der Grenze dieser Zellarten finden sich kleine, zackige Zellen mit vielgestalteten Kernen, welche sowohl neben, als ganz besonders auch übereinander liegen. In dieser Grenzschicht sind die Theilungsvorgänge viel lebhafter aber auch gesetzloser; die Zahl der pathologischen Mitosen ist beträchtlich vermehrt. $\mathrm{Um}$ diese so veränderten Drüsen ist keine Spur einer bindegewebigen Membran mehr zu erkennen und die Leukocyten der Umgebung sind schon zum Theil an einzelnen Stellen mit dem jungen, sprossenden Epithel in die Drüse hineingewandert. Diesen Ver- 
änderungen begegnet man vorzüglich da, wo an der Grenze zwischen Muskulatur und Schleimhaut die neugebildeten Drüsen sich mit dem wuchernden Bindegewebe in das Myometrium hineinschieben.

Ganz andere Bilder entstehen, wenn man Stricke aus der Gegend des Orificium internum, also dort, wo der Tumor scheinbar sein Eude hat, untersucht. Hier ist der Typus der interstitiellen Endometritis noch ziemlich rein gewahrt; in dem stark entwickelten interglandulären Bindegewebe ist eine nur sebr geringe Infiltration, theils von Leukocyten, theils Carcinomzellen. Je mehr man sich jedoch dem inneren Muttermunde nähert, desto mehr rerschwinden die Drüsen im Gewebe und durch eine ihrem Schwunde proportionale Einwanderung epithelialer Zellen nähert sich das Bild stets mehr dem eines Carcinoma glandulame simplex. Gerade hier kann man Figuren seben, welche als Debergangsformen yom Adenocarcinom in das gross-alveoläre angesprochen werden. Jedoch ist man hierbei vor Tauschungen und Trugschlüssen kaum sicher. Ich beschreibe kurz ein solches Gesichtsfeld. Mitten in dem fibrillären Stromagewebe der Mucosa an der einen Seite anstossend an das glanduläre Careinom jedoch von ihm getrennt durch einige feine, bindegewebige Fibrillen liegen drei Gebillde, welche um ein centrales Lumen eine concentrische Anordaung von Zellen erkenmen lassen. Auf den ersten Blick imponirt das Ganze als Drüsenquerschnitte und, da die Membrana propria fehlt, schliesst man auf den Uebergang rom Adenocarcinom in das gewohnliche Carcinom. Weit gefehlt! Betrachten wir uns die Figur Il genauer. Das fibrilläre Bindegewebe ist, vielleicht von einer geringen ödematösen Durchtränkung abgesehen, intact. Um die scheinbaren Drüsen ist zwar eine glashelle, homogen tingitte Membran vorhanden, aber ohne Kerne; es kann also unmöglich eine Drüsenmembran sein. Das scheinbare Dräsenparenchym ist blass, schlecht tingirt, die Kerne siad noch mit Wibe als solche zu erkennen, wahrend die Begrenzung der einzelnen Zellen ganz geschwunden ist. In dem Lumen liegt auch eine homogene, schlecht tingirte, kaum diagnosticinbare Masse. Müssen oder besser gefragt, können das uberhaupt Drüsen sein? Yan überlege Folgendes: Gerade im Carcinom kommen einmal in Folge der mangelhaten plysiologischen Qualitaten der jungen Epithelien, sodann unterstützt durch schlechte Ernahrung, besonders der centralen Partien, welche nur an osmotischem Wege von den langs der Peripherie der Nester verlaufenden, also weit entfernten Blut- Lmd Lymphbahnen ihr Nahrmaterial erhalten, sehr leicht regressive Metamorphosen vor, die zu Vacuolenbildung und schliesslich Zerfall der Zellen führen, wiarend die Zelltrimmer von den benachbarten resorbirt oder sonst wie fortgeschafft werden. Um den gleichen Vorgang wind es sich auch hier handeli; gerade der Härtungaprozess bat den aufgequollenen centralen Theilen ihr. Wasser entzogen und in den schon in Zerfall begriffenen Carcinom eine scheinbare Drüsenstrmetur hervorgezabert. Doch nun der positive Beweis. Fün den Zeriall des Gewebes spricht die schlechte Fubbarkeit; der linke Foblram and wohl am wenigsten einer Drüse, selbst nicht einem Sehieschnit, and in dem mittleren sind am unteren linken Ende auch awot Lamina, welche man $z$ weifellos als beginnende Zerfalls vorgănge ansprechen muss, da sich im Epithelsaum einer Drỉse keine Lumina nach eisen lassen.

Die spärlichen in Gewebe rorbandenen, sicher als solche anzusprechenden Drüsen zeigen alle Mehrschichtigkeit des Epithels no verschiedene Confignation der Zellen; der Kern liegt: gana peripher. Be- 
achtenswerth ist, dass die das Lumen umgrenzenden Schichten eine freie Sekretionsfläche aufweisen, während die basalen Zellen stark granulirt sind; in ersterer Lage liegen vereinzelte grosse, sehr blasse Zellen mit grossem blasigem Kern; diese Zellen enthalten in ihrem Plasma etwas schleimige Substanz.

Nun seien kurz die Befunde in der Gegend des inneren Muttermundes erwähnt. In der Mucosa sind die Drüsen total geschwunden und es ist auch kein Versuch einer Drüsenneubildung zu erkennen Das Stromagewebe ist auch stark in den Hintergrund getreten und eigentlich nur noch als Grenze zwischen den einzelnen Carcinomnestern vorhanden; an Stelle des normalen Drüsenparenchyms ist ein alveoläres Carcinom getreten, welches destruirend nach allen Seiten weiterwuchert, auch in das Myometrium binein. Hier verbreitet es sich sprungweise in den Lymphspalten, so dass rosenkranzartige Bilder eutstehen, besonders in den perivasculären, weniger in den intermuskulären Bahnen. Aber im Bereiche der ganzen Muskulatur findet man disseminirte Carcinomhaufen und reichliche kleinzellige Infiltration; die angeschnittenen Gefässe siud stark mit Blut gefüllt und lassen in ihrer Wand entzündliche Veränderungen erkennen. Interessant ist, dass zwischen, ja zuweilen noch innerhalb der Carcinomnester intacte, glatte Muskelfasern nachzuweisen sind. Sehr bald jedoch zerfällt das Bild des alveolären Carcinoms, indem das Bindegewebe sich verringert und die Zellen degeneriren; man trifft dann nur mehr Detritus an, bei welchem sich irgend welche Schlüsse nicht mehr ziehen lassen.

Wie schwierig oft die exacte histologische Diagnose sich gestalten kann, lässt sich leicht begreifen, wenn man bedenkt, dass in einem Präparate neben einem Adenocarcinom auch eine harmlose Endometritis gleichzeitig vorhanden sein kann. Hier ist eine energische Abrasio am Platze, um Stücke der malignen Erkrankung mit zu gewinnen. Als Beweis diene der

\section{Fall III.}

F. H., 54 Jahre alt, war stets gesund; Periode regelmässig; sechs Spontangeburten, letzte mit 40 Jahren. Seit 4 Jahren im Klimax; seit $1 / 2 \mathrm{Jahr}$ atypische Blutungen mit nur kurzen Zwischenpaused; starker übelriechender Fluss, keine Kreuzschmerzen. Stuhl, Harn und Cohabitation ohne Beschwerden.

Das diagnostische Curettement lieferte eine glanduläre Endometritis mit einzelnen verdächtigen Stellen. Daher nach 4 Wochen abermalige Auskratzung, auf Grund deren die Operation gemacht wurde.

Uterus ist fast faustgross; Muttermund und Cervicalkanal für Finger durchgängig; das ganze Cavum ist mit leicht blutenden Tumormassen angefüllt; Parametrium frei.

Therapie: Vaginale Totalexstirpation mit Hilfe des pararectalen (Schuchard'schen) Schnittes bis zum Sacrum. Nach Mobilisirung des Uterus Spaltung der vorderen Wand bis zum Fundus; Entfernung der bröckeligen Tumormassen mit der Curette; Abklemmung and Ligatur der Adnexe und Parametrien; Mikulicz'sche Tamponade; Naht der pararectalen Wunde. Weiterer Verlauf unbekamt.

Der Uterus in seiner Grösse etwa dem dritten Graviditätsmonat entsprechend, hat stark verdickte Muskulatur (im Mittel $3,5 \mathrm{~cm}$ dick). 
In der hinteren Wand des Corpus sitzt ein etwa walnussgrosser Knoten, welcher frei in das Cavum uteri hineinragt. An der Hinterfläcbe des Uterus bis zum Orificium internum herab sind noch eine Anzahl miliarer bis etwa stecknadelkopfgrosser Knötchen, welche blass verfürbt anssehen; die ubrige Mucosa ist giatt; das ganze Cavum ist angefüllt mit abgestorbenen Turnormassen und Blutcoagula.

Histologisch enthalten die angefertigten Schnitte Muscularis und Mucosa. Erstere weist das gewöhnliehe Bild der chronischen Metritis mit zahlreicher Neubildung von Bindegewebe auf. In der Schleirnhaut ist die Drüsenneubildung im Allgemeinen nicht sehr reichlich: dje vorhandenen sind durch ein in etwa gut entwickeltes Stroma von einander getrennt. Dieses ist unverändert und lässt vor allem jede Lenkocyteninfiltration vermissen.

Un die einzelnen Drüsen ist das Bindegewebe etwas dichter angeardnet, und die einzelnen Fasern sind dicker, während auch die Membrana limitans theils ganz unversehrt, theils unsehwer noeh um die einzelnen Individuen gu erkennen ist. Einige wenige Drüsen haben durch die Fixationsprocesse in der Art gelitten, dass vou der Wand sich an einzelnen Partien oder circulär das Epithel abgehoben hat. Hier läuft ein feinstes, structurloses Häutchen um die einzelnen Drüsen (Basalmembran). Der Drüsenbelag ist ein hohes, einschichtiges Cylinderepithel mit vielgestaltetem Kerne; Polymorphie am Epithel ist an diesen Stellen nicht zu erkennen.

Andere Schnitte des gleichen Tumors liefern dagegen ein wenn anch nicht so direct typisches, so doch mzweifelhaftes Bild von Adenocarcinom. An djesen Partien ist zunächst unter Schwund des interglandulären Stromagewebes eine viel excessivere Drüsenneubildng und Wucherung aufgetroten. Die Epithelien der Drüsen sind alle mehrschichtig, theils bestehen sie nus ziemlich hohen Cylinderzellen mit gut gefärbtem Kerne, theils aus helieren, mehr quadratischen, kieinen Zellen. Ganz besonders aber ist das Lumen der Drüsen nicht scharf abgerundet, sondern es ragen voch vereinzelte Zellen des mehrschichtigen Epithels in das Lumen hiyein; diese sind an ibrem freien Rande ganz fein gestrichelt.

Es sind das aber nur ganz vereinzelte Zellen, welche sich in nichts von sonst unverändertem normalen. Cylinderepithel unterscheiden. Die Mehrzahl der Zellen jedoch ist in dem oben beschriebenen Maasse hinsichtlich der Grösse und Gestalt verändert. An den Stellen, wo Polymorphie der Epithelien auftritt, sind die mitotischen Vorgange zahlreicher and weisen die bekaunten Degenerationserseheinungen auf, während in dem gesunden Epithel die Mitosen nur sebr spärlich und nicht von der Norm abweichend sind.

Einige wenige Drüsen sind in ihrer äusseren Form den unveränderten Mucosadrüsen sehr älnlich, zeiged jedoch eine Zweischichtung des Epithels und lassen keine Membrana propria mehr orkennen. In der Umgebung dieser Drüsen ist die kleinzellige Infiltration beträchtlicher, wäbrend in der weiteren das Gewebe von vereinzelten Carcinomzellen durchsetzt ist. An einzeinen Stellen dieser Gegend, wo durch die Härtung eine Retraction des Parenchyms von der Unterlage erfolgt ist, sieht man noch deutlich eine gut tingirte, mit Kemen versehene Hembran concentrisch um die ehemalige Drüsenperipherie herumlaufen. Aber trotzdem sind die Zellen dieser Drüsen schon sebr stark verändert. Das bohe einsehichtige Cylinderepithel ist gewichen einem 
polygonalen plattenförmigen Epithel mit grossen, excentrisch gelegenen, stark gefärbten Kernen; die Epithellage ist doppel- oder mehrschichtig. Dabei hat die ganze Drüse einen unregelmässigen, stark geschlängelten Bau angenommen. In diesen Fällen handelt es sich sicher nicht etwa um Schrägschnitt durch eine Drüse, denn bis zur äussersten Schicht sind die Kerne als ganze getroffen und peripher gelegen. Das Lumen dieser Drüsen ist gut erkeunbar und von einer Anzahl kleiner Zellen begrenzt, welche theilweise an der freien Oberfläche noch eine feine Strichelung erkennen lassen. Dicht neben diesen liegen Drüsen, welche zwar ein zweischichtiges Epithel führen, wo aber auch im Grossen und Ganzen der Charakter des Cylinderepithels gewahrt ist; es sind das hohe scharf und distinct tingirte Zellen mit länglichem Kern an der Basis. Aber hier ist die Membrana propria schon geschwunden; bei einzelnen dieser Zellindividuen sind zwei Kerne vorhanden und zwar liegen diese theils neben-, theils übereinander; bei starker Vergrösserung lässt sich bisweilen in ihnen ein Nucleolus erkennen.

Dagegen erkennt man auch an andern Schnitten, welche mehr der Ursprungsstelle des Tumors entnommen sind, das typische Bild eines Adenocarcinoms. Schon bei Lupenvergrösserung lässt sich unschwer eine excessive Wucherung der Mucosadrüsen feststellen, welche dicht neben einander liegen; sie zeigen die mannigfaltigste Form -- sind länglich, rund, geschlängelt (korkzieherartig), theils in einandergeschoben - und starke Variabilität in ihrem Epithel. Das bindegewebige Grundgerüst ist nur spärlich entwickelt, und weist ein Auseinandergedrängtseiu seiner Fibrillen auf; dieses ist bedingt durch eine kolossale kleinzellige Infiltration, der gegenüber die fixen Bindegewebszellen sehr in den Hintergrund treten. Diese Einwanderung weisser Blutkörperchen ist besonders zahlreich da, wo in dem Lumen der neugebildeten Drüsen sich eine homogen gefärbte, etwas gewellte Substanz befindet; hier ist auch direct ein mehrfacher zu den Drüsen concentrisch verlaufender Wall von Leukocyten anzutreffen. Sodann finden sich aber auch junge Carcinomzellen im interglandulären Stromagewebe; die Tunica propria um die einzelnen Drüsen ist total geschwunden und auch nicht mebr ungefärbt mit nur einiger Sicherheit zu erkennen. Die Parenchymzellen weisen die oben beschriebenen Veränderungen am Epithel und den Kernen auf, ganz besonders aber Hehrschichtung. In der Regel liegen an der Basis der Drüsen kleine, dunkle Zellen, während über diesen, also das Lumen einsäumend blasse, grössere Zellen mit basalem, gut tingirtem Kerne sich befinden. Der obere Theil dieser Epithelien ist blass und hat ein etwas geschichtetes Aussehen, der untere etwas durch Körnung bedingt dunkler; das Lumen selbst wird angefüllt von einem dunkel gefärbten fibrillären Gerüst, in welchem vereinzelte Farbstoffniederschläge enthalten sind. Nur ganz vereinzelt findet man Zellen, welche zwei Keme enthaiten; an diesen Stellen finden sich vereinzelt Triasterformen unter den Mitosen. Von hier geht es dann sehr schnell über in Doppelschichtung, wobei aber die Zellen polymorph werden und zuletzt ein regelloser Haufen kleinster Zellen das Drüsenlumen begreuzt. Ein Uebergang fehlt meist, bisweilen ist er da; es werden die Zellen kleiner und heller, nähern sich mehr der quadratischen Form, während der Kern keine Veränderung ausser Abnahme an Grösse erkennen lässt. 
316 Offergeld, Ueber die Histologie der Adenocarcinome im Uterusfundus.

Ein weiterer Trugschluss in der histologisehen Diagnose kann durch regressive Metamorphosen im Tumor entstehen; beweisend in dieser Hinsicht ist folgender Fall.

\section{Fall IV.}

Bei der 64jährigen Fran ergab das Probecurettement, dass es sich um ein Funduscarcinom handele; es wurde daher zur vaginalen Totalexstirpation mit Zurücklassung der Adnexe geschritten.

An dem gewonnenen Präparat war der Uterus in toto zwar nicht vergrössert, aber das Corpus stark aufgetrieben durch einen das ganze Innere ausfüllenden, auf der freien Oberfläche exulcerirton Tumor, welcher seinen Ursprung von der vorderen Funduswand hart am Scheitel genommen hatte. Die übrige Mucosa des Corpus und Cervix war intact, gleichfalls der peritoneale Ueberzug.

Histologisch ist auf den Präparaten Muscularis and Mucosa vorhanden; erstere zeigt die bekannten Veränderungen der chronisch-interstitiellen Entzündung; letztere hat reichlich neugebildete Drüsen. Theils ist diese Wucherung eine so starke, dass man nur noch mit Mühe eine Spar Stromagewebes, in welchem spärliche Gefässe verlaufen, erkennen kann, theils aber tritt sie mehr in den Hintergrund und das Bindegewebe ist reichlicher entwickelt. Diese Neubildung hat aber nicht an der Grenze der Mucosa Halt gemacht, sondern lässt sich noch etwas in das Myometrium hinein verfolgen, wobei die Fasern theils einfach dislocirt sind, theils wie angefressen aussehen. Wo die Stromaentwickelung reichlicher ist, sieht man eine Menge neugebildeter Capillaren und eine mächtige kleinzellige Infiltration, während da, wo das Bindegewebe nur spärlich entwickelt ist, diese fehlt.

Die l)rüsen sind in der Hauptsache langgestreckt, es finden sich aber auch einzelne, welche eine mehr ruade Form besitzen; sie sind durch ein verschieden stark entwickeltes Bindegewebe fon einander getrennt, besitzen jedoch keine Membrana propria mehr. Das Epithel ist ein ziemlich hohes, cylindrisches mit längliehen Kernen; die Zellen führen einen dentlichen basalen Saum und hellere centrale Partieen. Plötzlich treten aber im Verlaufe einer Drüse grössere, mehr helle Zellen mit rundlicbon Kernen auf, die auf die Kante gestellt sind; an diese schliessen sich dam ganz kleine quadratische an mit abnorm grossem Kern. Während das annăhernd normale Cylinderepithel nur einschichtig, allenfalls mehrzeilig ist, liegen, sobald der Zellcharakter sich ändert, die Zellen in mehrfacher Lage über einander. Neben diesen Arten giebt es an einzeInen Partieen benachbarter Drüsen wieder annähernd ein njedriges Cylinderepithel, dessen Zellen in zweí Lagen deutlich übereinander liegen. Es handelt sich hier sieber nicht u.m Sehrägschnitte, da beide Schichten gleich gross sind wnd die stets vorhandenen Kerne an der Peripherie der Zellen sich vorfinden; ztidem šst die basale Lage durehweg besser tingirt als die, welcbe das Drîsenlumen unschliesst. An diesen Stellen herrseht auch sonst eine gewaltige Polymorphie in Epithel vor: Einzelne Drüsen baben ein mehrschichtiges, annähernd quadratisches Epithel, bei anderen überwiegt der Typus der Cylinder von verschiedener Bohe; auch die Kerne wechseln sehr an Grösse und Gestalt. sowie an Tinctionsvermögen aller oder nur einzelner Kernsubstanzen. Die längeren Drüsenschläuche besitzen durchgehends ein höheres Cylinderepithel mit centralem Kern, welches sich in zxei 
oder mehr Schichten angeordnet hat; die basale sitzt auf einer bindegewebigen Grundsubstanz auf, in welcher sich keine Kerne mehr nachweisen lassen (degenerirte Membrana propria?); die Strichelung des Plasma fehlt; dieses ist vielmehr homogen hell gefärbt; in dieser Schicht sind die Mitosen sehr spärlich und nicht verändert. Es ergiebt sich bei scharfer Einstellung, dass die vorhin beschriebene Membran nur den letzten Rest des interglandulären Stromagewebes darstellt und mit der Drïsenmembran nichts zu thun hat. Die obere Schicht ist von der unteren durch eine in Absätzen verlaufende, glashelle Membran geschieden; die Zellen dieser Lage sind durchweg kleiner, mehr quadratisch, mit gut tingirtem, relativ grossem Kern; sie liegen aber nicht in einer Reihe nebeneinander, sondern sind unregelmässig durcheinander geschichtet; ihr Plasma ist an verschiedenen Stellen unregelmässig tingirt; in dieser Schicht sind die mitotischen Vorgänge zahlreicher, daruuter viele, welche die bekannten pathologischen Veränderungen darbieten; besonders zahlreich ist die Form des Triaster vertreten. Diejenigen Zellen, welche sich so in Theilung befinden, gehen stellenweise bis in die tiefere Schicht vor und drängen dort die nebeneinander stehenden Zellen auseinander. An anderen Stellen sind die Drüsen stärker geschlängelt und mit verschiedenen Einbuchtungen versehen; auch hier ist die bindegewebige Membrana propria um die einzelnen Individuen geschwunden. Das Epithel ist ein flachcylindrisches mit gut tingirten Kernen. Aber auch in solchen Drüsen finden sich Stellen, wo man statt einer Zelle zwei übereinander liegenden begegnet, welche ein viel belleres, nicht granulirtes Plasma und abnorm grossen, zackigen Kern führen. Diese Zellen liegen nicht einfach neben- oder übereinander, sondern sind sehr häufig mosaikartig angeordnet oder wirr durcheinander geschichtet. Jedoch hat der grösste Theil der Drüse die einfache Schichtung und Form der Cylinderzellen beibehalten; mitunter fundet man dann an der gegenüberliegenden Seite der gleichen Drüse ein ziemlich niedriges, zweischichtiges Cylinderepithel mit Neigung zum Uebergang in quadratische Zellen.

Einer Partie ist gesondert zu gedenken, da sie ein ganz anderes Bild aufweist; sie entstammt dem frei in das Cavum uteri himeinragenden Geschwulsttheil. Das noch ziemlich reichliche Bindegewebe umschliesst die Carcinommester und lässt neben spärlichen Gefässen eine nur geringe kleinzellige Infiltration und etwas Oedem erkennen. Das Parenchym der Carcinomnester besteht aus polymorphen, etwas abgeplatteten Zellen, deren Plasma homogen blass tingirt ist mit centralem Kern. Zwischen ihnen liegen in verschiedener Menge kleine, spindelförmige oder sternförmige Zellen mit zwar grossen, centralen, aber stark abgeplatteten, chromatinreichen Kernen. Im Innern dieser Zellstränge sind an verschiedenen Orten mehr oder minder scharf abgegrenzte Hohlräume, die man entweder als Reste von Drüsenlumina ansprechen kann, oder es handelt sich hierbei um die schon im Fall I erwähnten Psendoacini in Folge der Härtung. Auch die basalen Zellen, welche direkt an das Stroma angrenzen, baben meistens ihre cylindrische Gestalt unverändert bewahrt. Theils weisen aber auch die in den Nestern vorhandenen Carcinomzellen durchgreifende Veränderungen auf. Einzelne Zellen enthalten Vacuolen der Fetttröpfchen, theils findet man in ihnen Reste anderer Zellen als Zelleinschlüsse, oder Fragmentation von Kernen; eigentlicher Zerfall der Zelle ist aber nicht zu finden. Da diese stark mit Flüssigkeit imbibirten Stellen durch die Fixations- 
methoden leicht Risse und Sprünge erhalten, kommt es zu einer maschenartigen Structur in den Carcinomalveolen, wobei die Zwischensubstanz deutlicher sich differenzirt und hervortritt und die mehr oder minder. zwar noch erhaltenen, aber doch degenerirten Zellen, besonders aber die länglichen Kerne, welche wohl den fixen Bindegewebszellen ähueln, lassen Bilder entsteben, welche sehr an Sarkom erinnern (vgl. Tafel V. Figur 3). Hier hilft nur der Nachweis der Entstehung dieser Verhältnisse aus Epithelien, also ein eingehendes histologisches Studium des ganzen Tumors.

Sonst wäre noch kurz als das Gemeinsame auf allen Schnitten dieses Tumors zu erwähnen die Neigung der Cylinderzellen, kleine, mehr gradratische Zellen oder cylindroide Formen zu erzengen, welche in einer oder mehreren Lagen das Drüsenlumen umschliessen. Daneben finden sich auch Drïsen, deren einschichtiges, niedriges Cylinderepithel eine feine Strichelung aufweist, während dicht daneben sofort die regellose Proliferation dev Zellen losgeht. Je mehr man sich von der Matrix entfernt, desto mehr überwiegen die degenerativen Processe, bis man zuletzt im Gewebe nur. Detritus antrifft.

Besonders schöne Bilder des Ueberganges vom Cylinder- in polymorphes Epithel liess der folgende Fall erkennen, der auch noch in anderer Hinsicht böchst interessant ist.

Fill V.

53 jährige Parientin, welche noch regelmässig menstruirt ist, bemerkte, dass ihr Leib dicker wurde, wathrend sie selbst abmagerte, and die Periode in der letzten Zeit stixker wurde.

Status praesens: Portio mit Querriss steht in der Sp.-Linie: Uterus etwas vergrössert, nich schmerzhaft, anteflectirt. Dicht neben ihm und selbst in Narkose nicht sicher von ibru abzugrenzen zwei das ganze kleine Becken, und den Douglas ausfüllende, solide, höckerige Tumoren, welche wahrscheinlich den beiderseitigen Adnexen angehören; Ovarien nicht zu finden, Parametrien, so weit erreichbar, frei.

Da unsere Diagnose auf metastatische, sicher maligne Ovarialtumoren, wahrscheinlich secundare Ovarialcarcinome lautete, wurde durch Laparotomie der Uterus im Zusammentang mit seinen erkrankten Adnexen entfernt. Patientin ïberstand den Eingriff gut und ist noch nach $g^{1} / 2$ Jahren recidivfrei.

De* Uterus ist gut $11 / 2$ faustgross; in Corpus bofindet sich ein von der rechten Wand dicht unterhalb der Tube ausgehender, auf der Oberftache zerfallener Tumor, welcher bis fast zum inneren Muttermund hinabreicht. Die Nieubildung dringt weit in das Hyometrium hinein: diesas ist papierdīnn und etwas zom Tumor abgehaben; die Serosa ist intact; in der Cervix ein vereinzelter, haxter Knoten. Beide Tuben sind isolirt nicht zu erkemen, sondern gehen direct in einen links kindskopt-, rechts über mannskopfgrossen Tumor aber, der den reränderten Ovarien entspricht. Beim Durehschneiden ist die Ovarialsubstanz kaum mehr zu erkennen, sondem es senken sich ron der" Oberfluche des Tumors mehrere breite, weisse Stränge in das Innere hinab.

Zur mikroskopischen Untersuchung wurden un Schnitte aus dem Tumor im Fundus und den Ovarien entnommen.

Histologisch zelgt es sich, dass an die Muscularis anstossend and noch seho weit in sie hineinatehend eine rege Neubildung won Drüsen 
stattgefunden hat, deren Grösse und äussere Gestalt eine sehr wechselude ist, und die nur durch wenig Zwischengewebe getrennt sind; in diesem befinden sich neben reichlicher Leukocyteninfiltration auch die Blut- und Lymphgefässe. Meist fübren die Drüsen ein zweischichtiges, cylindrisches Epithel mit verschwommener Grenze und einen variabel gestalteten und gelagerten Kern. An diesen Stellen ist besonders der Uebergang des mehrzeiligen Cylinderepithels in mehrschichtiges und dann ein platteres, polymorphes zu erkennen. Um die Drüsen zieht ein mehrzeiliges Cylinderepithel mit abnorm hohen Zellen und grossen, peripher gelegenen Kernen. Mitosen sind zwar reichlich, aber nicht pathologisch und gegen das Lumen der Drüse zu vorgerückt. Die Zelle weist deutlich die Differenzirung in den basalen und secernirenden Theil auf; letzterer enthält ziemlich viel Schleim. Plötzlich werden die Cylinderzellen etwas niedriger, so dass sie die Höhe nicht mehr ganz erreichen und die benachbartc Zelle füllt durch Emporrïcken diese Läcke aus, während der Kern grösser, aber weniger lang wird; das mehrzeilige Epithel ist in das mehrschichtige übergegangen. Diese so veränderten Zellen geben nun auch schon bald ihre neue Gestalt preis, und es legt sich ein Stratum von 4-5 polymorphen Zelllagen übereinander, von denen in den obersten Schichten noch in etwa Anklänge an die Cylinderform zu erkennen sind, deren basale aber eine ganz willkürliche und regellose Formation und Zellcharakter aufweist. Auch die Kerne haben an der Veränderung theilgenommen; in den cylindroiden Zelien sind sie mehr länglich, in den polymorphen aber plump und rund. Figur 4 weist am besten diese Verhältnisse auf; es ist auch unschwer zu erkennen, wie bei letzteren die Zellgrenzen immer verwaschener werden und allmählig so zurücktreten, dass die eine in die andere überzugehen scheint.

Auch in diesen Präparaten giebt es Stellen, die auf den ersten Blick als ein Rundzellensarkom angesprochen werden könnten; daneben finden sich damn reichliche Leukocyten. Neben relativ gut gelungener Drüsenimitation findet man dort sehr vielen Detritus; es fehlen aber zwischen den eimzelnen Zellen die Intercellularbrücken; die Grenze ist oft sehr verschwommen, so dass scheinbar in einer grossen Zelle mehrere Kerne liegen; jedoch bei scharfer Einstellung lässt sich stets die Grenze, wenn auch nur mit Mühe erkennen. An anderen Stellen ist wieder ein durchaus anderes Bild vorhanden: In einzelnen dieser kleinen, quadratischen Zellen sind sehr grosse, fast die ganze Zelle ausfüllende Kerne, so dass der spärliche Rest Plasma wie an die Wand gedrückt erscheint; die Drüsenwand führt mehrschichtiges, etwas plattes Cylinderepithel mit nur sehr kleinen, aber distinct gefärbten Kernen. An diesen Partien ist das interglanduläre Bindegewebe bis auf den letzten Rest geschwunden und nur noch durch feinste Capillaren angedeutet. Wieder andere Partien Iassen in bunter Reihenfolge ein- und mehrschichtiges Fpithel wechseln; erstere haben noch eine Basalmembran und einen helleren centralen Theil, während aber die Tunica propria auch hier abgeht. Dort, wo benachbarte Zellen aneinander stossen, ist an Stelle der Cylinderepithelien ein mehrschichtiges, wirrgelagertes polymorphes Epithel getreten; es ähnelt hier ganz entfernt dem gewöhnlichen Carcinom.

Dann also folgt die Beschreibung der Ovarialtumoren. Das normale Gewebe des Ovarium ist total vernichtet, nur an ganz wenigen Partien sind die letzten Parenchymreste inmitten des Stromagewebes zu erkennen. An Stelle der Follikel und Eier ist eine ansgiebige Wucherung 
feinster Capillaren und bedeutende kleinzellige Tnfiltration erfolgt; in und besonders auch um die neu gebildeten Lymphspalten sind etwas grössere, den Epithelen äbnelnde Zellen mit sehr scharf tingirten. grossen Kernen. Nur die alleräusserste Rindensehicht ist noch ziemlich intact, aber auch hier zeigt das Epithel papilläre Wucherungen; das eigentliche Gewebe des ursprünglichen Ovarium ist an zahlreichen Stellen durchsetzt von verschieden grossen, neugebildeten Drüsen, ähnlich denen in der Uterusmucosa, welche durch ziemlich reichliches Bindegewebe mit kleinzelliger Infiltration von einander getrennt in Nestern zusammen liegen (Taf. V, Fig. 5). Sowohl um die Nester, als auch um die einzelnen Drüsen lässt sich keine Membrana propria finden; die grösseren der Nester lassen im Centrum eine homogene, hell gefärbte Masse erlsennen, in weleher sich neben spärlichen Leukocyten ganz vereinzelte Carcinomepithelien befinden; auch sind stellenweise Vacuolen und Löcher vorhanden, so dass ein siebartiges Aussehen resuitirt. Die Epithelverhältnisse der nen gebildeten Drüsen sind im Ganzen die gleichen wie beim Primärtumor, nur dass es einzelne Stellen giebt, wo die eine Seite der Drüse einschichtiges Epithel aufweist, während die andere plötzlich ohne Uebergangsformen die Vielschichtung erkennen lässt; es fehlen also in der Metastase im Gegensatz zum Primărtumor die Uebergänge einer Epithelformation in eine andere, sondern der Wechsel vollzieht sich ganz unvermittelt. Im Innem der selbst hochgradig veränderten Drüsen sind neben Schleim auch Fibrinniedersehläge (dureb die specifische Weigert'sche Färbernethode als solche erkenubar) an einzelnen Stellen des Ovarialadenocarcinoms zu sehen, während den neu gebildeten Uterindrüsen jede Fibrinausscheidung abgeht. Sonst wäre noch zu erwähnen der Befund einzelner Riesenzellen mit zahlreichen, wandständigen Kernen im Stromagewebe und der Umstand, dass in der Metastase die Polymorphie des Epithels einen noch viel höheren Grad erreicht hat, als im primären Carcinom des Fundus; jedoch findet man anch einige spärliche Drüsen im Gewebe, die ein ziemlich hohes, gut erhaltenes Cylinderepithel in nur einschichtiger Lage aufweisen, wo aber trotzdem schon die Tunica propria der Drüsen sich selbst ungefärbt nicht mehr nachweisen lässt.

In Fall I ist die pseudocarcinöse Zeichnung beschrieben, wie sie durch ein zerfallendes Carcinom gebildet wurde; nun giebt es aber auch zweifelsohne Uebergänge von Adenocarcinom in das gewöhnlich-alveoläre. Schön zeigt uns dieses Verhalten der folgende

\section{Fall VI.}

Die 43 jährige Patientin wal" stets gesund, klagt aber über Kreuzschmerzen, stinkenden Ausfluss und abnorm starke Periode seit drei Jahren, so dass die intermenstruelle Zeit stets kleiner werde, während der Blutabgang zunehme. In den zwanziger Jahren drei Spontangeburten und ein Abort mensis IIr.

Uterus liegt anteflectirt und stark vergrössert, entsprechend dem VI. Graviditätsmonat; Portio intact. Bei dex Untersuchung blutet es sehr stark and es gehen mit dem Blut einige Fetzen ab, bei welchen die Diagnose auf ein Carcinom gestellt wurde. Adnexe und Parametrien frei.

Darauf wurde die abdominale Totalexstirpation mit Zurücklassung- 
der Adnexe vorgenommen. Pat. starb jedoch schon nach 3 Monaten an einem Carcinomrecidiv der Narbe.

Der Uterus ist kolossal vergrössert; seine Höbe beträgt $21 \mathrm{~cm}$, seine Dicke $5 \mathrm{~cm}$, wovon jedoch auf die eigentlich noch als gesund za bezeichnende Muscularis nur $0,2 \mathrm{~cm}$ entfallen. Das ganze Corpus ist eingenommen von einem grossen Tumor, welcher von der hinteren, oberen Wand kurz unterhalb der Tube abgeht; seine Oberfläche ist ganz zerklüftet, theils blutig imbibirt. Nach unten erstreckt sich die Neubildung über den inneren Muttermund bis dicht an die Portio, lässt aber diese selbst intact. Serosa glatt; jedoch an der Uebergangsstelle zur Blase sitzt ein erbsengrosser Knoten, welcher sich später als carcinomatös erwies.

Histologisch enthalten die Schnitte Muscularis und Mucosa: die glatte Nuskulatur ist ödematös durchtränkt und enthält dort, wo eine reichere Bindegewebsanhäufung ist, eine ziemlich bedeutende kleinzellige Infiltration, welche besonders in den perivasculären Lymphräumen vorhanden ist. Die in dem Myometrium verlaufenden Gefässe sind strotzend mî́ Blut gefüllt und in ihrer Wand verdickt; die elastischen Lamellen sind theils in hyaline Schollen zerfallen, die ohne Zusammenhang neben einanderliegen, theils nicht gefärbt, aber als ungefärbte Tafelu deutlich noch erkennbar. In der Umgebung der Gefässe ist eine geringere kleinzellige Infiltration vorhanden. Dabei ist anch das Bindegewebe gewuchert und sind besonders dessen fixe Zellen beträchtlich vermehrt. An der Grenze zwischen Muscularis und Mucosa nimmt die kleinzellige Infiltration an Stärke zu, nnd das Gewebe ist stärker gelockert als in den anderen Partien.

Sodann findet man in den Lymphspalten ziemlich reichlich kleine, rundliche oder auch ovoide Zellen mit grossen Kernen, theils isolirt, theils zu mehreren ohne Intercellularsubstanz neben einander gelagert und die gleichen Gebilde, wenn auch viel spärlicher, im benachbarten Bindegewebe und zwischen den Muskelfasern zerstreut. Die Grenze zwischen Muscularis und Mucosa ist keine scharfe Linie, sondern es finden sich Vorsprünge und Ausbuchtungen, und zwar greift die Mucosa verschieden tief in das Myometrium hinein und durch solide Zapfen werden Theile der Muskulatur losgerissen und als Fragmente in die gewucherte Mucosa verschleppt. Der Drüsenbau der Schleimbaut ist nicht mehr zu erkennen. Grob histologisch ziehen derbe Bindegewebszüge nach verschiedenen Richtungen durch das Mucosagewebe, welche ein grossmaschiges Netz bilden, dessen Lücken mehr oder minder angefüllt sind mit kleinen, gut tingirten Zellen. Die Bindegewebsfibrillen sind stark auseinandergedrängt, theils durch Oedem, theils aber auch durch eine ungemein reiche Leukocyteninfiltration, welche sich in und um den Lymphbahnen befindet. Auch die fixen Zellen des Bindegewebes sind in ihrer Zahl sehr vermehrt; neben den Leukocyten aber finden sich auch in reicher Menge die Zellen vor, welche in den Maschen des Netzes liegen. Die sehr sparrichen Capillaren sind alle strotzend mit Blut gefüllt and weisen einen geschlängelten Verlauf auf, die Maschen des Netzes selbst sind ausgefüll mit Zellen verschiedener Grösse und Gestalt, welche theils isolirt, theils in Haufen dicht nebeneinander liegen ohne Intercellularsubstanz. Die Conturen der Zellen sind theils scharf, theils verwischt, theils gehen von einigen wenigen Zellen wie feinste Ausläufer ab, welche aber mit benachbarten Zellẹn nicht in Verbindung stehen. 
音

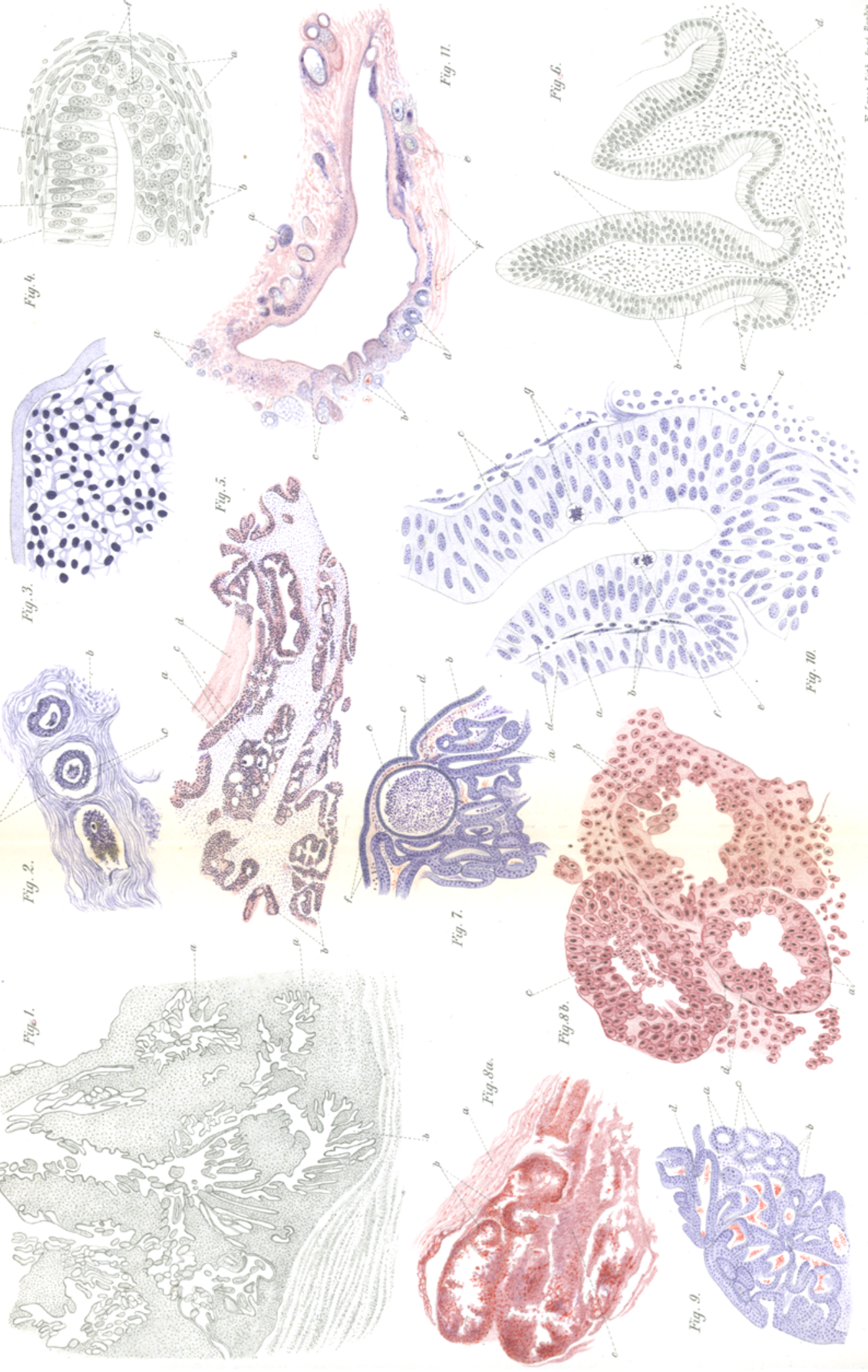


322 Offergeld, Veber die Histologie der Adenocarcinome im Uterusfundus.

Die Kerne sind meist in der Vitte gelegen, in nu: wenigen Fällen excentrisch, haben rundliche Gestalt und sind scharf gefärbt; es sind das eben dic Zellen, wie man sie in jedem Carcinoma simplex antrifft. $Z$ wischen diesen finden sich noch zahlreiche weisse Blutkörperchen einrelagert, welche man an ihrem gelappten Kern deutlich erkenuen kann. Nun sind an den Stellen des Präparates, welche an die Muscularis anstossen, also im Bereiche der ursprünglichen Schleimhaut des Corpus, noeh die Reste der Adenocarcinombildung zu sehen. Umgeben ron einem ziemlich dicht angeordneten Bindegewebe mit nur ganz geringer kleinzelliger Infiltration liegen verschiedene grössere Drüsen, deren Lumen yon einer Reibe concentrisch angeordneter, ziemlich hoher Cylinderzellen begrenzt ist, welche ein helles Plasma und tief dunkel gefärbten Kern aufweisen. Diese Zellen sind durchschnittlich an der Basis dunkler tingirt und haben einen helleren, fein gestrichelten Saum; aber selbst in diesen Stellen ist die Tunica propria total geschwunden und nicht einmal mehr ungefärbt zu erkennen. Jedoch giebt es auch in den gleichen Drüsen Partien, wo diese Cylinderzellen ein mehr quadratisches Aussehen annehmen, iln Fürbevermögen sich stark ändert und der Kern verblasst; an diesen Stellen sind statt einer Lage deren zwei oder noch mehr. vorhanden und diese liegen nicht concentrisch um das Lumen, sondern bunt durch einander. Hier gehen die Carcinomzellen direct in das umgebende Bindegewebe hinein und rertheilen sich dort weiter bis sie za denjenigen stossen, welche, wie oben beschrieben; die Maschen des bindegewebigen Netzes im Stroma ausfüllen. An einzelnen Drüsen wächst von der Stelle aus, wo die regellose Zellneubildurg in der Drüsenwand vor sich geht, von der Wand ein solider Zellstrang in das Lumen der Drüse hinein im Begriffe den alveolären Bau zu rerwischen und die Drüse als solche zu zerstören; auch in diesem Strange sind einige Leukocyten anzutreffen. Diese letzten Reste der Imitation von Drüsen liegen zerstreut im Gewebe, theils isolint, teils mehrere nahe bei einander. An einer Stelle sind zwei solcher Drüsen contiuirt, die Scheidewand ist durch eine stellenweise unterbrochene Reihe kleinerer Zellen in mehreren Lagen gebildet.

Neben diesen echten Drüsennembildungen finden sich zahlreiche, wie im ersten Falle beschrieben, durch centralen Zerfall und Degeneration entstandene Pseudoacini. Man kann sie am ehesten ron den echten dadurch unterscheiden, dass die Conturen ihrer Zellen stark rerwischt sind und die Farbbarkeit eine nur sehr mangelbafte ist. Man findet an diesen stellen ron einem xiemlich gut entwickelten bindegewebigen Stroma umschlossen, dessen fixe Zellen vermehrt sind, revschiedenartig gestaltete, theils isolnte, theils auch in Hanten zusammenliegende dritsenartige Gebilde, dessen eine Seite ans polymorphen Zellen besteht, walliend sich im Lumen und dem grössten Theil der Peripherie zahlreicher Detritus vorfindet: diese Zerfallsmasse setut sich danm weit in das umgebende Bindegewebe fort und lasst bald jede Andeutung ron neugebildeten Drüsen verschwinder.

Fernerhin muss man wohl unterscheiden, ob das Epithel wirklich mohrschichtig ist; diese Mehrschichtong kann bisweilen senr zu Täuschungen führen, wenn es sich um Sohrägschnitte handelt, oder aber das Epithel mehrzeilig ist, $d$. h. die einzelnen Keme in 
verschiedener Höhe der Zellen stehen; meist jedoch findet man dann an anderen Stellen typische Bilder.

\section{Fall VII.}

Die 40 jäbrige Patientin hatte stets 6-7 Tage dauernde Henses mit starken Blutungen in regelmässigen vierwöchentlichen Abständen; seit 2 Jahren sind sie häufiger und dauern länger; während 6 Wochen fortwährende Blutung, in der Zwischenzeit Fluor. Seit 2 llonaten bemerkt sie, dass sie abgemagert sei, führt das aber zurück auf ein vor zwei Jahren entstandenes Ulcus ventriculi. Sie machte 7 Spontangeburten, die letzte vor 13 Jahren durch; niemals puerperale Infection; wurde früher wegen Fluor und Erosionen an der Portio öfters gynäkologisch behandelt.

Portio zeigt viele Einrisse, steht in der Sp.-Linie; Uterus nicht vergrössert, anteflectirt, etwas schmerzhaft; Adnexe, Para- und Perimetrium ohne Besonderheiten.

Es wurde dann, nachdem die diagnostische Ausschabung eine maligne Neubildung im Uterus erkennen liess, die vaginale Totalexstirpation nnter Zurücklassung der Adnexe vorgenommen mit dem Thermokauter. Die beiderseits abgeklemmten Lig. lata wurden nicht genäht, sondern die Klammern blieben 48 Stunden liegen. Mikulicz'sche Tamponade; Entlassung nach 14 Tagen.

Weiterer Verlauf unbekannt.

Der exstirpirte Uterus ist nicht vergrössert; das ganze Carum ist vom Corpus bis zur Cervix eingenommen von einer etwa $1 / 2 \mathrm{~cm}$ breiten carcinomatösen Infiltration, welche in einzelne Lappen zerfallen ist. In der vorderen Muttermundlippe eine kirschkerngrosse Cyste mit serösem Inhalt; Serosa glatt; Muscularis nicht verdickt.

Histologisch enthalten die Schnitte Muskulatur und Schleimhant. Erstere ist im Stadium der chronisch-interstitiellen Entzündung; die Fasern sind auseinander gedrängt durch Oedem, das Bindegewebe ist gewuchert, seine fixen Körper vermehrt, gleichfalls sind Leukocyten in reichlicher Anzahl vorhanden; daneben weisen die Gefässe entzündliche Veränderungen zumal in der Media auf, sowohl die Venen als besonders die Arterien. In der Mucosa liegt in einem stellenweise reichlichen, sonst aber auch nur spärlichen bindegewebigen Stroma eine Menge neugebildeter Drüsen verschiedener Grösse und Gestalt. In diesem sind die Fasern einzeln auseinander gedrängt durch eine ungemein reiche, kleinzellige Infiltration, welche besonders reichhaltig und concentrisch ist um die neugebildeten Drüsen. Die fixen Bindegewebsellen sind nicht besonders vermehrt. Durch den Härtungsprocess sind an einzelnen Stellen die das Drüsenlumels umgrenzenden Epithelien von der Unterlage etwas zurückgewichen; hier hat es den Anschein, als sei die Tunica propria um die Drüsen erbalten, jedoch bei genauerem Zusehen zeigt es sich, dass es sich nur um einzelne Bindegewebsfasern handelt, zwischen welchen ziemlich reichlich Leukocyten eingedrungen sind - es sind das die gleichen Zellen wie sie ins Bindegewebe eingewandert sind - so dass sie nicht etwa als Kern im Gewebe selbst liegen, sondern nur auf den Bindegewebsfasern reiten. Diese um die Drüsen laufenden Fasern sind meist concentrisch angeordnet mit spärlichen Verbindungsbrücken zwischen den einzelnen Fibrillen; ganz besonders deutlich und klar wird der Sachverhalt da, wo einzelne Leukocyten über die Grenze des Bindegewebes hinausgegangen sind und in dem künstlich geschaffenen 
Hohlraum liegen. Auch in diesem Präparat ist stellenweise die gewucherte Mucosa gegen die Muscularis vorgedrungen, umgeben von einer ungemein zahlreichen kleinzelligen Infiltration, welcher in ibrem Bereiche das ganze muskuläre Element zum Opfer gefallen ist. Das Drüsenepithel ist ein niederes, cylindrisches, das Plasma hell, der Kern ziemlich gross, scharf conturixt und gefärbt.

Die Zellen liegen durchweg in zwei Schichten übereinander, sind aber im Allgemeinen wir durcheinander geworfen. Die das Lumen begrenzenden Partien sind ausnahmslos heller gefärbt als die basalen. An einer Stelle ist eine grosse Polymorphie des Epithels vorbanden, indem es sowohl zweischichtige, hohe Cylinderzellen giebt, als auch kleine, mehr cubische Zellen, welche in dreifacher Lage den Zellhelag ausmachen. Für gewöhnlich findet unter Zunahme der. Dicke des Epithelbelages auch eine Mehrschichtigkeit und Miedrigerwerden der Zellen statt, wobei sich gerade hier in der Umgebung eine beträchtliche Vermehrung der Leukocyten feststellen lässt. Das Lumen der neugebildeten Druisen hat mancherlei Gestalt; die annähernd noch normalen. also die, welche ziemlich hohes einschichtiges Cylinderepithel führen, sind scharf tingirt and unterschieden in der Färbung, während die kleinen platten Zellen sebr viel heller sind; ihr Plasma weist keine Körnung auf, der Kern ist abnorm gross und weniger scharf conturirt, wenn anch relativ gut gefärbt. Die Zellgrenzen sind aber anch hier noch deutlich zu erkennen. Daneben giebt es andere Drüsen, welche ein normales, hohes einschichtiges Cylinderepithel führen, welches zwar an einzelnen Stellen dadurch, dass die Zellen ihre Palisadenform verloren und benachbarte sich so gelagert haben. wie es gerade der Raum gestattet, zu einem mehrzeiligen geworden ist (Tafel V. Figur 6); aber in der gleichen Drüse giebt es Partien, wo sei es plötalich oder. unter Uebergangsformen das mehrzeilige in das mehrschichtige Epithel uborgeht; man trifft hier regelmässig eine Unmenge kleiner wirt durcheinander gewürfelter Zellen an, in deren Umgebung sich eine starke kleinzellige Infiltration befindet.

In diesen Präparaten giebt es nun eine Reihe von Schnitien, wo die Drüsen verschieden grosse Cysten gebildet haben (Cystadenocarcinome). Auch hier weist der Epithelbelag eine starke Polymorphie auf; man findet neben einschichtigem Epithel auch zwei- und mehrschichtiges. Der. Cysteninhalt besteht aus einer homogen gefärbten Masse; in der näheren und entfernteren. Umgebung hiervon befindet sich im Binde. gewebe eine reichliche Leakocyteninfiltration, deren Elemente in mehreren Schichten concentrigoh die Drüsen umspinnen; meist begegnet man den cystischen Bildungen an der Grenze der Muscularis. Dagegen sind wieder andere Stellen vorhanden, wo man nur Bilder zu Gesicht bekommt, wie man sie bei den Mischformen der glandulären und interstitiellen Endometritis antriff, wenn also neben einer Bindegewebshyperplasie gleichzeitig eine Nenbildung von. Drüsen eingesetzt hat.

Aber auch hier hat das Epithel schon jbm ganz fremde Eigenschaften angenommen. Zwar fehlt die Hehrschichtigkeit, aber die einzelnen Zellformen weichen in verschieden hohem Maasse von der Norm $\mathrm{ab}$, die Capsula propria um die Drüsen fehlt vollständig und trotz der entzündlichen Wucherung ist das interglandulare Bindegewebe zurückgedrängt. Dicht daneben ist ein fast volliger Schwond des Stromagewebes erfolgt und war durch eine ganz excessive. Neabildung won Drüsengewebe selbst, wahrend in dem nur spatrlichen Bindegewebe sich 
massenhaft Leukocyten befinden. Die Drüsenkapsel ist dahin, das Epithel ein- oder auch schon mehrschichtig; die Zellform ist theils cylindrisch, theils cubisch mit platten Zellen; nur einige wenige, aus dem Verbande isolirte Cylinderzellen sind den normalen durchaus ähnlich; sie führen einen feinen gestrichelten Saum; dieser aber fehlt dort, wo die Polymorphie des Epithels anfüngt unter gleichzeitigem Verlust des für die normalen secernirenden Epithelzellen so charakteristischen Differenzirungsvermögens Plasmafarbstoffen gegenüber. Von da geht es dann schnell zum typischen Adenocarcinom über: unter totalem Schwund des Bindegewebes kommt Drüse an Drüse zu liegen, deren Epithelsaum ein meist sehr schönes, ausgeprägtes zweischichtiges Cylinderepithel darstellt. Sehr schön ist in fast allen Schnitten dieses Tumors die Sekretproduction der selbst malignen Epithelien zu sehen und die wahrscheinlich charakteristisch hierdurch veranlasste starke kleinzellige Infiltration um die Drüsen herum.

Die folgenden 4 Fälle bieten histologisch nichts Neues; ich will sie nur der Vollständigkeit wegen hier kurz anführen:

\section{Fall VIII.}

Aus der Anammese liess sich bei der 47jährigen Patientin ein maligner Tumor im Uteruscavam diagnosticiren; diese Vermuthung wurde durch die Probeansschabung auch bestätigt. Daber wurde, weil gleichzeitig eine entzündliche (?) Verdickung des Parametrium bestand, der Uterus mit den Adnexen per laparotomiam entfernt. Schon 6 Monate später Recidiv in den rechten Iliacaldrüsen; dieses etwa faustgrosse Drüsenpacket wurde exstirpirt. Nach weiteren 8 Monaten Recidiv in der vaginalen Narbe, breite Infiltration im Stumpfe der Vagina. Exitus letalis 16 Nonate nach der Laparotomie an Kachexie.

Uterus ist nicht vergrössert, Serosa glatt; im Cavum sitzt an der rechten Tubenecke ein auf der Oberfläche zerfallener, etwa pflaumengrosser Tumor, welcher sich scharf vom Gesunden abgrenzen lässt. Muscularis nicht verdickt. Vom Corpus lassen sich einige Lymphbahnen als feinste weisse Stränge durch die Cervix bis ins Parametrium verfolgen.

Histologisch enthalten die Schnitte Muscularis und Vucosa; erstere weist die bekannten Veränderungen auf; besonders sind die Gefässe stark betheiligt. Die Grenze ist im Allgemeinen scharf, wenn auch einzelne Stränge der Mucosa in die Musculatur eindringen. Hier findet man eine zahlreiche kleinzellige Infiltration, welche in verschiedenem Maasse die bindegewebige Grundsubstanz auseinander gedrängt hat. In der Mucosa liegt Drüse an Drüse; das Zwischengewebe ist in Spuren vorhanden, nur an einigen wenigen Stellen etwas stärker entwickelt und lässt bier auch die Leukocyteninfiltration erkennen. Bei dem sehr excessiven Drüsènwachsthum ist die Tunica propria um die einzelnen Drüsen geschwunden, so dass stellenweise die weissen Blutkörperchen bis dicht an die Drüsen heranreichen. Soweít die äussere Form in Betracht kommt, herrscht bei den Drüsen die Neigung vor, lange Schläuche mit reichlicher Ramefication zu bilden; diese Hohlräume sind mit variabel gestaltetem Epithel ausgekleidet. Zunächst herrscht auch hier wieder die Form eines schmalen, ziemlich niederen Cylinderepithels vor in zwar Mehrzeilung, aber nur einer Schicht; sodann giebt es auch verschiedene, wo echte Mehrschichtigkeit des Cylinderepithels sich 
nachweisen lässt; in diesen Fällen werden die Zellen im Allgemeinen kleiner, während die Kerne so ziemlich ihre Grösse behalten, und die Zellform ändert sich insofern, als sie flacher werden und sich mehr auf die Kante stellen, so dass sie statt in Reih' und Glied sehr bald bunt durcheinander zu liegen kommen. Auf diese Weise kommen bis zu drei und mehr Schichten zu Stande, welche alle einen rundlichen, ziemlich grossen, central gelegenen Kern erkennen lassen. Beachtenswerth ist der Umstand, dass das Plasma der Cylinderzellen sich viel besser: tingirt hat, als das der polymorphen, dass ferner ersteres mur sebr wenige, letzteres dagegen viele Granula zeigt; es lassen sich aber auch hier die einzelnen Zeligrenzen noch scharf von einander unterscheiden, eine syncytiale Umwandlung findet nicht statt. An anderen Drüsen ist von vornberein entweder ein mehrschichtiges Epithel mit polymorphen Zellen vorhanden, oder aber ein zweischichtiges Cylinderepithel von mur sehr geringer Zellhöhe. Die nicht so spärlich vorhandenen Kerntheilungen sind häufig pathologisch, und zwar herrscht hier hauptsächlich die Form des Triasters vor; sodann haben andere Drüsen nur auf der oinen Seite einen annähernd normalen Cylinderepithelbelag, welcher dann unter Flacherwerden der Zellen in mehrschichtiges Epithel übergeht, wahrend der Kern in den kleinen Zellen seine Grösse, Gestalt und Lage beibehalten hat. An der Grenze der Sehleimhaut und Musculatur, wo erstere in letzere hineingewuchert ist, sind im Allgemeinen nur sehr wenig Drüsen von normaler Gestalt, dagegen sehr viele dendritiscls verzweigte; das Epithel zeigt ein sehr wechselndes Verhalten in Form und Gestalt; die Cylinderform fehl, dafür sind kleine, glatte Zellen eingetreten.

\section{FalI IX.}

Das Präparat entstammt einer 59jährigen Patientin, welche wegen atypischer Blutungen nach 14 jähriger Menopause zur Klinik kam; der Cterus wurde sammt den Adneren vaginal entfemt. Die Frau wurde nach kurzer Zeit entlassen, starb aber nach $21 / 2$ Jahren an Peritonealcarcinose, wobei leider nicht der Ausgangspunts zu erfahren ist, ror Allem, ob sie im Zusammenhang mit dem Cteruscarcinom stand.

Der Uterus ist nicht veryrössert, die Serosa glatt. Im Corpus sitzt an der hinteren Wand ein phaumengrosser Tumor mit glatter Oberfache, in der Vorderwand sind einige stecknadelkopf- bis bohnengrosse Neubildungen der gleichen Beschaffenheit, desgleichen noch zwei weitere an dem rechten uterinen Tubenostium. Ob erstere durch Contact mit dem soliden Knoten der hinteren. Wand entstanden sind, ist fraglich.

Histologisch enthalten die Prapparate Musculatur und Bohleimhaut; erstere ist im Ganzen wenig: verändert, dagegen sind die Gefasse atark verdickt und lassen auf entzündliche Veränderungen in ihrer Wandung schliessen. An der Grenze beider Schichten ist eine ziemileh starke, kleinzellige Influtration; die Grenze ist im Grossen und Ganzen zwar scharf, aber die Mucosa ist rerschiedentlich gewtehert and hat die Muscularis zurückgedrängt. Dje fibrilläre Grundsubstanz der Mucosa ist auseinander geschoben durch eine reiche Lenkocyteneinwandernng und in Lebrigen durchsetzt von dicht aneinander liegenden kleinen Zellen ohne Intercellalarsubstanz. Ihre Form ist wechselnd, meist cubisch, theils aber auch cylindroid, das Plasma hell, in nur gane rereinzelten Partien die Granulaton des Zellleibes leicht angedentes, der Kern selber auch scharf contmint und gefarbt. Diese Zellen liegen in 
Haufen beieinander und sind nur die Nester durch spärliche Bindegewebszüge voneinander getremnt. Sodann finden sich in zahlreicher Anzahl die bekannten, durch centralen Zerfall und Vacuolenbildung entstandenen pseudoacinösen Fijguren, deren Epithel ein rollständig polymorphes ist, und wo es den Anschein gewinnt, als sei von einer Stelle aus ein solider Zellstrang in die Drüse hineingewuchert, wäbrend in Wabrheit es sich nur um Degenerationserscheinungen in einem Carcinomstrang handelt. Dann giebt es aber auch vereinzelte, noch ziemlich wohlerhaltene Drüsen, denen zwar die Tunica propria fehlt, welche aber noch ein ziemlich hohes, zweischichtiges Cylinderepithel haben, mit tiefer tingirter, basaler und blasserer oberer Lage; die Kerne sind gut gefärbt und ziemlich gross, von rundlicher Form. Gerade in der Lmgebung der noch intacten Drüsen macht sich eine starke Leukocyteninfiltration bemerkbar; diese noch vorhandene Drüsenueubildung ist nur auf das Gebiet der Mucosa bescbränkt; die Stränge, welche gegen die Muscularis hineindringen, sind solide, bestehend aus typischen Carcinomzellen; in der Nachbarschaft dieser soliden Stränge sieht man nur geringe kleinzellige Infiltration.

\section{Fall X.}

Der nicht vergrösserte Uterus wurde unter Zurücklassung der Adnexe vaginal exstirpirt bei einer 63 jährigen Patientin, welche seit dieser Zeit - 4 Jahre sind es her - recidivfrei ist. Die Serosa ist glatt, die Musculatur nicht verdickt. Das ganze Carum uteri ist ausgefüllt mit zerfallenen Massen, nach deren Entfernung sich in der hinteren Wand des Fundus ein nussgrosser Tumor mit zerklüfteter Oberfläche zeigt.

Histologisch enthalten die Schnitte Muscularis nond Mucosa; die Grenze zwischen beiden ist gut erhalten, nur zeigt sich eine geringe kleinzellige Infiltration. Das Myometrium führt uns die bekannten Verhältnisse der chronisch-interstitiellen Entzündung vor Augen. Das Bindegewebe ist nur mässig. entwickelt und führt eine ziemlich stark entwickelte kleinzellige Infiltration; zwiscben den Lücken des Stroma liegen die neugebildeten Drüsen ziemlich zahlreich, sowobl einzelne grössere und auch mehrere kleinere in Nestern zusammen. Im Bindegewebe sind die fixen Elemente stark gewuchert; die Membrana propria um die einzelnen Drüsen ist geschwunden, das Drüsenepithel ist ein polymorphes, mehrschichtiges; die einzelnen Zellen sind klein, hell gefärbt, mit einem sehr grossen, gut tingirten Kem, welcher central liegt. Diese Zellen sind in vollkommener Regellosigkeit in- und übereinander gelagert; ein nur annähernd unverändertes Cylinderepithel ist nicht mehr zu erkennen. Daneben findet sich sowohl in den Nestern, als auch in den Drüsen sehr viel Detritus, welcher besonders nach der freien Oberfläche zu stark zunimmt.

\section{Fall Xl.}

Das Präparat stellt den durch vaginale Totalexstirpation gewonnenen Uterus einer 37 jährigen Virgo intacta dar, welche wegen grosser Blutung, stiukendem Fluor und Kreuzschmerzeu zur Behandlung liam. Da das diagnostische Curettement eine maligne Erkrankung erkennen liess, so wurde die Operation vorgenommen in typischer Weise unter Zuhülfenahme des pararectalen Hülfschnittes nach Schuchlard; die Adnexe blieben erhalten; Pat. überstand den Eingriff gut und ist nach 3 Jahren nocls recidivfrei.

Der Uterus ist nicht vergrössert, sein peritonealer Ueberzug ganz 
328 Offergeld, Ueber die Histologie der Adenocarcinome im Uterusfundus.

glatt. Beim Aufschneiden findet sich ein von der vorderen Wand ausgehender, etwa kleinapfelgrosser Tumor, welcher auf der Oberfäche zerklüftet, das ganze Cavum ballonartig aufgetrieben hat und die Musculatur iuf etwa $I-1,5 \mathrm{~cm}$ zuriekdrängte. Am inneren Muttermund hatte er, makroskopisch betrachtet, Halt gemacht.

Histologisch enthalten die Schnitte Musculatur und Schleimhaut; das Bindegewebe der Muscularis ist stark mit Leukocyten infiltirt; die Huskeln sind durch. Oedem etwas auseinander gedrängt, die Gefässe in der Wandung verdickt. Die Grenze zwischen beiden Elementen ist gut erhalten, weist aber starkere, kleinzellige Infiltration auf. In der Wucosa ist das Bindegewebe sehr stark reducirt; in die spärlichen Züge ist eine beträchtliche Anzahl weisser Blutkörperchen eingewandert. Hier liegt Drüse an Drüse, welche mebrere zusammen durch eine Spur Bindegewebe zu Nestern vereinigt sind. Die Ylembrana propria um die einzelnen Drüsen ist geschwunden, die Gestalt letzterer sebr variabel, sowohl rundlich, wie länglich, als besonders in den peripheren Schichten der Mucosa stark geschlängelt und ineinander geschoben. Das Epithe] besteht durchweg aus kleinen, cubischen, hellen Zellen mit sehr grossem, peripheren, gut tingirten Kern, dessen Umrandung sehr scharf ist. Diese Zellen liegen in doppelter oder mehrfacher Lage übereinander; irgend eine regelmässige Anordnung und Debergänge vom Cylinderepithel lassen sich nicht feststellen; da keine dieser Drüsen letztere Epithelformation führt. In diesem Tumor ist das Lumen aller Dröisen leer, daher auch die kleinzellige Infiltration in der Umgebnng der Drïsen nur recht spärlich.

Sodann will ich berichten äber die vier Fälle, welche während meiner Assistentenzeit in der Klinik operirt wurden. Es kam mir nierbei besonders darauf an, ganz frische Stücke zu erhalten zum Studium der karyokinetischen Vorgänge, wie des Verhaltens der Epithelien an sich. Daher wurden die mit der Curette entfernten Uucosafetzen sofort, entweder in 4 proc. Formalinlosung, oder noch besser in das bekannte Chromosmiumsäaregemisch, bereitet nach der Vorschrift yon Flemming, geworfen. Auch wurde hierbei neben den eben angeführten Färbemethoden die Carminfärbung, sowohl allein, wie als Doppelfärbung mit Hämatoxylin erfolgreich benutzt; zur Untersuchung der Mitosen verwandte ich ausschliesslich die Eisen-Hämatoxylinfürbung nach Heidenhain. Ausgehend von der Voraussetzung, dass die Methoden wobl Allen, dio gynäkologische Histologie treiben, hinlänglich bekannt sind, und um Raum zu ersparen, will ich die Technik hier nicht beschreiben, sondern nur bemerken, dass toh mich strenge an die Vorschriften bielt, wie sie in 0 . Kahlden's Teehnik der histologischen Untersuchungen pathologisch. anatomischer Präparate. Jena 1902, angefuhrt sind.

Jch beschreibe also sofort die Fälle. 
Fall XII.

Die 39 jährige Patientin giebt an, ihre Menstruation stets regelmässig gebabt zu haben; diese sei in der letzten Zeit stärker geworden, in der Zwischenzeit bätte sich stinkender Ausfluss eingestellt; seit fünf Monaten habe sie Kopfschmerzen und sei abgemagert. In den zwanziger Jahren hatte sie 2 Spontangeburten, keine puerperale oder gynäkologische Erkrankung.

Tou chirbefund: Ostium geschlossen, Vagina weit mit begimendem Descensus beider Wände; Portio steht in der Spinallinie, ist zerklüftet, Uterus anteflectirt, nicht vergrössert, schmerzfrei, gut nach allen Richtungen beweglich; Adnexe ohne Befund.

Zur Stellung der Diagnose wurde die Probeausschabung ausgeführt.

Dessen Schnitte lassen Mucosa erkennen, welche mit verschiedenen grossen und zahlreichen Blutpartien, durch die Abrasio bedingt, untermischt ist. Es liegt hier Drüse an Drüse, die interglanduläre Substanz scheint ganz geschwunden zu sein. Nur an einigen wenigen Stellen, und zwar dort, wo die Drüsen bei ihrem Aneinanderstossen noch etwas Raum übrig liessen, bat sich die bindegewebige Grundsubstanz noch erhalten; man sieht hier die Fasern etwas auseinander gedrängt und zwischen ihnen einzelne Lymphbahnen, welche ganz voll Leukocyten stecken; diese Infiltration ist besonders stark an der Stelle, wo an das Bindegewebe direct die neugebildeten Drüsen stossen. Diese selbst zeigen eine ungemeine Variabilität in ihrer Grösse und Gestalt; man findet einmal solche, welche die runde oder längliche Form der Uterusdrüsen noch gewahrt haben, daneben aber hat die Neubildung durch ein ungemeines Wachsen die bizarrstel Formationen gebildet. Neben Invaginationen und korkzieherartigen Gebilden findet man meistens solche, welchen überhaupt keine einheitliche Form mehr zukommt, und die man am besten als polymorphe Drüsen bezeichnet. Diese bilden nun ihrerseits wieder Vorsprünge in das Innere, wie sie Zacken nach aussen senden. Allen Drüsen ist das Eine gemeinsam, dass die Membrana propria geschwunden ist, denn, wenn auch zwischen vereinzelten Drüsen ein ganz feiner, bindegewebiger Strang sich hindurchzieht, so ist dieser doch nicht mehr mit nur einiger Sicherheit als Drüsenmembran anzusprechen, als vielmehr als der letzte Rest des normaler Weise zwischen dem Parenchym in der gesunden Uterusmucosa rorkommenden Stromagewebes, welches die Grundsubstanz für die Drüsen darbietet, zu deuten. Es geht dies wohl am besten daraus hervor, dass in diesen Bindegewebsfibrillen sich keine Kerne nachweisen lassen, nicht einmal sich eine Anschwellung vorfindet, welche man als eine solche ansprechen könnte. Was nun das Epithel angeht, so ist es verschieden, je nach der Form der Drüse: die rundlichen oder ovoiden zeigen ein hohes, in Reih' und Glied nebeneinander stehendes Cylinderepithel mit grossem, ganz basal gelegenen Kern. Das Plasma ist in den peripheren Schichten leicht granulirt, während in dem das Lumen begrenzenden Abschnitt noch eine ganz feine Strichelung erkennbar ist. Nun giebt es Drüsen, welche den Typus der unveränderten Lterindrüsen sehr scharf beibehalten haben, während in benachbarten die Zellen schon ihre militärische Anordnung eingebüsst haben und sich anschicken, Epithelien zwischen die pallisadenartig. angeordneten Epithelien zu senden. Das führt zum dritten Bilde, nämlich der Mehrschichtigkeit des Epithels, wo der grösste Theil der Drüse ein normales, einschichtiges Cylinderepithel führt, während an einer Stelle, meist ganz plötzlich, die Zellen. 
viel kleiner sind, der Kern rund geworden ist und die Zellen in zweioder mehrfacher Lage übereinander liegen. Hierbei bat auch das Plasma seine scharfe Differenzirung eingebüsst. Die Kerne liegen in allen diesen Fällen an der Peripherie der Zellen, es handelt sich also nicht atwa um Schrägschnitte durch eine Drüse. Bei den länglichen Drüsen herrscht schon eine grössere Polymorphie im Epithel vor; an einzelnen Stellen ist noch ein ziemlich intaktes, wenn auch weniger bohes, einschichtiges Cylinderepithel vorhanden, dessen Zellen auch schon von der Senkrechten etwas abgewichen sind, während aber die feinere Differenzrrung im Plasma noch ziemlich scharf zu erkennen ist. Zwischen diesen Cylinderzellen findet man einzelne, welche einen grösseren Umfang angenommen haben und deren Kerne mehr rundlich sind; diese stehen ganz unregelmässig und baben schon deutlich den Charakter der Mehrschichtung angenommen. Indem nun diese Zellen unter theilweisem Verlust ihres Tinctionsvermögens kleiner werden, während der Kern annähernd seine Grösse beibehält, tritt an einer anderen Stelle der Drüse ein zwei- oder mehrschichtiger Epithelbelag auf, welcher binsichtlich der Art und Gestalt der einzelnen Zellen selbst und ihres Verhältnisses zu einander ein sehr wechselvolles Bild bietet. Gerade so plötzlich sich diese Zellhaufen an das nur wenig veränderte Epithel der einen Seite anreihen, gehen sie auf der anderen Seite wieder in das einschich. tige Cylinderepithel über; nur mit dem Unterschiede, dass man 2 wischen diesen Zellen und ibnen aufgelagert, also das Lumen der Drüise etwas vorwölbend, ganz vereinzelte dieser kleinen Carcinomzellen antriffi. An anderen Stellen hinwiederum ist der Cebergang kein so schroffer, sondern er vollzieht sich allmählig. Die Cylinderzellen büssen zuerst ihre Pallisadenform ein. werden kleiner und im Ganzen mehr gleichmässig hell gefurbt, während der dunkle, grosse, peripher gelegene Kern sich scharf abgrenzt. Diese eylindroiden Zellen legen sich, so wie es der Ranm gestatet, über- und nebeneimander, theils auch schon zwischen die aus der Reihe gerathenen Cylindergellen und rufen auf diese Weise die Vehrschichtigkeit hervor. Dort, wo bei dem mehrschichtigen Cylinderepithel awe Drusen aneinander stossen, ist in exquisiter Weise die dos-ä-dos-Stellung der Epithelien zu erkennen; auch hierbei stossen die Kerne hart aneinander, liegen also alle peripherwärts. An einigen Wenigen Stellen kommen Einschiebungen vor, incem in den langen Drüsenschläuchen sich eine neugebildete rundiche Drïse eindrängt und den gesammten Epithelbelag vor sich in das Lumen vorgeschoben hat. Dort, wo der Epithelbelag, was in seltenen Fälen vorkomm, aus zweisohichigen, hohen Cyliuderzallen besteht, ist die Mehrschichtigeit nu eine Tausehung, dem eine genatue Einstellung lässt ohne allen Zweifel feststellex, dass es sich um keino Wucherung, sondern Einstülpung des eigenen Epithels hamdelt, welches die sparliche Stromasubstanz um aich nach innen gezogen hat; diese ist später zu Grunde gegangen und so sind die zwei Schichten hoher Oylinderzellen übereinander gekommen nod haben die Melrschichtigkeit vorgetauscht, wie sich auf Sevienschnitten verfolgen lässt; auch sind in diesem falle die Ferme alle centralwarts, d. h. sie liegen nicht nach einer Seite, sondern an der Grenze der zwei aufeinander stehenden Zellschichtem.

Gerade so variabel wie die äussere Form, ist auch das Drüsenepithel, welches man als polymorph bezeichnet, entstanden durch Ausund Einstülpungen benachbarter". Einmal findet man hier ziemlich hänig die zuletzt heschriebenen torgange, so dass es den Arschein ge- 
winnt als bestände der Epithelsaum aus einem zweischichtigen, hohen Cylinderepithel, während in Wahrheit nur eine Schicht vorhanden ist. Aber schon hier zeigt es sich, dass die ursprünglich zwei Drüsen, welche in eine zusammengeflossen sind, verschiedenes Epithel führen, da auf der einen Seite bisweilen das Cylinderepithel noch ganz intact ist, während auf der entgegengesetzten die Zelien abgewichen sind von der Senkrechten, sich quer gestelit baben und indem der freigelassene Raum ron kleinen polymorphen Zellen ausgefüllt wird, eine grosse Nehrschichtigkeit im Epithelbelag sich jetzt darbietet. Daneben giebt es andere Partien, wo sich plôtrlich ohne Uebergangsformen au das Cylinderepithel eine Stufe kleiner, hell gefärbter Zellen anschliesst mit grossen, excentrisch gelegenen Kernen, von denen ein Theil 2wischen die sonst unveränderten Cylinderepithelien gedrungen sind, während der andere sich an Stelle dieses Epithels gesetzt hat und das Drüsenlumen in zwei oder mehr Schichten umsäumt. Bei diesen Drüsen herrscht weiterhin eine beträchtliche Polymorphie vor im Bereich der Cylinderzellen selbst, sowohl was Grösse und Gestalt der Zellen und des Kernes als auch Färbung angeht. Man findet hier einzelne Zellen, welche in meisterhafter Weise die Tremnung in den basalen und secermirenden Theil des Plasma noch erkennen lassen, während dicht daneben audere Zellen vorhanden sind, wo sich diese Scheidung nicht machen lässt, in dem diese Zellen sich mehr homogen heller gefärbt haben und auch die Körcung im Plasma gesehwunden ist. Aber auch in diesen Fällen ist der Kern meist unbetheiligt. Was die Grösse angeht, so findet man neben sebr hohen und schmalen Zellen wieder gleich hohe aber breitere; die Form und Gestalt der Kerue ist sich gleich geblieben; meist sind sie rundlich, selten länglich. Aber allenthalben ist der Versuch zu bemerken, wie die kleinen Zellen sich in die Cylinderzellen hineinarbeiten wollen, oder wie diese die Tendenz verfolgen, die kleinen Zellen zu produciren. Diese selbst liegen in Haufen stellenweise zusammen und lassen sich oft noch lange Strecken durch das Gewebe hindurch verfolgen; sie ersetzen bisweilen auf lange Strecken hin das cylinderförmige Epithel. An der Stelle, wo wirklich zwei Lagen Cylinderzellen äbereinanderliegen, also das Epithel normale Form hat, aber $Z$ weiscbichtigkeit, hat die basale Schicht ihre Differencirung total verloren und ist etwas kleiner, während die centrale, grössere, sieb gut in den zwei Abschnitten differencirt hat und im peripheren leichte Körnung im Plasma aufweist; in diesem liegt der intacte, rundliche Kern. Besonders in den polymorphen Drüsen ist im Inneren ein Fibrinnetzwerk zu sehen, in welchem sich auch einzelne Leukocyten befinden. Diese entstammen gleichfalls der beträchtlichen kleinzelligen Infiltration, welche sich circulär um die Sekret enthaltenden Drüsen lagert, und man sieht wie an einzelnen Stellen die Leukocyten vermittels ihrer amoeboiden Bewegung sich zwischen die Epithelien der Drüsen hindurch in das Limen vorgedrängt haben. Auf dieser Wanderscbaft haben sie die mannigfaltigste Gestalt angenommen, meist sind sie länglich und gut erkennbar in ihren gelappten, scharf conturirten Kernen.

Auf einzelnen Präparaten ist zufälliger Weise der Ausführungsgang einer Drüse im Schnitt getroffen (Tafel V, Figur 7). Man sieht bier neben einew Conglomerat von Drüsen, wie sie aben besehrieben wurden. eiln Lumen, welches ein ganz niedriges Epithel fübrt und angefülit ist mit einer schleimigen Masse, die durch den Härtungsprocess sich etwas 
ron der Wand retrahirt hat; in der Umgebung ist nur eine geringe kleinzellige Infiltration vorhanden.

Sodann wäre noch zu erwähnen, dass man an den Stellen des Curettements, wo die Drüsenwucherung nicht so excessiv ist, sondern sich noch mehr Bindegewebe vorfindet, einzelne grosse blasse Zellen mit einer Reihe wandständiger Kerne vorfindet, dameben ganz spärliche mit radiär gestellten (Riesenzellen).

Neben diesen Partien bekommt man einzelne zu Gesicht, welche das typische Bild der glandulären Endometritis liefern. Das Stroma ist etwas infiltrirt und die Drüsenneubildung ist eine sehr reichliche; jedoch ist die Membrana propria um jede Drüse erhalten, das Bindegewebe nicht geschwunden und das Epithel ist ein uniformes, Cylinderepithel in einschichtiger Lage mit scharfer Differenzirung in den Zellen selbst.

Bei dieser Ausschabung muss nun irgend etwas passirt sein, denn am dritten Tage bekam Patientin plötzlich starke Schmerzen im ganzen Abdomen und Temperatursteigerungen.

Letztere nahmen bald einen pyämischen Charakter an, der Leib wurde aufgetrieben, die Schmerzhaftiglreit besonders intensis dicht unter dem Nabel. Im Douglas machte sich eine geringe Vorwolbung bemerkbar, in welche, da man an Abscess dachte, mit einer Aspirationsnadel eingestochen wurde; es entleerte sich aber nichts. In einer andern Attacke von Peritonitis starb eigentlich ziemlich plötalich die Patientin am elften Tage nach der Auskratzung. Sofort nach dem Tode wurde der Uterus entfernt und fixirt; auch die Section liess nur einen faustgrossen intraperitonealen Abscess im kleinen Becken finden, über welchen sich Darmschlingen gelagert hatten; eine Perforation am Uterus wurde nicht entdeckt. Die Serosa aller Eingeweide war entzündet und mit Fibrin belegt.

Histologisch liegen die Verbältnisse im Uterus folgendermanssen:

Getroffen in den Schnitten ist die Muscularis und die nen gewucherte Nucosa; in ersteren sind die Zeichen lang bestehender Entzündung. Die Fasern sind etwas durch Dedem auseinandergedrängt, in der Gegend der Gefässe besteht etwas kleinzellige Infiltration. Die Gefässe selbst sind etwas in ihrer Wandung verdickt mit charakteristischer Betheiligung der elastischen Elemente, welche theilweise schollig zerfallen sind; die Leukocyteninfiltration erstreckt sich nicht sehr weit von den Gefässen weg. Die Regeneration der Mucosa ist nur ziemlich spärlich erfolgt. Han findet neben den wenigen noch vorhandenen Drisenformationen. so wie sie im Curettement, ausführlich beschrieben sind, auch solche, von welchen ein Theil fehlt; offenbar durch die Curette weggeschniten. An solchen Stellen kann man die Regeneration des Epithels beobachten, welche im Allgemeinen den bekamiten Gesetzen einex jeden Reparation von Gewebe folgt. Die Zellen, welche dem abgeschabten Epithel am nächsten stehen, zeigen eine einfache Hypertrophie nach allen Seiten, welche man wohl als Entlastungshypertrophie bezeichnen kann; der Kern ist unverändert; dagegen nehmen ihre nnmittelbaren Machbam an der Proliferation und Regeneration theil. An diesen Stellen siebt man Zellen, die sich in rerschieden fortgeschrittener Weise in Theilung befinden, es ist eine Differenzirung. des Plaswas in zwei Hälften erfolgt, und der Kern in karyokinetischer Theilung begriffen; gleichfalls ist aber auch hier die Tendenz zu verzejchnen, dass die Zellen etwas Neues zu produciren bestrebt sind, dass ibre Tochterzellen jedenfalls einen stark vom Cylinderepithel abweichenden Typus anfeisen. Einmsil sind die 
verschiedenen Kerntheilungsfiguren verschieden stark mit dem spezifischen Färbestoff tingirt und sodann ist die Form der Mitosen eine durchaus unregelmässige; neben Triaster findet man häufig degenerative Formen, indem die Theilungsfigur eine central geschichtete, zwiebelförmige Masse darstellt, von welcher aus eine Reihe Ausläufer fortziehen. Ganz besonders ist aber an den Drüsen. wo die Regeneration schon weiter fortgeschritten ist und sich ein neuer Epithelbelag gebildet hat, eine Aenderung im Zellcharakter der Epithelien deutlich zu erkenjen. Wo die Schicht der lädirten Drüsen, welche sich in Regeneration befinden oder schon regenerirt haben, anzutreffen ist, da ist nämlich bis auf den letzten Rest das Cylinderepithel vollständig geschwunden (Tafel V, Figur 8) und ersetzt durch ein flaches Epithel mit polymorphen Zellen und ahnorm grossen, gut tingirtem Kern; das Differenzirungsvermögen dieser Zellen in dem basalen und secernirendem Theil ist total geschwunden, gleichfalls hat sich das Fürbevermögen so geändert, dass sie sich mit saurer Hämatoxylinlösung nicht mehr färbt, dagegen in neutraler Karminlösung homogen roth erscheint; macht man hierbei die Contrastfärbung, so sind allenfalls einzelne Formen etwas blau gefärbt; kurz, die Zelle hat ihr Tinctionsvermögen mit sauren Farbstoffen verloren und dafür ihre fremde Färbeeigenschaften erworben. Was die Schichtung angeht, so liegen die Zellen ganz willkürlich durcheinander. Im Allgemeinen ist aber daran festzuhalten, dass die Drüsenneubildung nur sehr spärlich vor sich geht, dass vielmehr das Bindegewebe die Tendenz hat, den Defect zu ersetzen, denn man findet im Stroma entgegen den Befunden bei der Alrasio eine reiche Proliferation der fixen Zellen und Hineinwachsen in die zum Theil noch erhaltenen Drüsen hinein. Die nur sehr spärlich schon vollständig neugebildeten Drüsen weisen daher ein sehr variables, polymorphes Epithel auf und führen im Innern eine Unmenge kleiner Epithelzellen, so dass das Lumen fast ganz verschwunden ist. In der Umgebung ist keine kleinzellige Infiltration zu seben; es ist also hier das interstitielle Gewebe stark gewachert und hat die Drüsenneubildung in den Hintergrund gedrängt, aber trotzdem giebt es auch bier noch Stellen, wo Drüse dicht an Drüse liegt.

Genauer wurden die mitotischen Vorgänge im folgenden Falle studirt, wo sie in ungemein reicher $\mathrm{Zahl}$ anzutreffen waren.

\section{Fall XIII.}

Die 46 jährige Patientin kam herein mit der Anamnese, ihre Periode sei vor zwei Jahren ganz ausgeblieben und zeige sich seit etwa sechs Monaten in vermehrtem Masse; in der Zwischenzeit habe sie öfters Kreuzschmerzen, - wehenartig - und Schmerzen entlang beider Bauchseiten zu den Genitalien und Oberschenkeln; seit etwa Jahresfrist sei sie auch etwas abgemagert und habe den "weissen Fluss".

Sie hat 5 Spontangeburten und 2 Aborte durchgemacht; bei der vierten Geburt, der fünften Gravidität überhaupt, wurde sie inficirt und machte eine schwere puerperale Sepsis durch; sonst war sie angeblich stets gesund.

Genitalbefund: Vulva ohne Befund, Vagina sebr weit, beide Wände descendirt; Portio steht in der Spinallinie, ist stark zerklüftet and lässt einen tiefen Cervixriss links oben erkennen, welcher fast bis 
in das Parametrium geht. Cervix kolbig verdickt, Fundus leicht vergrössert; Uterus in toto anteflectirt, gut beweglich; Adnexe frei, gleichfalls das Parametrium.

Cystosk opischer Befund: Blasengefässestark hyperämisch, Fundus ohne Besonderbeiten. Beide Ureteren sind durchgängig und secerniren gleichmässig; in der Mucosa keine Prominenzen zu finden.

Die Probeausschabung lieferte ein typisches Bild von Adenocarcinom.

Daraufhin wurde, da man nach dem Touchierbefunde nicht ganz einen Tumor im Cervix ausschliessen konnte, die etwas modificirte Wertheim'sche Totalexstirpation 8 Tage nach der Ausschabung ausgeführt.

Eröffnung der Bauchhöhle vom suprasymphysären Querschnitt aus; Abbinden der Adnexe beiderseits mit dem Ligaturinstrument in zwei Etagen. Die Blase wird stumpf vom Cervix und oberen Theil der Vagina gelöst und an die Fascie vorläufig fixirt. Dann wird der rechte Ureter, welcher sehr tief liegt, herauspräparirt und die Art. uterina doppeit ligirt. Der Ureter wird verfolgt bis zu seinem Eintritt in die Blase und das Paracolpium lateral von der Cervix tief umstochen und dann medial abgeklemmt, zwischen beiden Stellen durchschnitten. Auf der linken Seite wird in der gleichen Weise der Ureter von der Krenzungsstelle bis zum Blasenwirbel freigelegt und die Art. aterina, sowie die beiden Vesicales unterbunden. Nach medianer Abpräparirung des Douglasperitoneum von der Cervix werden die Lig sacro-uterina abgeklemmt und durchtrennt. Nach Elevation des Uterus über die Sympbyse wird ganz distal die Vagina mit zwei starken Klemmen gefasst und durchtrennt. Die hintere Vaginalwand wird dann mit dem Douglasperitoneum, die vordere mit dem der Blase in breiter Ausdehnung vernäht. Dann Vernälien der seitlichen Serosadefecte, wodurch die Adnexstimpfe und die Ureteren intraperitoneal gelagert werden; zavor jedoch wird auf der linken Seite an der" Theilungsstelle der lliaca eine baselnussgrosse, harte Drüse entfernt, welche fest mit der Venenwand verwachsen war" rechts sind in der Nähe des Leistenringes zwei haselnussgrosse Drüsen ştumpf ausgeschält worden. Einlegen eines Jodoformgazedochtes in die Vagina, leichte Fixation der Flescrar sigmoidea die Vagina. Schluss der Laparotomiewunde in typischer Weise. Pat. erhielt sofort auf dem Operationstisch $11 \mathrm{Na} C l$ mit 1.0 Nucleinsäure. Am rweiten Tage paralytischer Ileus und Peritonitis, velcher Patientin trotz Darmfistelanlegung nach zwei weiteren Tagen erliegt.

Pathologisch-anatomischer Befund: Diffuse Peritonitis der Organe des Kleinen Beckens.

Histologischer Befund der ausgeschabten Massen: Auf den Schnitten sind Fetzen von Mucosa mit etwas Blut vermischt. Das Stroma ist im Ganzen stark reducirt durch das wuchernde Drüsenparenchym; nur einzelne grössere Packete ron Drüsenschnitten sind durch einzelne gröbere und feinere Bindegewebsfasern getrennt, so dass es fast den Anschein gewinnt, als lägen sie in Mitten eines bindegewebigen Netzes eingesprengt. In den groben Zỉgen sind zahlreiche Lymphbahnen; die fixen Bindegewebsellen sind stark vermehrt, die einzelnen Fasern bei Seite gedrängt durch eine reiche Leukozyteninfiltration, welche besonders stark um die benachbarten Drïsen ist und dort sich concentrisch angeordnet hat. Von diesem Gerïst aus gehen spärliche, ganz feine Fasern zwischen die einzelnen Drüsen and mit ihnen wenige Leukocyten. Im 
Ganzen jedoch ist das Bindegewebe sehr spärlich vertreten und die neugebildeten Drüsen stossen dicht aneinander; selbst bei schwacher Vergrösserung ist auf Taf. V, Fig. 9 die dos à dos-Stellung der Epithelien deutlich zu sehen. Die Form der Drüsen ist durchgehends so wie im vorigen Falle beschrieben; nur führen viele von ihnen im Centrum eine dunkelblau gefärbte Masse, welche aus einem dichten Conglomerat von Fibrin besteht (bewiesen durch die specifische Färbung), zwischen welchen sich theilweise Leukocyten eingelegt haben; um diese so angefüllten Drüsen ist die kleinzellige Infiltration viel stärker und zahlreicher, als in der Umgebung anderer, und die Leukocyten haben sich hier in Reih' und Glied gestellt, oftmals in mehreren Colonnen hintereinander und bilden einen die Drüsen gewissermaassen concentrisch abschliessenden Wall. An einigen wenigen Stellen sind dann auch von dieser Umgebung aus die Leukocyten durch die Drüsen zwischen ihren Epithelien hindurch auf der Wanderung in das Lumen begriffen. Gemeinsam ist allen diesen Drüsen das. Fehlen der Membrana propria. Entsprechend der mannigfaltigen äusseren Form der Drüsen ist auch das Epithel sehr variabel. Man findet also ziemlich hohes, einschichtiges Cylinderepithel, welches sehr bald unter Kleinerwerden der Zellen in ein mehrschichtiges mit sehr niedrigen, schmalen Zellen übergeht. Die Proliferationsfähigkeit der Zellen ist eine sebr lebhafte; man findet neben noch ziemlich normalen Mitosen eine Menge dicht nebeneinauderliegender patbologischer Kerntheilungsfiguren; hier herrscht nicht die Form des Triaster vor; es finden sich jedoch, wie z. B. auf Figur 10, auch uni- und multipolare Mitosen. Bei anderen trifft man in den Kernen theilweise Vacuolenbildung und scholligen Zerfall neben normalen karyokinetischen Vorgängen an. Bei der Mehrschichtung liegt der Kern stets peripher in allen Schichten. An anderen Stellen besteht der Epithelbelag aus mehreren Schichten kleiner, polygonaler Zellen, es ist ungefähr das gleiche Bild wie früher, nur sind die Mitosen sehr zahlreich und durchgehends mehr oder minder in der bekannten Weise verändert. Hauptsächlich besteht die Polymorphie der Epithelien in Grösse, Gestalt und Färbung der Zellen zu einander und im Verhältniss der Lage und Grösse des Kernes zum Plasma; sodann ist die räumliche Lage auch sehr verschoben, die Zellen stehen nicht nebeneinander, sondern sind je nach den Raumverhältnissen besonders angeordnet.

Histologisch enthalten die Uterusstücke Muscularis und Mucosa. In ersterer ist eine lang bestehende Entzündung sofort zu erkennen; zwischen den wahrscheinlich durch Oedem auseinander gedrängten Muskelfasern findet sich Fibrin; das Bindegewebe ist in Wucherung begriffen, seine fixen Elemente sind vermehrt und es ist eine ziemlich bedeutende kleinzellige Infiltration vorbanden. Die Gefässe sind ziemlich beträchlich mit Blut gefüllt und weisen eine Verdickung der Wand auf, welche besonders die Media betrifft; weniger verdickt ist die Intima, während die Adventitia kaum verändert ist. Die Membrana elastica externa und interna sind, erstere stärker, rissig und in Lamellen zerfallen. Die Mucosa schiebt sich theilweise in die Muscularis binein, die Grenze zwischen beiden ist also verwischt. Von der Schleimhaut geht eine sehr spärliche Leukocyteninfiltration in die ersten Schichten des Myometrium hinein. Allgemein ist in der Mucosa das bindegewebige Stroma zurückgetreten, wenn auch an mehreren Stellen sich starke Wucherungsvorgänge bemerkbar machen; seine fixen Zellen sind ver- 
mehrt. Neben diesen kann man unschwer zwei weitere Arten von Zellen unterscheiden; einmal ziemlich polymorphe, verscbiedener Grösse, mit stark tingirtem, oft gelapptem Kem, welche die Zellen der Leukocyteninfiltration darstellen, und sodann etwas grössere von sehr verschiedener Gestalt, welche einen centralen, runden, stark tingirten Kern tragen; während bei den Blutkörperchen das Plasma gut granulirt ist, fehlt bei diesen die Körnung, und die Zelle sieht homogen blass aus; letztere Art lasst sich sowohl wie die kleinzellige Infiltration von dem Parenchym del Mucosa her verfolgen. Was nun dieses selbst angeht, so ist bier die Drüsenwucherung sehr stark eingetreten. Einmal sind bier die schon im vorigen Präparat beschriebenen Regenerationsvorgänge zu erkennen, die sowohl in sehr seltenen Fallen zu einer Restitutio ad integrum der adenocarcinomatösen Drüsen geführt baben, als auch ganz besonders in der erdrückenden Mebrzabl den abgerissenen Theil der lädirten Drisen durch ein polymorphes Epithel ersetzten. Ganz auffallend ist in diesen Präparaten der Reichthum der mitotischen Kerne, besonders wieder der pathologischen Karyokinese; man begegnet hier einmal wieder der Form der Triaster, weniger der uni- oder multipolaren Mitosen, als ganz besonders, wo die Spindelform nicht parallel zur Basis der Zellen steht, sondern unter irgend einem Winkel zu ihr geneigt ist; auch hier herrscht keine senkrechte Stellung zar Zellbasis vor, daher wohl die Cylinderform ganz fehlt, sondern durch scheinbar regellose Anordnung der Mitosen sind die polymorphen, but dureheinander gewürfelten Zellen entstander. Aber es haben sich lange nicht alle Drüsen regenerirt; beim Vergleich mit den Schnitien des Curettement fallt sofort der relativ geringe Gehalt ron Parenchym im bindegewebigen Stroma auf: statt dessen haben sich eine Unmenge kleiner, polymorpher; meist etwas platter Zellen unregelmässig im ganzen Nest zwischen Stroma und Drüsen vertheilt, welche dicht ohne Intercellularsubstanz nebeneinander liegen. Ihr Plasma ist nur sebr wenig granulirt, im Ganzen etwas homogen blass gefärbt, der Kern liegt central, ist scharf conturirt und tingirt; im Verhältniss zur Zelle selbst als gross zu bezeichnen. Auch bier spielen sich lebhafte Theilungsvorgänge ab, meist in der oben beschriebenen Weise. Es lässt sich nun unschwer aachweisen, wie die polymorphen, kleineren Carcinomzellen sowohl von dem regenerirten Epithel der Drüsen ihren Ausgang nehmen, als auch an anderen Orten in die Drüsen hineinwuchern, gleichfalls wie sie um das bindegewebige Gerüst verlaufen und sich dort weiter verbreiten. Die neugebildeten Drüsen sind im Grossen und Ganzen sehr einfach gebant; man findet nur rundliche oder lingliche Formen, während die bizarren des Curettements nur sehr selten sind und stellenweise ganz feblen. Dann finden sich aber auch einzelne Nester, wo die Dritsenimitation ganz geschwunden ist und die kleinen polymorphen Zellen dicht nebenefinder liegen. Diese Stellen sind umso lyafuger, je mehr man sich der Muscularis nabert; das Bild wird stets einfacher und geht ganz in das des Carcinoma glandulare simplex über. Die nun vorbandenen Drüsen, sei es mit anuabemd cylinderförnigem oder polymorphem Epithel, enthalten in ihrem Lumen nur sehr wenig Fibrin oder Schlein; dahel ist auch die kleinzellige Infitration in ihrer Umgebung lange nicht so intensiv, wie im Curettement des gleichen Falles.

Was zuletzt das Bindegewebe angeht, so ist es stellenweise ziemlich reichlich wertreten and lässt mit Leichtigkeit die Wuchermngsworgänge erkennen, sowie die Neigung, den Defect in den Drüen durch Hinein- 
wachsen zu ersetzen; seine fixen Elemente sind zahlreicher als gewöbnlich vorhanden.

\section{Fall XIV.}

Die 53 jährige Patientin kam mit den für eine maligne Neubildung im Fundus typischen Klagen; sie war zwar eine Nullipara, jedoch wegen Gonorrboe des Endometrium und der Adnexe bis vor 5 Jahren bebandelt worden; sonst war sie angeblich stets gesund.

Die Genitalorgane waren bis auf eine geringe beiderseitige Verdickung und Schmerzhaftigkeit der Tuben und geringe Vergrösserung des Uterus normal. Man schritt darauf zur diagnostischen Aussehabung.

Histologisch zeigte es sich, dass das Stroma noch ziemlich reichlich entwickelt ist. Die Fasern sind zwar etwas auseinander gedrängt, die fixen Bindegewebszellen sehr stark gewuchert, die Leukocyteninfiltration ist spärlich; die Neubildung der Drüsen eine ziemlich reichliche. ihre Form rundlich oder länglich. Die erstere Gruppe führt ein niedriges, einschichtiges Cylinderepithel mit ziemlich grossen, wandständigen Kernen. Das Plasma ist gut tingirt und reichlich granulirt. Es lässt noch eben angedeutet die Trennung in dem basalen und secernirenden Theil erkennen; Uebergänge zur Polymorphie oder mehrschichtigem Epithel sind 'aber auch da in Menge zu finden. Das Lumen der Drüsen ist meist leer, nur in einigen sehr wenigen Drüsen findet man eine ziemlich homogene blaue Masse, offenbar Schleim (später auch durch die specifische Färbereaction bewiesen), aber keine Fibrinniederschläge. Die kleinzellige Infiltration ist in der Umgebung der Drüsen nicht stärker als sonstwo im Gewebe. An einer Stelle ist das Cylinderepithel zwar etwas höher, reicht aber bei Weitem nicht an das normale Epithel heran. Es hat überall seine Pallisadenform gewahrt; das Gewebe ist in nicht besonders starker Proliferation begriffen, da man bei diesen Drüsen nur wenige Mitosen findet. Dagegen sind die Drüsen mehrfach ineinander geschoben, da man neben Mehrzeiligkeit des Epithels auch Partien findet, wo nur scheinbar Mehrschichtigkeit besteht, welche aber zweifelsohne Schrägschnitte von Drüsen darstellen.

An einzelnen Stellen sind im Zwischengewebe typische Riesenzellen mit wandständigen Kernen. Hier findet sich echte Mehrschichtung des Epithels. Die Zellen werden plötzlich kleiner, mehr quadratisch, im Ganzen etwas heller, verlieren ihre normale Anordnung und liegen wirr durch- und übereinander; ihre Kerne sind alle an der Peripberie und gleich gross. Was nun die langen Drüsenschläucbe angeht, so weisen sie durchweg ein hohes, einschichtiges Cylinderepithel auf, welches im Ganzen die Pallisadenform bewahrt hat. Die Zellen sind aber homogen hell tingirt und lassen keinen Unterschied erkennen in den beiden Theilen. Der Kern liegt peripher an der Basis, seine Gestalt ist polymorph, meist länglich oder rundlich, seine Contouren sind scharf. Daneben sind aber an einzelnen Stellen mehrschichtige Lagen zu erkennen. Bei oberflächlicher Betrachtung scheint es den Eindruck einer syncytialen Umwandlung zu erwecken, jedoch die genauere lässt unschwer erkennen, dass zwischen den einzelnen Zellen feine Linien als Zeichen der Grenze sind, so dass also eine Verschmelzung des Plasma nicht stattgefunden hat. Die Zellen selbst sind hierbei kleiner geworden und haben sich in noch höherem Grade als vorhin homogen gefärbt, die feineren Granulationen im Plasma sind geschwunden und die ganze Zelle ist eintönig blass; auch fehlt hier die Längsschraffirung vollständig. 
Der Uebergang des einschichtigen Kpithels in das mehrschichtige findet meist ganz plötzlich und unvermittelt statt, nur sind an der Grenze einzelne Mitosenvorgänge zu beobachten, von denen man nur sehr schwer sagen kann, ob sie noch in den Bereich des Normalen fallen oder schon pathologisch sind. Die typische dos-à-dos-Stellung benachbarter Drüsen ist ganz aufgehoben; der ganze Saum ist von kleinen, vielgestalteten Zellen eingenommen.

Daraufhin wurde die abdominale Totalexstirpation vorgenommen; Patientin überstand den Eingriff sehr gut und ist seit dieser Zeit (11/2 Jahre) frei von Beschwerden; sie hat anch an Körpergewicht bedeutend zugenommen; bis heute ist sie recirdifrei.

Der Uterus ist nur mässig vergrössert; der Tumor geht von der hinteren Funduswand aus und ist etwa taubeneigross. Serosa ist glatt, Mlusedaris nicht besonders verdickt.

Histologisch ist in der Musculatur eine lang bestehende, interstitielle Entzündung zu erkennen; die Schleimhaut ist so wie oben beschrieben: regenerative Vorgänge, da die Operation schon zwei Tage nach dem Curettement gemacht wurde, finden sich nur wenig.

Höchst interessant in mehrfacher Hinsicht ist der letzte meiner Falle.

\section{Fall XV.}

Der Vater der 42 jährigen Patientin starb an Apoplexie, die Mutter an Oyarialcarcinom (secundiares?); ihre Geschwister leben und sind gesund. Sie selbst war stets gesund und machte mit 25 und 27 Jahren je eine Spontangeburt durch. Die Menses begannen mit 16 Jahren, waren stets sebr unregelmässig und schwach, obschon sie meist 4 bis 5 Tage anhielten. Seit 3 Jahren nahmen sie einen 14 tägigen Typus an, und der Blutverlust war ein grösserer; seit 3 Monaten sind sie abnorm stark; seit dieser Zeit ist Patientin auch abgemagert; Krenzschmerzen oder Austluss aus den Genitalien bestanden nicht.

Status praesens: Vulva geschlossen; kleine Labien etwas prominent. Vagina weit mit Querialten; Perinaeum intact. Portio steht etwas hinter der Spinalliwie, Muttermund geoffnet, quergespalten; Cervicalcanal geschlossen. Uteras anteflectirt, gut beweglich, etwas vergrössert und weich, aber nicht schmerzhaft. Adnexe ohne Befund. Parametrium frei.

Sodann befindet sich auf dor rechten Seite unmittelbar aut der Höhe des Labium majus und noch etwas auf die Innenseite übergreifend eine etwa haselnussgrosse, der Patientin bisher entgangene Prominenz mit zerklüfteter, nässender Oberfäche und infiltrirten gerötheten Rändern. Diese Prominenz lässt sich gut nach allen Richtungen hin verschieben und ist nicht schmerchaft.

Als man darauf zur Probeausschabang schritt, zeigte es sich aus der Brüchigkeit des ganzen Gewebes, der starken Blutung und besonders der Weichheit des Uteruscavun, dass irgend eine maligne Erkrankung: vorliegen musste.

Daher wurde die Narkose sofort dazu benutzt, die radikale Operation zu machen. Fs gelang leicht durch die weite Vagina mit dem Messer die typische vaginale Totalexstirpation ohne Spaltung des Organs mit Zurucklassung der Ovarien wa machen. Sodann wurde der zweifelsohne metastatische Knoten an der Vulva mit dem Paquelin weit im Gesunden 
abgetragen und der Defect bis auf eine geringe Strecke hin durch Nähte wieder vereinigt. Patientin erholte sich sehr schnell, der Ernährungszustand besserte sich und sie ist jetzt, allerdings erst 10 Monate nach der Operation, bei gutem Wohlbefinden; ein Recidiv oder eine bis jetzt diagnosticirbare Metastase lässt sich nicht nachweisen.

Histologisch enthalten die aus dem Tumor im Uterusfundus angefertigten Schnitte Muscularis und Mucosa; erstere ist nur wenig verändert; ihre Blutgefässe sind hyperämisch, aber in der Wand intact; entzündliche Vorgänge fehlen vollständig. Die Schleimbaut ist mit ihren Drüsen gegen das Moymetrium vorgewuchert und hat theilweise Inseln von noch ziemlich gut erbaltener Uterusmuskulatur umgeben von den neugebildeten Drüsen gebildet. Letztere liegen in Nestern zusammen, welche durch ein ziemlich gut entwickeltes Stroma von einander getrennt sind; die fixen Bindegewebszellen sind nicht besonders reichlich vermehrt; dagegen ist eine an verschiedenen Stellen verschieden reichhaltige kleinzellige Infiltration vorhanden. Die Drüsen aber, welche in Nestern liegen, sind dicht aneinandergedrängt, das Bindegewebe ist hier ganz in den Hintergrund getreten. Das Drüsenlumen ist angefüllt mit einem spinngewebeartigen Netzwerk, welches mit seinen letzten feinsten Ausläufern sich an die Epithelien ansetzt und gewöhnlich im Centrum die einzelnen Fäden nicht mehr erkennen lässt. Durch schlingenförmige Anordnung der Fäden entstehen an einzelnen Stellen Lücken, so dass das Ganze etwa wie ein Netz aussieht. Es handelt sich hierbei, wie die spätere Färbung. ergiebt, um Scbleimproduction der Epithelien in das Lumen der Drüsen. Diese selbst sind nun sehr mannigfach gestaltet; einmal findet man eine rundliche oder rundlich-ovale Form; dann giebt es mehr länglich gestreckte und zuletzt solche von ganz anregelmässiger Gestalt, welche gewissermaassen dazu dienen, die Lücken auszufüllen zwischen den regelmässig gebildeten und dem spärlichen Bindegewebe. Um die einzelnen Drüsenindividuen fehlt, wie schon gesagt, die bindegewebige Grundsubtsanz, es fehlt aber auch die Membrana propria. Das Epithel ist ein sehr wechselndes: in den mehr rundlichen Drüsen ist ein niederes Cylinderepithel mit sehr grossem, runden Kern, welches dort, wo die Drüsen an anders gebaute Drüsenneubildungen anstossen, die typische dos à dos-Stellung erkennen lässt. Bei den länglichen Drüsen ist Zweischichtigkeit vorhanden, die Zellen sind entsprechend höher; auch dieses weist die charakteristische Rückenstellung auf. Die Zellen sind hier bedeutend heller gefärbt und das Verhältnis von Kern zur Zelle und dieser zu ihrem Nachbain ist so verändert, dass es sowohl abnorm grosse Zellen mit kleinem Kern giebt, wie anch das Umgekehrte der Fall sein kann, während gleichzeitig sich auch noch Zellen vorfinden, welche für sich allein betrachtet, sich kaum von denen der glandulären Endometritis unterscheiden, eben mit Ausnahme der Mehrschichtigkeit. An einer Partie ist sehr schön der Epithelübergang zu sehen: die Drüse fübrt ein niederes zweischichtiges Cylinderepithel, welches plötzlich an einer Stelle in einen Haufen kleiner, platter Zellen übergeht, welche dicht aneinanderliegen; diese Proliferation hat sich sowohl nach aussen als auch nach innen in die Drüse fortgesetzt; dann folgt eine Strecke weit ein Epithelsaum von ziemlich grossen, quadratischen Zellen mit sehr grossem Kern; dann wieder ganz plötzlich eine Anbäufung der kleinen Carcinomzellen, zwar nicht so reichlich wie zuerst, aber doch immerhin eine zwei- bis dreifache Schicht bildend, so dass das Drüsenlumen an dieser Stelle fast ganz aufgehoben ist. 
Das umgebende Bindegewebe des Carcinomnestes ist nicht rerändert, besonders fehlt jede kleinzellige Infiltration. Daneben giebt es aber auch Stellen, wo der Epithelbelag von zwei aufeimanderstehenden, ziemlich hohen Cylinderzellen gebildet wird, nur mit der Einschränkung, dass auch hier schon die Pallisadenform etwas Schaden gelitten hat, dass nicht die eine Zelle dicht an die andere stösst, sondern dass Verschiebungen vorkommen, derart z. B., dass die Zellen etwas von einander abrutschen und sich $z$ wischen die Nachbarn einkeilen. Diese Zellen fallen sofort durch ihre langgestreckte Form auf, sind im Allgemeinen gut tingirt, nur ist der Kern abnorm in die Länge gezogen, hat sich aber gut differenzirt und ist scharf umgrenzt. An den sehr geschlängelten Drüsen sind oft neben einem Cylinderepithel in zwei Lagen noch Zellen zu erkennen, welche mehr quadratisch sind und sich viel weniger differenzirt haben; die Zellen haben alle langgestreckte Kerne, etwa so wie die des Bindegewebes, ihre Grösse wechselt sehr; in wenigen Zellen ist die Körnung des Protoplasma ausgeprägt. Die nicht spärlichen Mitosen sind fast alle pathologisch, meist als Triaster angedeutet, daneben aber findet sich auch Quer- und Schichtstellung der Theilnngsaxe der karyokinetischen Zellen zur Zellbasis.

Sodann kann man auch einen nur allmählichen Uebergang der Epithelformationen feststellen. Das einschichtige Epithel bestebt aus fast quadratischen Zellen mit sehr grossen Kernen; diese Zellen werden wun allmählich etwas schmäler, aber dafür auch entsprechend höher: der Kern wird mehr Iänglich-oval; sie stellen sich sowohl neben als auch schief $\mathrm{zu}$ einander und so entsteht die echte Mebrschichtigkeit von Cylinderepithel; ihr Plasma lässt sowohl die Körnung als auch die ausgeprägte Theilung in basale und freie, secernirende Fläche vollständig vermissen.

An andern Stellen ist der mehrsehichtige Epithelbelag gebildet won ganz abnorm schmalen cylindrischen Zellen, mit spitzem Ausläufer versehen, durchaus ähnlich den Zellen des Spindelzellensarkoms; sie führen neben einem sehr deutlichen, grossen. Kerm, dessen Nucleolus sehr scharf hervortitit, auch ein ziemlich gut granulirtes Plasma. Einzelne ihrer Fortsätze strecken sich füblerartig zwischen die benachbarten Zellen hinein und verdrängen sie aus ibrer Lage. In sehr vielen Drüsed laufen die ziemlich bohen Gylinderzellen in zwei concentrischen Sebichtep um das Drüsenlumen herum; es handelt sich hierbei nicht etwa no Einstülpungen oder Schrïgschnitte, da sich auf Serienschnitten der Beweis erbringen lässt, dass alle Korne gleich gross sind wnd peripher liegen. Auch hier sind die Kerne, besonders in den basalen Theilen sehr gross, wäkrend die Zellleiber auch in der centralen Schicht sich nur homogen blass farbten und ihnen die Differenzirung und Gramulirung abgebt.

Dazu gehört auch die Metastase der Vulva, welche histologisch untersucht wurde. Auf den Schniten ist Cutis und Subcutis getroffen; in lesterer bofindet sich ziemlioh reiche Eettansammlung. Wan erkennt noch riemlich gut das Plattenepithel, das Stratum proprium und mu. cosum mit den entzündlich verunderten Gefassen und dann das, wahrscheinlich durch Oedem auseinander gedrängte Bindegewebe. Im Stratum Malpighi sind die Gefiasse alle strotzend mit Blut gefullt, und in ihrer Umgebung ist eine ziemlich beträchtliche kleinzellige Infiltration zu erkennen. Auffallend ist die homogen trübe Beschaffenheit und das blasse Aussehen der Zellen, welche theils won einander abgelöst sind und theilweise in threm Plasma eine homogene Sohollenanotdnung an- 
statt der feinen Körnung erkennen lassen; weiterhin begegnet man verschiedenen, deren Plasma zerbröckelt oder ganz zerfallen ist. Das ganze Gewebe ist ödematös stark durchtränkt und weist reichliche Fibrinfäden und Niederschläge auf. An einzelnen Stellen ist in den Zellen kein Kern, selbst in ungefärbtem Zustande mehr zu erkennen, während in der Mehrzahl er zwar erhalten, jedoch gewaltig verändert ist. So ist seine Tinctionsfähigkeit eine anormale, es heben sich theils scharf gefärbte Partien aus der homogenen Unterlage ab; theils ist er aber auch schon in verschiedene Fragmente zerfallen und hat seine scharfe Umrandung vollständig eingebüsst. Kurz wir haben es mit nekrotischen Vorgängen als Folge der Anwendung des Ferrum candens zu thun, und erblicken in der reactiven Entzündung der Umgebung das Bestreben des Körpers, dem infiltrirenden Carcinom eine Schranke entgegenzusetzen. In den grösseren Lymphbahnen des subcutanen Zellgewebes, da, wo die Fetteinlagerung sehr in den Hintergrund getreten ist, sind die grösseren Lymphräume angefüllt mit einer Menge kleiner, polymorpher Zellen mit excentrischem, scharf conturirtem, aber, wahrscheinlich auch durch die Coagulationsnekrose bedingt, nur schlecht tingirtem Kern; diese Zellen liegen in Haufen zusammen, so dass sie die Bahnen, wie gesagt, ganz ausfüllen; in der Umgebung ist nur eine sehr spärliche, kleinzellige Infiltration. An einigen wenigen Stellen ist in diesen Lymphspalten der Versuch der Drüsenneubildung, also des Adenocarcinoms, gemacht, indem die Zellen etwas grösser werden und in zwei oder mehreren Schichten sich um ein centrales Lumen gruppiren; diese Drüsen führen keinen Inhalt. Es handelt sich bierbei sicher nicht etwa um eine pseudoacinöse Zeichnung, denn die Zellen ähneln denen des Primärtumors besonders in ihrer äusseren Gestalt und Färbung aufs Haar.

Auf den Schnitten eines anderen Blockes wird dieses Verhältniss noch deutlicher. Im Stratum Malpighi befindet sich unter anderen Gefässen auch eins, welches im Schrägschnitt getroffen und leer ist, während die benachbarten strotzend mit Blut gefüllt sind. Seine Intima ist glatt mit nur spärlichen Kernen der Intimazellen; die Muscularis ist stark hypertrophisch mit vielen elastischen Fasern; die Membana elastica externa und interna sind unverändert und scharf abgegrenzt; desgleichen ist die Adventitia intact. Die zahlreichen, um das Gefäss verlaufenden perivasculären Lymphbahnen und theils auch die feinsten Vasa vasorum sind angefüllt mit kleinen, platten Zellen, welche ohne Intercellularsubstanz djcht nebeneinanderliegen; ihr Kern ist gut gefärbt, verhältnissmässig gross und liegt peripher. Stellenweise baben diese Zellen sich so angeordnet, dass sie ein central gelegenes Lumen einfassen. Die Fig. 11, Tafel V, lässt diese Verhältnisse klar erkennen. In diesem Lumen liegt theils eine mucoide Substanz, theils ist es leer. Auf Serienschnitten lässt sich nun verfolgen, wie diese Carcinommetastasen sich aus den in den grossen Lymphbahnen enthaltenen Zellen herleiten lassen, indem diese stets sich etwas schärfer tingiren und zuletzt radiär anordnen; die Sekretionsvorgänge treten erst dann auf, wenn die Zellen histologisch den Charakter der Cylinderzellen angenommen haben. Aber lange nicht alle Hetastasen haben den adenomatösen Bau, sondern die Figur zeigt eine Menge, welche nur die Zellanordnung im gewöbulichen Carcinom erkennen lässt; hierbei sind die Zellen durchgehend kleiner und niedriger und nehmen mehr quadratische Gestalt an. Und wenn man nun in dem umgebenden Bindegewebe fast gar keine Leukocyten- 
ansammlung findet, so ist das wohl ein Beweis für die Aenderung im sekretorischen Charakter gegenüber den Zellen des Primärtumors im Uterusfundus. In anderen Schnitten ist in der Cutis im Schrägschnitt ein grösseres Lymphgefäss getroffen, Die Endothelien sind alle gut gefärbt und fast längs del ganzen Peripherie enthalten. Das ganze Lumen ist angefüllt mit einer Unmenge sehr kleiner, verschieden gestalteter Zellen, welche alle einen relativ grossen Kern führen und dicht nebeneinander liegen; ihr Färbevermögen ist gut erhalten. Daneben sind nun in wechselnder Zahl etwas grössere, runde Zellen mit theilweise stark gelapptem Kern. Die erste Art ist an verschiedenen Partien bis an die Umsäumung des Lymphgefüsses fortgeschritten und hat dort den Endothelbelag zerstört; sodann sind sie wie die Leukocyten in den perilymphatischen Spalträumen and zwar in nur geringerer Zahl auch im Gewebe selbst anzutreffen. In anderen Lymphbahnen hingegen ist eine ziemlich gut gelungene Drüsenimitation zu finden; man begegnet dort hauptsächlich längeren Drüsenschläuchen, welche ein noch relativ gut ausgeprägtes Cylinderepithel in zwei oder mehreren Lagen führen. Die einzelnen Zellen sind länglich mit homogenem, wenig oder gar nicht gekörntem Plasma; der gut erhaltene Kern liegt peripher. Die Pallisadenform der Zellen ist gewahrt, wenn auch einzelne kleinere Zollen scheinbar bemüht sind, zwischen das Cylinderepithel vorzudringen und sich an seine Stelle zu setzen. In diesen Bildern allen sind die Drüsenneubildungen, gleichfalls auch die carcinomatöse Infiltration auf die Lymphwege und Blutgefässe, allenfalls noch auf das Bindegewebe der allernächsten Nachbarschaft beschränkt; sie verbreiten sieh nicht diffus im Gewebe weiter. So lässt sich auch sehr schön in allen Schnitten zeigen, dass die Drüsenneubildung mit den in der gesunden Haut vorhandenen Talg- und Schweissdrüsen gar nichts zu thun hat, dass diese yielmehr, von den oben beschriebenen durch die Verbrennung verursachten Verändernngen abgesehen, vollständig unversehrt sind.

Als Ergebniss dieser Aufstellung möchte ich daher, soweit der klinische Verlauf in Betracht kommt, ehe ich zu histologischen Einzelheiten übergehe, und soweit man aus einer so geringen $\mathrm{Zahl}$ von Fällen überhaupt nach irgend einer Richtung hin einen Schluss ziehen darf, Folgendes sagen. Es wird ja von vielen Seiten bebauptet, dass ganz besonders das Uteruscareinom seinen Ursprung längere Zeit hindurch einwirkenden Reizen verdanke. So hat man ja bekanntlich die grosse Zahl der rasch aufeinanderfolgenden Geburten hierfür beschuldigt. Nun finden wir bei einer Nulliparen ein typisches Drüsencarcinom im Fundus, und auch noch mehrere andere haben nur eine oder allenfalls zwei Geburten durchgemacht. Wenn ja daher auch wohl zweifelsohne in der bäufigen Gravidität ein Moment zu suchen ist, welches die Uterusmucosa so eingreifend verändert, dass sich schliesslich einmal ein Carcinom entwickeln kann, so wird wan doch wohl auch daran festhalten müssen, dass beide Vorgänge ganz unabhängig yon einander sich ereignen können, wir also kein Recht haben, selbst bei abnormer Häufigkeit eines 
an sich physiologischen Vorganges daraus den Grundstein für einen pathologischen, destruirenden Process in allen Fällen abzuleiten. Viel eher schon könnte man daran denken, dass in diesem Falle die Jahre hindurch bestehende gonorrhoische Entzündung des Endometriums schliesslich durch die permanente Einwirkung des gleichen Reizes die abnorm stark secernirenden Epithelien der Uterusdrüsen so verändert hätte, dass sich aus diesen ein Carcinom entwickelte. Dem aber widerspricht die tägliche Erfahrung. Der Ausspruch: "Ein starker Fluor schützt vor Carcinom", hat, wie die Statistik ergiebt, zweifelsohne eine Berechtigung. Wie oft hört man in der Anamnese einer Frau mit Uteruscarcinom, dass sie stets gesund gewesen, dass sie vor Allem nie unterleibskrank gewesen wäre. Umgekehrt lehrt die tägliche Erfahrung, dass Patientinnen, welche viel gynäkologisch behandelt wurden, dass ganz besonders bei Prostituirten, wo doch gewiss schädliche Momente, welche irritirend auf das Epithel einwirken können, in reichster Fülle vorhanden sind, das Carcinom eine Seltenheit ist. Es ist nun fraglich, ab dieser Satz so allgemeine Geltung hat; sehen wir diese Fälle an, so geben zwei Patientinnen mit aller Bestimmtheit an, niemals unterleibsleidend gewesen $z u$ sein $(13,3$ pCt.). Man wird daher wohl gut thun, hinsichtlich der Wirkung entzündlicher Processe und ihrer therapeutischen Massnahmen dem Carcinom gegenüber sich mit grösster Reserve zu äussern.

Was sodann die weitere Verbreitung des Funduscarcinoms angeht, so bieten diese Fälle auch manches Interessante. Schwer zu entscheiden bleibt es, wie im Falle IX die kleinen Knoten an der Vorderwand des Fundus entstanden sind. Dass sie echte Impfmetastasen im Sinne von Winter ${ }^{1}$ ) sind, glaube ich nicht recht; sie sind meiner Ansicht nach entstanden als regionäre Metastasen auf dem Lymphwege, oder wir haben es zu thun mit zwei von einander unabhängigen Neubildungen in der Mucosa, wie ja bekanntlich es Formen giebt, wo an verschiedenen Stellen die Mucosa erkrankt (papillosum).

Neben diesen regionären Metastasen haben wir in zwei Fällen weitere Metastasen zu unterscheiden, deren lymphatischer Ursprung, um das gleich vorwegzunehmen, wohl nicht zweifelhaft sein kann. Obwohl das Corpuscarcinom viel länger streng localisirt bleibt, als das der Portio oder gar Cervix, befällt es doch gelegentlich auch

1) Winter, Ueber die Recidive des Uteruskrebses. Stuttgart 1893. 
344 Offergeld, Ueber die Histologie der Adenacarcinome im Uterusfundus.

mit Vorliebe die benachbarten Lymphstrassen. Zunächst kommt hier diejenige in Betracht, welche von der Portio durch die Cervix in den Fundus verläuft [beschrieben genaver durch Seelig')], diesen quer durchsetzend, weiter in den perivasculären Lymphgefässen und in der mittleren Schicht des Myometriums verlanfen und in das parametrane Netz einmünden. Von dieser ist eine besonders ausgeprägte Bahn vorhanden, welche im oberen Theile des Lig. latum entlanglaufend, direct an das Ovarium zieht, mit dessen Lymphgebiet sie breite, sinusartige Anastomosen eingeht. Auf diesem Wege dürfte im Falle $V$ die Ovarialmetastase wobl zu Stande gekommen sein; er wäre dann dieser Fall den in der Publication von Litta uer2) beschriebenen 14 Fällen von secundären Ovarialtumoren bei Uteruscarcinom hinzuzurechnen. Mit welcher Vorliebe gelegentlich das Funduscarcinom bei seinem Weiterwachsen diese Strasse bevorzugt, ist sehr interessant; so fand Littauer ${ }^{2}$ ) in seinen 14 Fällen 12 mal ein Corpus- und nur 2 mal ein Collumarcinom. Aehnliche Erfahrungen haben Löhlein ${ }^{3}$ ) Gebhard $)$, Stones ${ }^{5}$ ) and Reiche ${ }^{6}$ ) uns mitgetheilt. Von hier geht es meist sehr rapid weiter in der Tasche zwischen Tube und Ovarium, entlang der Arter. spermatic. intern. nach oben bis zur Wirbelsäule, und $\nabla \circ \mathrm{d}$ da in die Drüsen am unteren Pol dor Niere (untere, lumbale Driosen) and in die Ungebung der grossen Gefässe und zu den retroperitonealen, moseraischen Drüsen; in sehr seltenen Fällen wird der Fundus perforirt und die Zellen verbreiten sich entlang der Lig. rotunda zu den äusseren Inguinaldrüsen. Dass aber auch schon gelegentlioh früh die Drüsen an der Iliaca, ja sogar in der Schenkelbeuge erkrankt sein können, dafür haben wir $\mathrm{z}$ wei Fälle anzuführen, wo der primäre Tumor eigentich noch gar nicht besonders gross war. Ja sogar diese Lymphstrassen oder die Drüsen selbst können wahrscheinlich lange Zeit Carcinomzellen in sich zurückhalten, denn wir finden im Fall VIM, dass nach der Totalexstirpation sich ein Recidiv der Drüsen an der Theilungsstelle der lliaca einstellte; allerdings waren hierbei am exstirpirten Uterus mit dem Parametrium die Lymphbahnen stark injicirt,

1) Seolig, Virchow's Aroh. Bd. 140.

2) Littauer, Centralbl. $\mathfrak{f}_{a}$ Gynäk. 1895 ,

3) Löhlein, Deutsch. med. Wochenschr. 1889.

4) Gebhard, Centralbl. f. Gynäkol.

5) Stones, The New Yoxk med. Journ. 1890.

6) Reiche, Zeitschr. f. Geburtsh. u. Gynähol. Bd. 15. 
milchig verfärbt, schon makroskopisch ohne Zweifel als carcinomatös infiltrirt mit absoluter Sicherheit zu bezeichnen. Hieraus ergiebt sich die Nothwendigkeit, dass selbst schon bei einem anscheinend kleinen Carcinom im Fundus schon weitgehende Veränderungen der Drüsen vorliegen können, auch das Corpuscarcinom, wenn es nur ebenangeht, auf abdominellem Wege anzugreifen, weil wir nur so die Möglichkeit in der Hand haben, uns über die Beschaffenheit der Drüsen Gewissheit zu verschaffen, und das schon infiltrirte Parametrium nach Freilegung der Ureteren gründlich zu entfernen. Es ist das jedenfalls ein sicherer Weg, als die Rückbildung der erkrankten Drüsen den Schutzkräften des Körpers zu überlassen. Dass sehr selten und jedenfalls erst recht spät der Einbruch in das Parametrium erfolgt, einmal, da im Uteruscavum zu unbeschränktem Wachsthum Raum genug vorhanden ist, und dann wegen der durch die Metritis bedingten starken Gewebespannung scheinen diese Fälle auch zu beweisen.

Ueber die Entstehung der vaginalen Metastase wird später berichtet.

$\mathrm{Da}$ in meinen Präparaten sich kein Hornkrebs befindet, also kein Carcinom, welches seinen Ausgang nimmt vom Oberflächenepithel, welches dann später metaplasiren und in die Tiefe als solide Stränge wuchern soll, so kann ich hierüber nichts Näheres sagen, als nur betonen, dass hier gerade grosse Vorsicht am Platze ist, weil häufig Fälle beschrieben wurden, wo der primäre Knoten in der Cervix sass und der Tumor im Corpus sich nur als secundärer erwies.

Was nun die Drüsenkrebse im Fundus uteri angeht, so verdienen alle malignen epithelialen Neubildungen diesen Namen mit vollem Rechte, mag auch immer das histologische Bild ein anscheinend noch so eindeutiges sein. Sowohl das maligne Adenom wie das Adenocarcinom haben einen ausgesprochenen Drüsentypus, der selbst bei letzterem meist in exquisiter Weise vorhanden ist, nicht etwa nur angedeutet. In welchem Verhältniss beide zu einander stehen ist ja noch strittig; ob ersteres ein Vorstadium des letzteren ist, welches stets oder nur in einigen Fällen vorhanden ist, darüber sind die Acten heute noch nicht geschlossen. Jedenfalls haben wir kein Recht mehr, allein aus ein paar Sehnitten eines Tumors die Diagnose eines malignen Adenoms zu stellen, da oft genug die von vielen Autoren als charakteristische Eigenschaften angegebenen Merkmale anzutreffen sind, daneben sich aber auch 
346 Offergeld, Ueber die Histologie der Adenocarcinome im Uterusfundus.

unzweifelhaft rein carcinomatöse Bilder finden. So ist der Schwund des interglandulären Bindegewebes bis auf den letzten Rest, und die treue Beharrlichkeit in der Bildung hoher, einfacher Oylinderzellen nur etwas, was es mit dem Adenocarcinom gemeinsam haben kann. Mitunter lässt sich auch unschwer bei diesen darthun, wie es seinen Ausgang ron einer glandulären Endometritis nahm, wenigstens in der Art, dass die Drüsenneubildung ganz excessiv vor sich ging, und erst recht darf man aus der Art der mitotischen Vorgänge keine weitgehende Schlüsse ziehen. Den Eauptwerth legt man auch heute noch darauf, dass beim destruirenden Adenom die Form des hoben einschichtigen. Cylinderepithels gewahrt bleibt mit ganz typischer dos à dos Stellung der an einander stossenden Epithelien. Gerade aber die Rückenstellung der Zellen, und ein Blick auf die Tafeln und den Text wird es lehren, findet man gar nicht so selten selbst in den ausgesprochensten Fällen von Adenocarcinom, und zwar dann, wenn die Polymorphie der Zellen in den Hintergrund getreten ist, und uns die secretorischen Vorgänge in dem mehrschichtigen Cylinderepithel noch eine relative Ausbildung der Funktion erkennen lassen. Und wenn Gebhard ${ }^{1}$ ) das Postulat der Einschichtigkeit in den Vordergrund stellte, so kann ich nur sagen, dass man sehr häufig auf Serien ron Schnitten keine Mehrschichtigkeit zu Gesicht bekommt, bis auf einmal die Drüsen, sei es nun mit oder ohne Vebergänge, ein zweischichtiges Oylinderepithel führen; diese Bilder sind nicht etwa mit Schiefschnitten zu verwechseln, sondern durch eine Reihe ron Mitteln lässt sich darthun, dass die Zellen ihr ganzes Wesen geändert haben. Es ergiebt sich daher die Nothwendigkeit, in zweifelhaften Fällen ans einer Reihe verschiedener Stücke des Tumors sich Serienschnitte herzustellen, bis man sich absolute Klarheit verschafft hat. Wie berechtigt diese Forderung ist, beweist wohl am besten der Umstand, dass, seit man die Tumoren überhaupt genaner untersucht, die Fälle von malignem Adenom stets seltener werden, und auch einige der classischen Fälle bei intensiver Nachuntersuchung endgültig von der Liste verschwunden sind. Man wird daher wohl nieht felil gehen mit der Annahme, dass beide Tumoren sich auf einen Grundtypus nämlich eines Drüsencarcinoms mit langem Erhalten“ bleiben des adenomatösen Baues zurückführen lassen, dass man als malignes Adenom nur eine Spielart erblickt, welches neben

1) Gebhard, Path. Anatomie der weibl. Sexualorgane. Leipzig 1899. 
seinen klinischen Eigenschaften auch die histologischen, wenn auch versteckt, eines Drüsencarcinoms trägt. Da man bei vollständiger Durchmusterung eines malignen Adenoms stets vereinzelte Stellen mit typischem mehrschichtigen Epithel finden wird, so haben wir kein Recht mehr von einem adenomatösen Vorstadium oder einer Unterabtheilung der Drüsenkrebse des Uterus zu reden, wir müssen also den Begriff einer eigenen Species fallen lassen; den klinischen Begriff der Malignität können wir unmöglich auf einen Tumor übertragen, der histologisch gutartig ist, also ein Adenom. Aber selbst wenn wir mit dem Namen nur bezeichnen wollten, dass hauptsächlich einschichtiges Cylinderepithel vorhanden ist, so verleitet er doch zu schweren Missverständnissen; davor schützt nur die Umschreibung: "Adenocarcinom mit vorwiegend einschichtigem Cylinderepithel ${ }^{a}$. Denn wie gesagt in jedem malignen Adenom giebt es bei genauerem Suchen Stellen mit Mehrschichtigkeit, genau wie in jedem Sarkom auch Rundzellen zu finden sind. Nun bezeichnen wir doch nur die Sarkome als Rundzellensarkome, wo auf den ersten Blick neben dem Sarkombau die runden Zellen uns auffallen, wir müssen also, wenn wir bei einem adenomatösen Bau die nur bei Drüsencarcinom rorkommenden sonstigen Veränderungen (Schwund des Stroma und der Membrana propria, pathologische Mitosenvorgänge u. s. w.) antreffen, naturgemäss sagen, es ist das ein Adenocarcinom mit vorwiegend einschichtigem Epithel.

Ebensowenig sich ein genereller Unterschied also zwischen diesen beiden Tumoren construiren lässt, kann man auch eine scharfe Trennung zwischen Adenocarcinom und dem gewöhnlich alveolären zu Recht bestehen lassen, ohne mich direct der Ansicht anzuschliessen, dass nun alle Drüsenkrebse, wenn man sie lange genug vegetiren lässt, in das Carc. glandulare simplex übergehen müssen. Beide Arten sind von Hause aus nicht vollstänig verschieden; es beweist dies am besten die Thatsache, dass beide Formen sich im gleichen Tumor finden können. Es gibt sehr oft Fälle, wo die Drüsenimitation so zurücktritt, dass auch hinsichtlich der Polymorphie des Epithels durchaus der Eindruck eines Carc. glandulare simplex entsteht, wenn man auch auf anderen Schnitten wieder ein wohlgelungenes Bild des Drüsenkrebses antrifft. Gerade hierbei hat man sich sorgsam vor Täuschungen und Trugschlüssen zu hüten; es kann sich ereignen, dass gerade die polymorphen, also schon vom normalen Cylinderepithel weit entfernte (entdiffe- 
348 Offergeld, Veber der Histologie der Adenocarcinome im Uterusfundus.

renzirte, anaplasirte) Zellen auch hinsichtlich ihrer biologischen Fähigkeiten sich so gewaltig umgeändert baben, dass sie als kranke und im Zerfall begriffene anzusprechen sind. Nachen sich diese Vorgänge im Centrum eines Nestes bemerkbar, so kann es direct den Anschein gewinnen, als hätte man einen Drüsendurchschnitt vor sich und die Vermuthung wird erst zur Gewissheit durch die im scheinbaren Lumen angehäuften Secretionsproducte, welche aber in der That nur erkrankte oder schon zerfallene Epithelien sind.

Gegen solche Fehldiagnosen schützt nur der Nachweis des Gewebszerfalles, besonders in der scheinbaren Umrandung des Pseudocarcinoms, sowie der des unbegrenzten Weiterwachsens solider Carcinomstränge in die Muscularis; es ist das ein infiltrirendes hauptsächlich in den intermusculären Lymphbahnen. Denn das Adenocarcinom dringt zwar auch in das Myometrum hinein, aber lange nicht so weit, und hat stets seinen drüsigen Typus gewahrt, während im anderen Falle ganze Carcinomnester, von Bindegewebe begleitet, vorwuchern, und noch weiter einzelne disseminirte Zellen ausschicken, welche weit das Gewebe durchsetzen im Verein mit den Leukoeyten. Andererseits kann aber auch ein typiscbes Adenocarcinom aus uns noch ganz unbekannten Ursachen plötzlich seine Zellformation so umändern, dass nun an verschiedenen Stellen neben einem Schwund des adenomatösen Baues auch eine Aenderung in Grösse, Gestalt und Lagerang seiner Epithelien erfolgt. ob hierbei wirklich degenerative Processe im Spiele sind, oder, wie Manche annehmen wollen, es um Alterserscheinungen in den Zellen selbst sich handelt, ist bislang noch durchaus nicht aufgeklärt. Um kurz zu wiederholen, der ganze Verlauf und das Wachsthum sprechen dafür, dass die von Kaufmann aufgestellte Eintheilung der Funduscarcinome wesentlich wiel einfacher sich gestaltet, dass, wenn wir die Existenz eines verhornten Plattenepithelcarcinoms einmal als bewiesen voraussetzen, wir keine Unterabtheilungen sondern nur Abarten des Drüsencarcinoms za erwähnen haben.

Was nun den klinischen Verlauf angeht, so lässt sich auch bierin kein entscheidender Unterschied feststellen. Alle Spielarten der destruirenden Epithelwucherung sind als absolut maligne Tumoren zu bezeichnen; sie zeigen ein progredientes, schrankenloses Wachsen, können selbst jahrelang nach der Exstirpation regionäre wie auch echte Metastasen bedingen, sind also im Stande die Resorptionsfähigkeit und Zerstörungstracht des Organismus fremd- 
Offergeld, Ueber die Histologie der Adenocarcinome im Uterusfundus. 349

artigen Zellen gegenüber auf's Stärkste zu irritiren. Ganz besonders verursachen sie den bekaunten Symptomencomplex, welchen wir als Kachexie bezeichnen. Und wenn auch ihr Wesen uns noch durchans schleierhaft ist, so kann doch gesagt werden, dass die dauernde Unterernährung des Körpers - in der That ist bei Carcinom der N-Stoffwechsel so verändert, dass stets mehr $\mathrm{N}$ ausgeschieden als in der Nahrung aufgenommen wird -, die durch den Zerfall der jüngeren Epithelien in Freiheit gesetzten albuminoiden Körper, den Cytolysinen ähnlich, toxisch wirksam, und besonders die Sekrete der Carcinomzellen, die als Fermente einen direct nachweisbaren abnormen Gang im Stoffwechsel, besonders des Eiweisses bedingen, in ihrer Gesammtheit den schnellen Tod des Kranken gewissermaassen an einer Vergiftung erklären.

Lässt also der Verlauf der Erkrankung uns unmöglich einen principiellen Unterschied aufstellen, lässt das histologische Bild in so fern im Stich, als durchaus verschiedene Bilder im gleichen Tumor sich finden können, was hat es da für einen Sinn noch an der alten Eintheilung festzuhalten, als vielmehr von einem Adenocarcinom des Uterusfundus zu reden, welches verschiedene Spielarten aufweist. Nicht einmal das Tiefenwachsthum schützt uns vor Irrthümern, da auch bei den typischen Formen des Drüsenkrebses entgegen der Ansicht von Gebhard ${ }^{1}$ ) ein Tiefenwachsthum sich fiudet, wenn auch lange nicht so ausgeprägt, als wenn solide Stränge hineinwuchern; im ersten Falle kann man bisweilen, wie ieh es selbst beschrieben habe, noch intacte Muskulatur zwischen den gewucherten Drüsen finden.

Wenn man von diesem Gesichtspunkte aus die Adenocarcinome betrachtet, so findet man zunächst, dass dic Drüsenimitation ganz regellos im Gewebe vertheilt sein kann. Zwar ist sie meist eine sehr lebhafte mit fast völligem Schwund des interglandulären Gewebes; die äussere Form ist dabei eine durchaus regellose, wenn auch in ganz wenigen Fällen noch Anklänge an die bei der glandulären Endometritis erhalten sind; man findet dort noch annähernd korkzieherartige, welche aber auch schon eine beträchtliche Veränderung erkennen lassen. Diese betrifft das Epithel. Wir treffen neben unverändertem Cylinderepithel, welches allenfalls die Form in verschiedener Höhe trägt, also mehrzeiligen Charakter hat,

1) Gebhard, Pathologische Anatomie der weiblichen Sexualorgane. Leipzig 1899. 
auch solches, wo das gleiche Epithel in zwei oder mehr Schichten concentrisch um die Drüse läuft und die Zellen bei ihrem Aneinanderstossen cine typische Rückenstellung eingenommen haben: hierbei können die Drüsen selbst invaginirt sein, oder sonst die mannigfaltigste Gestalt annehmen. Nun braucht nicht etwa der ganze Epithelsaum aus diesen Zellen zu bestehen, sondern die Formation kann sich auch in der Weise ändern, dass die Zellen ihre längliche Gestalt einbüssen und mehr quadratisch werden, wobei gleichzeitig der Kern statt seiner mehr länglichen Gestalt eine rundliche annimmt. Dieser Uebergang in der äusseren Gestalt, welcher zweifelsohne mit einer Aenderung der biologischen Eigenschaften verbundev sein muss, findet nun entweder ganz plötzlich statt, oder erst allmälig. Im ersten Falle muss man sich wohl hüten ihn mit Schrägschnitten zu verwechseln. Es kann ja gelegentlich bei einer harmlosen Endometritis dadurch eine Mehrschichtigbeit des Epithels vorgetäuscht werden, dass der Saum schief angeschnitten wurde. Um sich vor solchen Bildern zu schützen, muss man den Nachweis erbringen, dass einmal in allen Zellen glejch grosse Kerne vorhanden sind und diese alle peripher liegen. Im letztern spricht man won Uebergängen. Warum die Cylinderzellen nun einmal die gleichen Tochterzellen produciren, das, andere Nal nur die niedrigen quadratischen, welche die Höhe des Cylinderepithels in mehreren Lagen ausfüllen müssen, ist uns ganz unbekannt. Ob wir das Recht haben, hierin einfach einen regressiven Forgang zu erblicken, ist sebr fraglich, wenn es auoh wahrseheinlich ist, dass hierin eine ganze Aenderung des gesammten Charakters der Zelle sich dokumentiren wird. Nun kann aber dieser Wechsel sich auch so wiederholen, dass auch wieder einmal, sei es mit, sei es ohne Zwischenform das typische, hohe Oylinderepithel in Erscheinung tritt; dieser Umstand gerade muss uns davon abbalten einfach durch die Annahme regressiver Veränderungen diesen mannigfachen Wechsel erklären zu wollen.

Neben diesen gröberen Veränderungen; wiche sich im Epithel in seiner Gesammtheit documentiren, giebt es nun eine Menge feinerer, welche die einzelner Zellindividuen als solche und in ihrem Verhälniss zu ihren Nachbarn betreffen. Lis ist vjelleicht am Platze, hier sofort des Verhaltens der Membrana propria zo gedenken, da es sich eng an das des Epithels anschliesst. In den ausgesprochenen Formen von Adenocarcinom ist sie ja bekanntlich geschwunden, es liegt Drüse an Drüse, und wie das gesammte 
Zwischengewebe dahin ist, so lässt sich auch von der eigenen Drüsenhülle keine Spur mehr erkennen. Diesem Stadium des definitiven Schwundes geht aber in manchen Fällen ein anderes voraus, in welchem die Drüsenkapsel zwar auch schon sehr eingreifend verändert sein muss, wo sie aber als ungefärbte, um die Acini circulär verlaufonde Membran noch mit verschieden grosser Sicherheit oder nur Wahrseheinlichkeit zu erkennen ist. Es ist auffallend, dass bisher dieses Vorstadium des definitiven Schwundes übersehen wurde. Wir haben. es in diesen seltenen Fällen sicher mit einer zwar schon degenerirten Membran, sei es nun durch die vom Carcinom ausgehenden Stoffwechselproducte, sei es durch die Leukocyten zu thun, aber das Bindegewebe ist noch nicht bis auf den letzten Rest aus den Bildern wie ausgelöscht, gleichsam verdaut von dem wuchernden Epithel. Denn es ist doch höchst auffallend, dass manchmal schon bei einschichtigem, noch relativ gut ausgeprägtem Cylinderepithel die Membran ganz geschwunden ist, während stellenweise bei unzweifelhafter atypiseher Epithelwucherung sie in ungefärbtem Zustande die Drüsen umspinnt. Was nun die feineren Verhältnisse der Zellen selbst angeht, so bleibt meist der Kern bis zum Zerfall der Zellen verschont. Die Cylinderzellen erhalten zuerst den Typus der Mehrzeiligkeit, indem die Kerne in verschiedener Höhe auftreten, werden dann etwas kleiner, so dass, um die Höhe des Saumes auszufüllen, von den Nachbarzellen feine Plasmafortsätze ausgesandt werden und verlieren so ihre scharfe Nebenmannstellung. Unter stetiger Grössenabnahme werden die Zellen stets breiter und bald muss zur Ausfüllung der Höhendifferenz eine zweite Zelle aufücken; während nun das Epithel aus seiner niedrig cylindrischen Form in eine mehr quadratische übergeht, entstehen in Folge der Raumverhältnisse bald Zellen, deren Aeusseres eine ganz bizarre Gestalt aufweist und welche man daher als polymorph bezeichnet. Diese Veränderungen müssen wir unbedingt als grobe ansprechen, denn schon lange, ehe wir im Stande sind, diese nachzuweisen, treten in noch scheinbar ganz unverändertem Cylinderepithel Vorgänge auf, die mit Sicherheit als pathologische angesprochen werden müssen; sie äussern sich hauptsächlich in der Färbung der gesammten Zelle und ihrer einzelnen Theile. Und wenn wir auch über die Ursachen des Tinctionsvermögens der Gewebe noch herzlich wenig wissen, es jedenfalls noch unentschieden ist, ob nur chemische oder rein osmotische Verhältnisse, oder endlich beide zusammen vorkommen 
352 Offergeld, Ueber die Histologie der Adenocarcinome im Uterusfundas.

können, so sind wir doch in der Lage, allein aus diesem immerhin einige Schlüsse zu ziehen. Zuerst ist auffallend die Differenz in der Färbung der einzelnen Zellen unter einander, denn man triff neben gut und scharf tingirten auch vereinzelte homogene, blass. gefärbte an; dieses beweist uns eben, dass einzelne Zellen sich in ihrer anatomischen Structur eine Sonderstellung erworben haben, welcher vielleicht auch eine gleiche ihrer biologischen Verrichtungen und Reactionen parallel laufen wird. Diese Thatsache allein deutet an schon, dass bei einem sonst für einfache Entzündungen typischen. Bilde einzelne Zellen hinsichtlich ihres physiologisehen Charakters eine Sonderstellung einnehmen; auf diese Erscheinung ist deshalb ein solcher Werth zu legen, obsehon ja geringe Differenzen der Nuancirung in der Färbung von einer Menge Nebenumständen abhängig sind, weil sie sich stets paaren mit andern gesunden Zellen fremden Eigenschaften. Sie betreffen hauptsächlich die feinen Vorgänge im Plasma selbst. Während man bei unverändertem $\mathrm{Cy}$ linderepithel deutlich den basalen Theil, in welchem der Kern enthalten ist, von dem secernirenden der Zelle trennen kann, ist dies bei schon beginnender Aenderung in dem normalen Verhalten durchaus anders geworden. Hier ist die Zelle homogen blass geworden; der basale Theil lässt die hauptsächlich in der Nähe des Kernes vorhandene feinste Kömung vollständig vermissen, ebenso wie der centrale die feine früher als Porenkanäle angesprochene Strichelung; es hat also gewissermaassen das Plasma seine hohen physiologischen Eigenschaften, aus seiren Eiweisskörpern durch vitale Thätigkeit die normalen Secrete zu produciren, total eingebüsst. Fränkel 1) hat zuerst diese Verhältnisse gestreift, und jch muss ihm durchaus beipflichten, dass sehon sehr frühzeitig, wenn auch sonst das histologische Bild wenig Charakteristisches bietet. unzweifelhaft bei malignen epithelialen Fundustumoren sich Stellen finden, die eine vollständige Umwandlung in den innersten Forgängen des Zelllebens uns vor Augen fübren, also neben dem histologischen Beweis aut die tiefe und eingreifende Veränderung in den physiologischen Vorgängen der Zellen schliessen lassen. Wenn Gebhard ${ }^{2}$ ) und Hansemann ${ }^{3}$ ) ron diesen Documenten nichts

1) Fraenke1, Hegar's Beiträge. Bd. II. H. 3.

2) Gebhard, Pathologische Anatomie der weiblichen Sexualorgane. Leipzig 1899.

3) Hansemann, Die mikroskopische Diagnostik bösartiger Geschwülste. Berlin 1902. 
Offer̈geld, Ueber die Histologie der Adenocarcinome im Uterusfundus. 353

wissen wollen, so muss man bedenken, dass sie sich selten gehäuft finden, sondern an nur wenigen Stellen und auch hier nur vereinzelt auftreten, dass sie eben die allerersten uns direct nachweisbaren histologischen Abnormitäten darstellen und daher wohl gelegentlich übersehen werden können, wenn man nicht ganz besonders scharf darauf achtet. Auch eine schon sehr frühzeitig bemerkbare Abnormität besteht darin, dass, wie Ribbert 1 ) ganz richtig bemerkt, manchmal als eins der frühesten Zeichen für die Sonderstellung der Zellen die normaler Weise vorkommenden Intercellularbrücken $z$ wischen den Cylinderepithelien fehlen.

Eine weitere fast gleichzeitig mit der Mehrschichtigkeit, meist ihr jedoch unmittelbar vorhergehende Erscheinung betrifft die Vorgänge bei der Zelltheilung. Schon allein der grosse Reichthum der in den Schnitten vorhandenen Mitosen, welche sich in verschiedener Phase der Entwickelung befinden, beweist aufs Deutlichste das mächtige progrediente Wachsthum der Gewebe. Dieser Ueberfluss der Mitosen ist so gross, dass stellenweise die Zelltheilungsvorgänge vollständig die unentwickelten Individuen in den Hintergrund treten lassen. Nun darf man aber nicht glauben, dass das Gewebe den Typus und Charakter der Mutterzellen in Treue bewahren würden, sondern es zeigt verschieden grosse Variationen in seinem Bau. Dass trotz der enormen, ja fast krankhaft gesteigerten Proliferationsfähigkeit das Gewebe kein reifes ist, sondern dem raschen Zerfall unaufhörlich entgegeneilt, lässt sich unschwer an den Mitosen selbst erkennen. Wenn bei diesen Präparaten auch viel weniger die Stellung der Axen der Theilungsfiguren zu einander und besonders zu den Mutterzellen eine abnorme war, als man sonst gerade diese Verhältnisse bei Adenomcarcinom anzutreffen gewöhnt ist, so auffallender war das Ueberwiegen der karyokinetischen Figuren, welche wir mit Bestimmtheit als anormale, vielleicht durch ihre Folgezustände direct als pathologische ansprechen müssen. Neben den bekannten Figuren wäre dann noch die nschollige Degeneration" der Mitose hinzuzufügen; die übrigen sind schon sattsam von anderen Autoren beschrieben. Bei dieser Form ist die Mitose homogen blass und weist in ihrem Innern einige zwiebelförmige Scheiben auf, die etwas dunkler gefärbt sind und wahrscheinlich die Theilungsfäden enthalten werden. Aus den zahlreich vorhandenen Mitosen und ganz besonders

1) Ribbert, Lehrbuch der allgemeinen Pathologie. Leipzig 1901. 
354 Offergeld, Veber die Histologie der Adenocarcinome im Lterusiundus.

den von der dem betreffenden Gewebe specifischen, normalen Form abweichenden hat Hansemann ${ }^{1}$ ) sehr weitgehende Schlüsse gezogen, durchaus hypothetischer Natur, welche dann wiederum von Anderen benutzt wurden zur Erklärung der Histogenese. Ersterer nahm bekanntlich einen Rückbildungsprocess gesunder, unveränderter Epithelien zu carcinomatösen an, ausgehend von der Voraussetzung; dass durch die asymmetrische Karyokinese Zellen verschiedener idioblastischer Fähigkeiten entständen; die Folge sei dann eine Entdifferenzirung (Anaplasie), durch welche die ganz specifischen, physiologischen Eigenschaften dahin sehwänden und ganz nebensächliche in das Vordertreffen rückten; andererseits sei auch die Möglichkeit zuzulassen, dass durch asymmetrische Mitosen galz neve Qualitäten erworben werden könnten. Nun könne sich aber auch ein der Entwicklung der Geschlechtszellen analoger Vorgang abspielen; die Fntdifferenzing fühe nicht mehr anf den emoryonalen Stand zurück, sondern mache schon eher Halt, so dass nu eine Zellentwicklung in anormalen Bahnen daraus resultire. Offenbar stützt er sich hierbei auf die bekannte Marchand-Bonnetsche $^{2}$ ) Theorie zur Erklärung der Histogenese der teratoiden Geschwülste in den Keimstücken beider Geschlechter, nachdem sich für die sinnreiche, aber der Wirklichkeit direct entgegengesetzte von Wilms ${ }^{3}$ hat kein Beweis erbringen lassen. Aber dieser Tergleich ist doch ein durchaus unzutreffender. Ganz abgesehen davon, dass die Zellen der Embryome den Charakter der Eizelle durchaus beibehalten und in Nohts ron inm abweichen, ganz besonders aber, entgegen mancher Autoren Ansicht, weder maligne Eigenschaften besitzen, noch sie später erwerben, lässt sich Hansemann's Ansicht heute nicht mehr verfechten, weil uns Stroebe ${ }^{4}$ ) den positiven Beweis auf experimentellem Wege erbracht hat, dass asymmetrische Hitosen bei der einfachen Gewebsnekrose durch Ligatur der Arterie auch in Massen anzutreffon sind; weiter beobachtet man sie bei Entzindungen und Regenerationsvorgängen, sowie zuweilen auch bei histologisch und klinisch absolut gutartigen Neubilungen; und zuletzt darf man nicht etwa glauben, dass bei

1) Hansemann, Die milkroskopische Diagnostil bösartiger Geschwülste. Berlin 1902.

2) Marchand, HI. Verhandl. d. Doutsch. path. Gesellschaft. 1899. Bonnet, Monatsschr. f. Geburtsh. u. Gynäkologie. Bd. 13.

3) Wilms, in Martin's: Krankheiten der Eierstöcke. Leipzig 1902.

4) Stroebe, Ziegler's Beitx. Bd. XI. - Centralbl. f. Path. Bd. 2, 5. 
Carcinom reguläre Mitosen überhaupt fehlen, sondern sie sind stets neben den pathologischen anzutreffen. Diese Umstände mögen denn wohl Beneke ${ }^{1}$ ) veranlasst haben, eine irreguläre prosoplastische Epithelbildung anzunehmen, für welche er den Namen Kataplasie in Vorschlag bringt. Als einzig zulässige Schlussfolgerung aus diesen Thatsachen lässt sich daher bislang nur daran festhalten, dass die zahlreichen asymmetrischen Mitosen nur den Beweis liefern für eine hohe Stufe der Degeneration und fortschreitenden Zerfall, dem das Gewebe entgegeneilt trotz schrankenlosen Weiterwachsens; die innere Ursache hierfür ist uns Allen noch unbekannt.

Dass die schon von Hause aus abnormen Mitosen krankhafte Zellen und Kerne hervorbringen werden, liegt wohl direct auf der Hand. Nun ist es sehr beachtenswerth, dass, selbst wenn die Zelle schon abnorme Veränderungen mit Sicherheit erkennen lässt, der Kern meist noch unverändert ist. Ja er bleibt noch länger bestehen als sie selbst, denn oft ist in den Detritusmassen nur an den noch vorhandenen Kernen irgend eine Orientirung möglich. Man darf aber nicht glauben, dass er sich stets gleich bleibe, überhaupt keine Aenderung erleide; das ist nicht der Fall. Zuerst verliert er meist seine scharfe Umrandung und sieht angenagt aus, erst dann ändert sich sein Tinctionsvermögen und zuletzt zerfällt er unter dem Einfluss seiner abnormen Entstehung und der durch das aufgelöste umgebende Gewebe in Freiheit gesetzten Zellproducte in verschieden grosse und versehieden scharf tingirte Fragmente, welche denn bald von Leukocyten aufgenommen und forttransportirt werden. Dem vollständigen Zerfall schien in einigen Fällen eine Degeneration voranzugehen, unter derem Einflusse die Kerne homogen blass wurden und meist um das in der Mitte gelegene Kernkörperchen sich concentrisch einige verschieden tingirte Schichten legten; das ganze Bild ähnelt sehr dem Durchschnitt einer Zwiebel. Ob die Kerne wie auch die Zellen sich aus diesen ersten Degenerationsstadien erholen werden, ist nicht recht $\mathrm{zu}$ glauben, da Alles darauf hinweist, dass sie anormalen mitotischen Vorgängen ihre Existenz verdanken.

Ziehen wir also den Schluss aus diesen Auseinandersetzungen, so müssen wir zugeben, dass schon sebr frübzeitig sowohl an einzelnen Zellen, wie an ganzen Zellcomplexen beim Adenocarcinom Veränderungen auftreten, welche uns in den Stand setzen, mit

1) Beneke, Deutsche Zeitschr. f. klin. Medicin. Bd. 64. 
3 Эอ Offergeld, Ueber die Histologie der Adenocarcinome im Uterasfundus.

höchster Wahrscheinlichkeit diese Zellen als fremdartige $z$ u bezeichnen, ihnen auf den ersten Blick, wenn man sie mit ihren Nachbarn vergleicht, eine ganz abnorme, fehlerhafte Richtung, einen krankhaften Aufbau und ein pathologisches Zellleben abzulesen. Diese Erkenntniss von den feinsten, gewissermaassen allerersten Veränderungen sichtbarer Art der carcinomatösen Epithelien ist noch sehr jung; Borst hat sie meines Wissens zuorst stricte hervorgehoben. Als er auf der VIII. Tagung der Deutschen pathologischen Gesellschaft 1904 in Breslau seine Auseinandersetzungen über die histologische Strictur der Carcinomzellen beendet hatte, sagte er am Ende seines Vortrages: "Ich ziehe den Schluss ans den vorliegenden Betrachtungen. Für die Frage nach đen primären, carcinomatösen Epithelveränderungen an Drüsen hat sich als Resultat ergeben, dass weder Gestaltsveränderungen der Epithelzellen, noch ungeordnete Aufschichtung der Epithelien, noch solide Anfullung der Drüsenlumina mit gewucherten Epithelien, beziobnngsweise die Bildung solider, sprossenartiger Fortsätze der Drüsen; noch solide Epithelformationen irgend welcher Art überhaupt sogar die Membrana propria kann bei allen diesen Veränderungen fehlen, beziehungsweise aufgelöst sein - an sich unbedingt für carcinomatös gelten können. Derartige Veränderungen kommen vielmehr auch bei regenerativen, entzündlichen und hyperplastisehen Productionen vor; sie gehören in die Kategorie der sogenannten atypischen Epithelwheherugen, wie sio für das Deckepithel bereits länger bekannt und auch vielfach beschrieben sind." Für maligne hat zu gelten, wie er weiter fortfährt: "die Willkür in der individualistischen Ausgestaltung der producirten Zellen, die sich in der oft sehr weitgehenden und wechselvollen Abweichung der Kerne and Plasmastructur vom Normalen zu erkennen giebt, z. B. nach Grösse, Lage, Structur und Chromatingehalt. Diese Punkte sind zwar auch nicht specifisch für Carcinom, jedoch dürfen sie den Aussehag geben in strittigen Fallen."

Wir werden also nicht fehlgehen, wenn wir die Carcinomzellen auf eine abnorme, krankhafte Anlage zurückführen, in ihnen also Abkönmlinge einer Perversität erblicken, die, sobald pathologische oder auch nur gesteigerte physiologische Reize auf sie einwirken, sich durchans anders verhalten werden, als die normalen Zellderivate. Müssen wir daher die Carcinomepithelien als Degenerationsproducte im gesammten Organismus ansprechen; so liegt es aut der Hand, dass sie allerorts ihre abnorme Anlage, ihre krankhafte 
Sonderstellung werden erkennen lassen. Sie werden sich daher den physiologischen Wechselzuständen des Körpers und erst recht pathologischen Einflüssen gegenüber als sehr zart und hinfällig erweisen und empfindlich auf jede Störung in ihrem krankhaften Zellleben reagiren. Einmal finden sich mit Vorliebe im Uteruscarcinom aller Gattungen Riesenzellen. Ihre Entstehung ist eine mannigfaltige.

Man kann denken, dass es sich um typische Fremdkörperriesenzellen, wofür die centrale Anordnung der Kerne spricht, handelt; sie hätten sich also um irgend eine fremde Substanz im Carcinom, etwa verhornte Epithelien oder von aussen hereingedrungene Fremdkörper gebildet. Dann aber kann man auch gelegentlich typische Tuberkel beobachten, wo die Riesenzellen ihre Kerne alle radiär gerichtet haben; dieser Umstand hat Ribbert ${ }^{1}$ ) veranlasst, auf den Zusammenhang von Tuberculose und Carcinom hinzuweisen. Endlich wird man nicht direct die Auffassung ron der Hand weisen dürfen, dass sie durch abnorme Confluction des Plasma benachbarter Zellen unter dem Einfluss abnormer mitotischer Vorgänge entstanden sein können; wir hätten es dann also mit unfertigen, besonders in physiologischer Hinsicht nicht ausgebildeten, nicht differenzirten Elementen zu thun, welche stets einen Locus minoris resistentiae für das Gewebe darstellen. Und es ist ja wohl bekannt, dass gerade die Existenz und der Reichthum der Riesenzellen den schnellen Zerfall des Carcinoms bedingen, die Neubildung also durch diese direct selbst in ihrem Bestande auf's Aeusserste gefährdet ist. Es ist nun sehr interessant, dass sie sich, obwohl man ihnen auch beim Adenocarcinom garnicht so selten begegnet, in gehäufter Weise beim einfach glandulären Carcinom vorfinden. Dort rufen sie auch den schnellen Gewebszerfall und die Autolyse der Carcinomzellen hervor, und es ist sicher kein Zufall, dass, während das Drüsencarcinom noch sehr beständig ist, gerade der Uebergang in das alveoläre von einem Zusammenbruch des ganzen Parenchymgewebs begleitet ist.

Sodann gehen in den Carcinomzellen Veränderungen vor sich, auf die wir zwar nur schliessen können, da es so unendlich schwer ist an der lebenden Zelle die feinsten Einzelheiten zu studiren, die aber sicher verhanden sein müssen, da wir an den getödteten, in

1) Ribbert, Carcinom und Tuberculose. Münchener med. Wochenschrift. 1894. 
358 Offergeld, Ueber die Histologie der Adenocarcinome im Uterusfundus.

ihrer Structur daher fixirten Zellen ganz prägnante Merkmale finden. Aus diesen Erscheinungen müssen wir den Schluss ziehen auf einen ganz abnorm hohen Wasser- und Saft- d. h. Lymphgebalt der carcinomatösen Epithelien, die auch hierin den normalen embryonalen Zellen sehr nahe stehen würden. Da nun das gefässhaltige Bindegewebe in den typischen Formen ron Adenocarcinom fast ganz verdrängt ist, während beim alveolären wenigstens an der Grenze der einzelnen Carcinominseln es sich meist ziemlich reichlich vorfindet, also gewissermaassen die Stützen des Netzes darstellt, dessen Haschen von den Carcinomzellen ausgefült sind, so werden in riel höherem Grade als sonst in Körper die Verhältnisse der Osmose und Diffusion zwischen gasförmigen und flüssigen Körpern zu Recht bestehen, vielleicht auch eine elective Auswahl der Epithelien für verschiedene Stoffe, sodass einzelne Substanzen nur wenig oder garnicht, andere dagegen in grosser Menge aufgenommen werden. Lässt man die sicher bewiesenen physikalischen Verhältnisse zu Recht bestehen, so liegt es auf der Hand, dass gerade die centralen Partien der Carcinomnester am wenigsten Ernährung und Gasaustausch erhalten werden, in ihnen sich daher auch die Stoffwechselvorgänge am trägsten abspielen werden, diese Stellen also den Punkt darstellen, wo sich am ehesten pathologische Torgänge regressiver Art eroignen kömen. Denn ob die Carcinomzellen einfach wie ein Filter alle Lösungen passiren lassen oder als einen Act ibrer vitalen Thätigkeit nur einzelne, ist durchaus unklar. Wenn ja auch letztere eine höhere Differenzirung im Plasma als erste Vorbedingung nöthig hätte, ein solch ausgesprochene Arbeitstheilung der protoplasmatischen Körper, wie wir sie sonst bei den auf niedriger Stufe rangirenden earcinomatösen Epithelien nicht finden und wohl auch nicht recht erschliessen können, so muss man doch bedenken, dass besonders den gereifteren Formen auch eine sekretorische Thätigkeit zukommt, diese also wenigstens ein auch nach aussen thätiges, physiologische Arbeit leistendes Plasma aufweisen. Es wird sich daher sehr leicht im Centrum eines solchen Nestes fettige Degeneration, dann Nekrose und zuletzt vollständiger Gewebszerfall ereignen können, durch welehen einmal pseudoacinöse Bilder entstehen, sodass man noch Drüsenreste vor sich zu haben glaubt (Taf, V, Fig. 2). Die im Text beschriebenen und in Fig. 3 Taf. V abgebildeten Partien, welche sehr einem Rundzellensarkom ähneln, verdanken ihre Entstehung nur dem abnormen Reichthum des carcinomatösen Gewebes an Wasser. Nach dessen Entziehung 
kommt es zu Sprüngen und Rissen und die degenerirten Epithelien erscheinen als Zellen in einem fibrillären Grundgewebe, das sich durch charakteristische Färbemethode als ein theilweise Fibrin enthaltendes dokumentirt. Sonach enthalten also die Carcinomzellen neben einfachen Transsudationsprodukten auch in ziemlich reicher Anzahl sicher in der Umgebung, wahrseheinlich aber auch in ihrem Leibe selbst, das normalerweise flüssige Vorstadium des Fibrins, also eine fibrinogene Substanz, welche den gesunden Epithelien fremd ist und sich in ihrer Umgebung nur bei entzündlichen Processen vorfindet. Da man solche Bilder nur bei vorgeschrittenem Gewebszerfall zu Gesicht bekommt, so lässt sich vielleicht die Vermuthung aussprechen, dass sie erst in Freiheit gesetzt wurde, mithin vielleicht schon vorher in den Carcinomzellen enthalten war. Sollte dies der Fall sein, so müsste das krebsige Epithel eine ganz andere Zusammensetzung im histologischen und chemischen Sinne haben als das normale und auch einen hiervon grundverschiedenen Stoffwechsel.

Nehmen wir einmal, worauf ja alle Thatsachen hinweisen, die abnorme Stellung des carcinomatösen Epithels den andern Gewebseinheiten des Organismus gegenüber als noch sicherer als bisher erwiesen an, so wird es uns ein Leichtes sein, $\mathrm{za}$ verstehen, dass zwar die regenerativen Vorgänge dieses absonderlich ausgestatteten Epithels im Allgemeinen den dafür bekannten Gesetzen sich unterwerfen werden, dass aber auch hierbei die Neigung der Zellen zu einer Sonderstellung, einer Abweichung vom Hergebrachten mit Macht hervortreten wird, so dass wohl stets der Versuch zu erkennen ist, etwas Neues zu produciren, also Zellen hervorzubringen, die der Mutterzelle in ihrem allgemeinen Charakter zwar ähnlich sind, jedoch wieder andere Eigenschaften besitzen, die jener vollständig abgehen, also eine histologisch andere Gestalt und Struktur anfweisen, die ihren Grund hat in einem abnormen Zellleben. So finden wir denn in der That die Regeneration des Adenocarcinoms, wenn durch die Curette in grösserer Ausdehnung ein Defect im Epithel erfolgt ist, insofern in abnormen Bahnen verlaufen, als keine restitutio ad integrum erfolgt, sondern an einzelnen Stellen der Defect durch das üppig wuchernde Bindegewebe gedeckt wird, was zwar für den Organismus eine Art Selbstheilung bedeutet, für die Zellen des Tumors aber nur einer Minderwerthigkeit in so fern gleichzusetzen ist, als ihre Thätigkeit gleiche Tochterzellen zu produciren im Grossen erschöpft ist, und wenn wir die Fortpllanzung 
360 Offergeld, Ceber die Histologie der Adenocarcinome im Uterusfundus.

der Zellspecies als die höchste physiologische Leistung der Zelle mit vollem Recht ansprechen, so müssen wir eingestehen, dass dieser Fähigkeit das carcinomatöse Epithel verlustig gehen kann. Daneben findet aber auch eine Regeneration von Epithel, also gleicher Derivate, statt, nur hat hierbei die Tochterzelle jede Aehnlichkeit mit der Mutter verloren, wenn sie auch noch durch das Fehlen der Intercellularsubstanz als zur selben Gattung gehörig sich erweist. Diese Abweichung erstreckt sich sowohl auf die äussere Form, die Zellen sind kleiner und haben statt der cylindrischen eine mehr quadratische, oder durch die Raumverhältnisse bedingt, polymorphe Gestalt, als auch besonders auf eine Aenderung der Struktur und des Charakters des Plasma, welches seine Affinität zu sauren Färbstoffen ganz eingebüsst hat und die basischen begierig in sich aufnimmt. Es weist dieses Alles auf eine tiefgehende und $z$ war noch ganz unbekannte Aenderung im Leben and Chemismus der Zelle hin, durch welche sie so umgestimmt wird, dass sie ganz andere Formen und besonders Qualitäten wie die Mutterzelle besitzt, wenn sie auch noch wie diese zur gemeinsamen Gruppe der epithelialen Gebilde gehört.

Wenn auch die Carcinomzellen eime gewisse Sonderstellung in der Reihe der Epithelien einnehmen, so ist doch die Annahme, dass sie durchaus selbständig sind und die allgemeinen Gesetze der Pathologie für sie keine Geltung haben, durchaus falsch. Besonders Gebhard ${ }^{1}$ und $d^{\prime}$ Erchia? haben sich lange bemüht, für eine syncytiale Umwandlung im Uteruscarcinom den Beweis zu erbringen. Van muss ja zugeben, dass gerade bel Carcinoma glandul. simplex, zumal bei schlechter Härtung and Färbung es den Anschein erwecken kann, als seien die Zellgrenzen ganz verwischt und das Plasma der einzelnen Individuen zusammengeflossen. Ersterer hat auch in seiner Abhandlung einzelne ganz gute Zeichnungen, die das beweisen sollen, hinzugefügt. Solche Bilder trifft man gar nicht so selten an, aber es handelt sich nicht um eine syncytiale Cmwandlung. Einmal liegen die Keme niel zn regelmässig, als dass auch nur der blosse Verdacht entstehen könnte, und dann lässt sich, sobald der Gewebszerfall nicht schon allzuweit vorgeschritten ist,

1) Gebhard, Syncytioma malignum. Zeitschr. f, Geburtsh. u. Gynäl. Bd. 37.

2) d'Erchia, Beitrag zom Studium des primären Uteruscarcinoms. Zeitschr. f. Geburtsh. u. Gynäk. Bd. 38. 
Offergeld, Ueber die Histologie der Adenocarcinome im Uterusfundus. 361

bei scharfer Finstellung unschwer die scharfe Grenze zwischen den einzelnen Zellen erkennen.

Man muss natürlich noch gesundes Gewebe sich daraufhin ansehen, nicht etwa solche Stellen, wo sich nur Detritus oder wenigstens degenerative Vorgänge in den Zellen finden; in solchen Fällen kann zwar mit dem Zerfall der Zellen an sich auch einmal gelegentlich benachbartes Plasma confluirt sein, das ist aber nur ein Beweis für den vollständigen Zerfall. Daneben ist es aber auch nicht recht denkbar, wie Epithel, selbst wenn es Varietäten in seinem Charakter erkennen lässt, plötzlich in Zellen des Syneytium übergehen kann.

Ganz besonders aber hat man stets geglaubt, bei Cteruscarcinom die $z$ war auch heute noch wenig beachteten und bekannten Gesetze über die Metaplasie ganz ausser Acht lassen zu dürfen und ist so zu schweren Trugschlüssen gelangt. Zum Verständniss dieser Vorgänge ist es nöthig, ganz streng sich an den von Virchow eingeführten Begriff zu halten, "nur eine Veränderung des Zellcharakters unter Persistenz der Zellen selbst" als Metaplasie zu bezeichnen. Aus dieser Definition ergiebt sich ihre Seltenheit, gleichzeitig aber auch, dass sie beim Embryo, welcher mehr Qualitäten in einer Zelle besitzt als der Erwachsene, eher aufţreten wird. Einmal differencirte Gewebe gehen später nicht mehr in einander über, wenn auch eine Rückbildung bis anf gewisse embryonale Stufen nicht scharf von der Metaplasie trennbar ist. Die echte Metaplasie - bei der falschen handelt es sich nur um die histologische Akkomodation an veränderte Lebensbedingungen stellt den Ersatz einer specifischen Zelle der Gewebsstructur durch bestimmte andersartige differencirte Gewebe gleicher Structur dar. Es können sich daher weniger differencirte Zellen in höherstehende umwandeln, aber gerade so gut auch voll differencirte unter Verlust ihrer morphologischen Qualität solche erlangen, welche man gewöhnlich nur in anderen Zellen zur Ausbildung gelangt antrifft, oder sie ninmt nur einen einfachen Bau an, obne ihren Charakter zu ändern. Während Klebsi) und Hansemann²) das als Entdifferencirung bezeichnen, hat Lubarsch ${ }^{3}$ ) unter ausdrücklicher

1) Klebs, Allgemeine Pathologie. I. u. II. S. 69-80. Jena.

2) Hansemann, Die mikroskopische Diagnostik bösartiger Geschwülste. Berlin 1902.

3) Lubarsch, Ergebnisse der allgemeinen und speciellen Pathologie. Bd. V u. VI. 
362 Offergeld, Deber die Histologie der Adenocarcinome im Uterusfundus.

Betonung der Nothwendigkeit des wegen Zusammenhanges ihrer genetischen Abstammung und der physiologiseben Aufgaben den Namen "Umdifferencirung" in Vorschlag gebracht, da der Zellcharakter keine totale Aenderung erlahren, sondern diese sich hauptsächlich auf die Form erstrecke. Nach Allem diesen sind der Metaplasie enge Grenzen gezogen. Da die Erwerbung der Specifität der Zelle durch fortgesetzte ungleiche Vertheilung des Erbplasma oder durch eine zwar gleichmässige Vertheilung, aber mit verschiedener Differencirung durch Arbeitstheilung und Adaption an äussere Verhältnisse, wie aus entwicklungsgeschichtlichen Thatsachen gefolgert werden muss, vor sich geht, und es sich auch ereignen kann, dass bei der Differencirung Qualitäten der Mutterzelle in den Töchtern erhalten bleiben, zwar oft nur latent, aber doch entwicklungsfähig, so liegt die Möglichkeit der Metaplasie bei den mesodermalen Derivaten auf der Hand, während die ecto- und entodermalen, wenn überhaupt, nur sehr ungünstig wegkommen. Die Bindegewebsmetaplasie ist so bekannt, dass ioh nur erwähnen will, dass das Wesen in einer Aenderung der Intercellularsubstanz besteht; über die Verhältnisse bei den Endothelien ist wenig bekannt, wenn auch v. Baumgarten ${ }^{1}$ ) für die Möglichkeit der bindegewebebildenden Fähigkeit der Endothelien Merkel gegenüber eingetreten ist. Uns interessiren wohl die Ferhattnisse beim Epithel. Zwar kamn bier gelegentlich einmal nach Verletzungen aus dem Epithel einer Hautdrüse Epidermis entstehen, aber das ist nur ein reparativer Vorgang, keine echte Metaplasie. Diese nimmt zwar Borst ${ }^{2}$ ) für einzelne Fälle an. Wenn man an der Ribbert'schen ${ }^{3}$ ) Anschauung des innigen Zusammenhanges zwischen Fpithel und Bindegewebe festhält, so ist es leicht verständlich, dass einzelne Epithelarten auf ganz bestimmten bindegewebigen Boden angewiesen sind, mit dessen Aenderung sie sich gleichfalls ändern werden. So trift man z. B. bei Enzündungen, besonders chronisch-interstitiellen, eine Umwandlung des Flimmerepithels der Nase zu Plattenepithel an; beide sind aus dem gleichen Körperoberflächenepithel im embryonalen Leben entstanden; ährliches findet auch in der Blase, Rectum, Trachea and den Bronchien statt. Ob aber diese Voraussetzung ganz sicher ist, lässt Ribbert ${ }^{3}$ ) dahingestellt. Sehr

1) v. Baumgarten, Verhandl. d. deutsch. pathol. Gesellsch. 1903.

2) Borst, Die Lehre von den Gesohwulsten. Wiesbaden 1902.

3) Ribbert, Allgemeine Pathologie. Leipzig 1902. 
schwierig aber gestalten sich die Verhältnisse, wenn genetisch nicht rom Plattenepithel abstammende Epithelien Mehrschichtigkeit oder Verhornung zeigen, wie z. B. das im Uterus und der Blase; bei ersteren kann es sich vielleicht um Verschleppung von der Vagina her handeln (Implantation des Epithels), andererseits wird man aber auch ein abnormes Eindringen von Plattenepithel in Folge entwicklungsgeschichtlicher Störungen nicht ganz in Abrede stellen dürfen, man müsste also in diesen Fällen die Metaplasie mit einer embryonalen Keimausschaltung identificiren. Klebs $\mathbf{s}^{\mathbf{1}}$ ) and Hansemann ${ }^{2}$, welche unter normalen Verhältnissen die echte Metaplasie bestreiten, reserviren sie merkwürdiger Weise für die Geschwülste, wo eine Entdifferencirung und Anaplasie der Zellen erfolge, so dass diese sich morphologisch und biologisch änderten. Diesen Vorgang kann man aber unmöglich als Metaplasie im Sinne der anderen Autoren anffassen, wenn man sich an Virchow's klassische Definition hält; wir werden daher $\mathrm{Marchand}{ }^{3}$ ) beipflichten, dass „die verwandelten Zellen eine neue Entwicklungsmöglichkeit gewinnen: in den Geschwülsten aber, zumal den malignen, sind die Zellen histologisch und biologiseh den Mutterzellen gegenüber verwandelt, aber sie befinden sich ausserhalb jeder typisehen Entwicklungsrichtung. "t

Es folgt aus diesen Auseinandersetzungen, wie selten die Metaplasie beim Epithel stattfindet, und dass wir kein Recht haben eine solche in Geschwülsten anzunebmen. Trotzdem giebt es Viele, die bei verschiedenen Formen des Uteruscarcinoms eine Metaplasie der Epithelien vermuthen. Auch ich habe des Oefteren bei der Beschreibung der histologischen Einzelheiten den Ausdruck „quadratische oder cubische Zellform" gebraucht; das soll sich nur auf die aussere Zellgestalt beziehen, nicht etwa als eine Metaplasie der Cylinderzellen in Plattenepithelien gedeutet werden. Denn nach allen diesen Thatsachen dürfte es wohl verfehlt sein $z u$ glauben, dass, wie es Gebhard ${ }^{4}$ ) noch annimmt, bei Adenocarcinom die Zellen zwar erhalten bleiben, aber eine Aenderung des Zellcharakters erfahren. Er hat ja bekanntlich eine Combination

1) Klebs, Allgemeine Pathologie, I-II. 69-80. Jena.

2) Hansemann, Die mikroskopische Diagnostik bösartiger Geschwülste. Berlin 1902.

3) Marchand, Verhandl. d, deutsch, pathol. Gesellseh. 1899.

4) Gebhard, Pathologische Anatomie der weiblichen Sexualorgane. Jeipzig 1899. 
364 Offergeld, Ueber die Histologie der Adenocarcinome im Uterusfundus.

von Drüsen- und Plattenepithelcarcinom construirt und bei letzteren Zellen mit angeblich typischer Verhornung nachgewiesen. Platte und polymorphe Zellen findet man bei jedem Schnitt haufenweise; diese haben aber meist ihren Tinctionscharakter und ihre histologische Structur genau so ausgeprägt wie die benachbarten Cylinder- oder cylindrische Zellen auch; desgleichen lässt sich am Kern und im Plasma keine Erscheinung auffinden, auf Grund derer wir Berechtigung erhielten eine Aenderung.des Zellcharakters eingreifender Art von der carcinomatösen Cylinderepithelmutterzelle herzuleiten. Wir haben es daher nur mit einer durch räumliche, äussere Verhältnisse bedingten Aenderung der Form der Zellen zu thun, während ihr Charakter, ihre gesammten inneren Eigensehaften im Ganzen mit denen der Mutterzellen übereinstimmt, wenn vielleicht sich auch feinste, uns durchaus noch nicht wahmehmbare Unterschiede, schon abgespielt haben. Da wir aber nur bei nachweislicher Aenderung der Biologie ron einer Metaplasie reden, so dürtte dieser Ausdruck jedenfalls noch verfrüht sein, und, wenn gar keine Aenderung eintritt, überflüssig. Man wird daher wohl daran festhalten dürfen, dass zwar scheinbar grosse Aenderungen in der Form, vielleicht auch kleinste, uns entgehende im Zellleben sellust gelegentlich beim Adenocarcinom, selbst in gebäufter. Form auftreten können, dass aber eine eingreifende wie sio vielleicht die Secretion oder Production fester Substanzen (Horn) betreffen könnte, jedenfalls nicht stattindet. Daher kann von einer echten Metaplasie, von einer Veränderung des innersten Wesens der Careinomzelle keine Rede sein, zumal wo sich die angeblich nachgewiesene Verhornung auch auf andere Weise erklären lässt, es sich 7. B. um Degenerationsproducte der Zeller mit concentrischer Schichtung handeln kann.

Die Eigenthümlichkeit der Carcinomzellen schien unersehöpflich in der Entwicklung selbst nener Zellarten za sein, bat zu einem weiteren schweren Irrthum geführt; zwar ist auch heute noch die Mehrzahl der Autoren nicht geneigt, diesen einzusehen. Man kann bisweilen auf einer Reihe von Schnitten nur die Bilder einer Endometritis oder eines einfachen Adenoms erhalten, bis auf einmal die Zellen ihre Gestalt und ihr Färbungsvermögen ändern und sich in mehrfacher Lage anordnen; auf weiteren Schnitten findet man dann das typische Adenocarcinom. Solche Uebergangsbilder kommen unzweifelhaft for und diese Beobachtung ist durchaus richtig, nur ist der Schluss ebenso falsch wie verhängnissvoll. Wenn 
z. B. einmal die Membrana propria geschwunden ist, oder das Epithel Mehrschichtung zeigt, muss da das Carcinom aus einer gutartigen Geschwulst oder gar einer Entzündung entstanden sein, muss also eine "maligne Degeneration" stattgefunden haben? Die Kliniker behaupten das unter allen Umständen und stützen sich, wie später erörtert wird, auf gewisse Erfahrungssätze. Nun ist zunächst der Ausdruck ein höchst unglücklicher; die Zellen degeneriren nicht, sondern, wenn sie wirklich aus einer anders gearteten Zelle hervorgingen, lieferten sie nur einen Beweis für ihr Differencirungsvermögen, also einer bohen physiologischen Ausbildung und Function, selbst dann, wenn sie sich auf eine niedere Stufe zurückbildeten (Anaplasie); sie befinden sich also in einem physiologischen, nicht pathologischen Zustand. Finden wir also solche Uebergangsbilder, so entsteht die Frage, wie kann man sich ihr Zustandekommen anders als durch Annahme des Ueberganges einer Formation in eine andere erklären. Hierfür giebt es meines Erachtens mehrere Möglichkeiten.

Zunächst kann es sich um ein Adenocarcinom mit vorwiegend einschichtigem Cylinderepithel handeln, also um das Adenoma malignum anderer Autoren, wo ja, wie früher erwähnt, bei genauem Studium des ganzen Tumors stets mehrschichtiges Epithel an einzelnen Stellen gefunden wird; trifft man nun zufälliger Weise gerade diese Partien, so hat man ein- oder mehrschichtiges Epithel mit den verschiedenen Uebergangsformationen vor sich, und der Schluss einer Umwandlung der Zellen mit Erwerbung maligner Eigenschaften ist durchaus falsch. Dann ist es eine ganz bekannte Thatsache und meine Fälle beweisen das Gleiche, dass neben Carcinom auch eine chronisch interstitielle Entzündung des Endo- und Myometriums einherläuft, welche für gewöhnlich aus einer lang andauernden parenchymatösen der Mucosa entstanden ist. Strittig ist nur, ob das Carcinom vielleicht durch einen irritativen, von den Secretionsproducten seiner Zellen ausgehenden Reiz secundär die Endometritis bedingt hat, oder ob diese als Primärerkrankung in später zu erörternder Weise auf das Wachsthum, nicht die Entstehung des Carcinoms eingewirkt hat. Man wird natürlich einmal eine Grenze finden, wo die Entzündung an die Neubildung stösst und letztere schon mit ihren ersten Vortruppen die entzündeten Drüsen angegriffen hat; diese Stellen mussten den Beweis abgeben für die Entstehung des Tumors aus der vielleicht vorhandenen entzündlichen Wucherung. Und zuletzt können, wie vorhin verschie- 
366 Offergeld, Ueber die Histologie der Adenocarcinome im Uterusfundus.

dene räumliche Verhältnisse, so auch zeitlich von einander getrennte vorliegen. Tch erwähne hier nur als Beispiel das gleichzeitige Vorkommen von Infarct und Abseess der gleichen Lungenpartie bei der Obduction. Das sind Befunde, von denen auf den ersten Blick der eine den andern direct ausschliesst, da der Abscess nur dem strömenden Blute seine Entstehung verdankt, der Infaret aber nur nach Erlöschen des Kreislaufes im Gewebe sich später durch Wiedereinströmen des Blutes entwickelt; und doch kann das vorkommen. Der Abscess, durch metastatisch verschlepptes septisches Material bedingt, ist zuerst entstanden, bei einem zweiten Schub wurde die zuführende Arterie verlegt und das Gewebe erkrankte, besonders wurden die Capillaren durchlässig für gelöste und feste Bestandtheile; nach einiger Zeit wurde der Embolus fortgerissen, das Blut strömte wieder in das Stromgebiet der Arterie und drang durch die lädirten Capillaren in das Gewebe, also auch in den Abscess, dort den Infaret bedingend. Uebertragen wir das auf diese Fälle, so ist es erklärlich, dass bei gleichzeitigem Vorkommen von Adenom und Carcinom letzteres erst später entstanden ist, aber durch sein progredientes Wachsthum ersteres sehr schnell überholte und gewissermaassen verzehrte. Daher kommt es denn, dass man auf Schnitten beide Epithelarten vertreten finden wird, und dass man die Polymorphie der Carcinomzellen als Cebergangsformen aus dem Adenom deutete, so dass man glaubte, es sei maligne degenerirt. Da wir uns ungezwnngen die Verhältnisse der Uebergangsbilder auch auf eine andere Weise erklären können, so ist es meines Erachtens an der Zeit, mit dieser unpassenden Bezeichnung zu brechen. Gerade so wenig die carcinomatöse Zelle durch Metaplasie aus dem gesunden Epithel entstanden sein kann, ist auch der Ursprung dureh degenerative Vorgänge zu vertheidigen, da eine Aenderung der Form oder der Eigenschaften mit einer hohen physiologiseher. Anpassungsfähigkeit und Differenzirungsmöglichkeit des Protoplasmas aufs Engste rerlmüpt ist, und wir eine physiologisehe That unmöglich als das Product eines krankhaften Zelllebens auffassen dürfen. Selbst das Zurückgehen auf eine embryonale Stufe, oder auf phylogenetisch einfach gebaute und kaum different arbeirende Zellen beweist, dass die Zelle das Bestimmungsrecht über ihre Functionen sich gewahrt hat, dass ihr Plasma noch alle von der Eizelle exhaltenen Eigenschaften in unverfälschter. Reinheit aufweist, wovon sie ans uns noch unbekannten Gründen jederzeit Gebrauch machen kann. Wir düren 
Offergeld, Ueber die Histologie der Adenocarcinome im Uterusfundas. 367

daher bei solch hohen Eigenschaften nicht mehr von degenerativen Vorgängen sprechen, sondern müssen sie als in das Gebiet des physiologischen Lebens der Zelle gehörig betrachten, zumal wir nicht wissen, was die Zelle damit bezweckt, und wie sie mit dieser Aenderung auf sie einwirkende Reize hin reagirt.

Getrennt sind zuletzt die Secretionsverhältnisse im Adenocarcinom zu erwähnen. Auch hieran betheiligen sich die Drüsenzellen in einer sehr regen Weise, während der Ausführungsgang und sein Epithel an der Production keinen activen Antheil nehmen, wie aus dem Fehlen der Flimmerepithelzellen in der Neubildung zu schliessen ist. Wie rege die Drüsenthätigkeit ist, geht woh] am besten aus Taf. V, Fig. 7 hervor, wo das Epithel des Ausführungsganges ein ganz plattes, an die Wand gedrücktes ist und der ganze Gang mit Secret angefüllt ist. Es müssen die Drüsen hier offenbar noch weiter thätig gewesen sein, obschon ihrem Product der freie Abfluss versperrt war. Es wird daher im Ausführungsgange liegen bleiben und ist dort anzutreffen. Die Fähigkeit der Secretion hat Hansemann ${ }^{1}$ ) als den geringsten Grad der Anaplasie von den Parenchymzellen des Mutterbodens gedeutet; er war es auch, der unsere Aufmerksamkeit auf die höchst frappante Thatsache lenkte, dass, wenn in einem Organ ein secernirendes Carcinom als Primärtumor auftritt, wohl die Kachexie sich einstellt, aber nicht die charakteristische Stoffwechselstörung, die sonst bei Erkrankung des gleichen Organs gefunden wird; so fehlt z. B. bei einem Adenocarcinom des Pankreas stets der Diabetes, wie die Bronzefärbung bei einem secernirenden Carcinom der Nebennieren. Was producirt nun die Zelle im Adenocarcinom? Direct histologisch lassen sich zwei Substanzen nachweisen: zuerst in ziemlicher Anzahl Fibrin, wie man unschwer durch die Weigert'sche Färbung beweisen kann, und dann Schleim, der mit der Thionin-Toluidinblaufärbung wundervoll rothviolett erscheint. Die Schleimproduction lässt sich stellenweise auch noch eine Strecke weit in das Zellplasma verfolgen, welches wie einen feinen Saum, etwa feinsten Flimmerhaaren vergleichbar, dadurch erhält. Doch damit ist unmöglich die Zellarbeit erschöpft, und wir müssen auch auf die Bildung albuminoider Substanzen, vielleicht direct Toxine, schliessen aus einer Reihe von Gründen. Zunächst ist es höchst auffällig, dass man an einzelnen Stellen, wenn die Drüsenwuche-

1) Hansemann, Berliner klin. Wochenschr. 96 . 
368 Offergeld, Ueber die Histologie der Adenocarcinome im Uterusfundus.

rung noch gar nicht excessiv ist, doch schon die bindegewebige Kapsel ganz gesehwunden sieht, oder sie allenfalls als ungefärbte Membran mit einiger Sicherheit noch za erkennen ist. Nach analogen Vorgängen bei anderen Organen wird es sich hierbei wohl um eine Degenerationserscheinung handeln, durch welche vor vollständigem Schwunde die Membrana propria ihr Tinetionsvermögen eingebüsst hat. Beweisend für diese Annahme sind gerade die Stellen, wo in der Nachbarschaft die Drüsen in ihrem Lumen entweder Eibrin oder sonst foinst gefärbte corpusculäre Elemente tragen, während die freien Drüsen diese Kapselveränderung vermissen lassen. Weiter muss man das wechselvolle und höchst merkwürdige Verhalten der Lenkocyten berücksichtigen. Während sie stellenweise recht spärlich sind, trifft man sie an anderen Orten geradezu gehäuft an. Auch hier fällt es auf den ersten Blick auf, dass einzelne Drüsenquersehnitte von einer geringen kleinzelligen Infiltration umgeben sind, während die benachbarten eine sehr starke erkennen lassen, die sich stellenweise so verdichtet, dass die Drüsen yon einem mehrsehichtigen, fast concentrisch angeordneten Wall ron weissen Blutkörperchen umgeben sind. Ja sogar an einzelmen Stellen sind sie auf der Wanderang durch das carcinomatöse Epithel in das Drüsenlumen begriffen und lassen sich auf Schnitten durch ihre stark und distinct tingirten, gelappten Kerne sofort von allen andern Zellen herausfinden. Wie wollen wir uns diese Bilder anders erklären, als das bekannte Verhalten der Leukocyten zu Hülfe zu nehmen, vermöge ihrer amöboiden Fähigkeit, sich sofort überall dorthin zu begeben, wo pathologisch-chemische, oder auch biologische Processe von besonderer Intensität sich abspielen? Und zuletzt müssen wir wohl bedenken, dass, wie bei jedem Carcinom schliesslich die Kachexie als Folge der durch die Autolyse der jungen Epithelien in Freiheit gesetzten albuminoiden Plasmasubstanzen in Verbindung mit den Secretionsproducten der Zellen erfolgen wird, gerade beim Drüsencarcinom dio secretorische Fabigkeit sehr Jange gewaht bleibt und im Uebermaasse vor sich goht, nur mit dem Unterschiede, dass das Resultat nicht nach Aussen befördert wird, sondern im Organ selbst rerbleiben muss. Gerade der Reichthum der kleinzelligen Infiltration muss den Gedanken Platz greifen lassen, dass mit der Aenderung des Drüsenepithels in das careinomatöse eine ebenso eingreifende Umgestaltung des Plasmas und somit auch seiner Secretion erfolgt ist, dass also das Secret der normalen 
Uterindrüsen ein wesentlich anderes, als das des Adenocarcinoms der Uterusmucosa sein muss. Es hat ja bekanntlich Bonnet ${ }^{1}$ ) als die vornehmste Aufgabe dieser Drüsen ihre Mitbetheiligung an der Bildung der Uterinmilch angesprochen, einem Gemisch von Secretionsproducten und einfacher Transsudation aus den zahlreichen röhrenförmigen Einstülpungen der Schleimhaut, welche den Zweck verfolge, den Uterus mit der für die Aufnahme des Eies nöthigen Ernährungsflüssigkeit zu versehen. Inwiefern diese Annahme zutrifft, steht noch dahin; die Thatsache allein, dass in der Mucosa der geschlechtsreifen Fraa sich verschiedene Zellformen in normalem Zustande vorfinden, die erst in der Pubertätszeit auftreten, lässt die Bonnet'sche Theorie nicht so ohne Weiteres als unmöglich erscheinen. Wir könnten uns dann ja leicht vorstellen, dass die von den normalen Drüsen gelieferte Substanz zwar auch von den carcinomatösen erzeugt wird, aber in ihrer chemischen Zusammensetzung durchaus anders ausfällt, als die normale. Da nun die Leukocyten auf jede Aenderung des Zelllebens sehr empfindlich reagiren, so ist es ganz natürlich, dass, wenn die Zellen abnorme Eiweisskörper hervorbringen, die weissen Blutkörperchen aus den benachbarten Lymphgefässen sofort in das Gewebe auswandern, ja sogar durch das Epithel der Drüsen in das Lumen hinein. Was sie da bezwecken, ist durchaus noch unklar; vielleicht versuchen sie unter Aufopferung ihrer eigenen Existenz die toxisch wirkenden Producte des pathologischen Zelllebens der carcinomatösen Epithelien in sich aufzunehmen, um sie zu neutralisiren oder durch die Excretionsorgane des Organismus zu eliminiren. Ob diese Substanzen in Verbindung mit dem Fibrin ausgeschieden werden, lässt sich sehr schwer sagen; jedenfalls ist die Thatsache sehr interessant, dass eine besonders starke kleinzellige Infiltration stets in der Umgebung der fibrinführenden Drüsen vorkommt, während die, welche nur Schleim enthalten, eine nur geringe Infiltration erkennen lassen; dass aber das Fibrin nicht allein die Ursache ist, erhellt daraus, dass man auch sehr zahlreich die Leukoeyten in solchen Drüsen antrifft, deren Lumen leer ist oder einzelne amorphe, corpusculäre, stark gefärbte Elemente trägt.

Mit den Sekretionsvorgängen als solchen hat gar nichts zu

1) Bonnet, Zur Kenntniss der Uterinmilch. Deutsche Zeitschrift für Thiermedicin. Bd. VI. 
370 Offergeld, Ueber die Histologie der Adenocarcinome im Uterusfundus.

thun ein Befund, welchen Gebhard ${ }^{1}$ ) hierhergehörig aufzufassen geneigt ist. Man findet in der That in seltenen Fällen das Lumen der Drüsen mit Epithelmassen mehr oder minder angefült. Das sind aber nur Zeichen dafür, dass Veränderungen im Carcinom vor sich gehen, unter deren Einfluss das Epithel zerfällt. Man wird sie daher nur im Verein mit anderen Zerfallsproducten antreffen; sie haben mit der Sekretionsthätigkeit der carcinomatösen Zelle gar nichts zu thun, da diese nur flüssige Bestandtheile wie jede andere secernirende Zelle hervorbringen kann, aber keine fertige Zellen oder deren Theile aus ihrem Plasma secernirt.

Es entsteht nun die interessante Frage, ob sich die bisher erhobenen Befunde vielleicht in irgend einer Richtung verwerthen lassen um uns Aufschluss zu geben über die Histogenese der Drüsencarcinome oder über ihre Ursachen äberhaupt. Denn, um das gleich vorweg zu nehmen, werden wir wohl heute schon mit vollem Recht behaupten dürten, dass es keine Ursache für das Entstehen des Krebses giebt, sondern mehrere Ursachen (Entzündung, Traumen, mechanische, chemische, thermische Reize) ähnlich wie ja auch das pathologisch-anatomische Substrat der Entzündung sich bei einer Menge ganz verschiedener Ursachen vorfindet. Leider stellen sich ihrer Beantwortung ganz enorme Schwierigkeiten in den Weg. Wenn man von den ganz alten Ansichten absieht, so kommen heute noch 3 in Betracht, die won Hansemaan ${ }^{2}$ ) angenommene Anaplasie, für welche der positive Beweis noch ausstelt, die parasitäre und die alte Cohnheim'sche, zu welcher sich neben Anderen auch Ribbert ${ }^{3}$ ) bekennt, welcher bekanntlich eine embryonale Keimausschalung annimmt, so dass heterologe Gem sehwülste entständen. Die parasitäre ist nicht nur unbewiesen, sondern auch höchst unwahrscheinlich; wir kenren kein Lebewesen, welches die Gewebe zu schrankenloser Proliferation anregt; erst recht fällt die Impfung negativ aus, da man auf diese Weise nur die Bildung epitheloider Zellen hervorrufen kann. Ganz besonders aber ist der Unstand hervorzuheben, dass jedes Gewebe, in welehes ein Carcinom hineinwuchert, unter dessen deletärem Einfluss zerfällt

1) Gebhardt, Pathologische Anatomie der weiblichen Sexnalorgane. Leipzig 1899.

2) Hansemann, Specifität, Altruismus and Anaplasie der Zellen. Berlin 1893.

3) Ribbert, Lehrbuch der allgemeinen Pathologie. Leipzig 1901. 
und nicht za unbegrenztem Wachsthum angeregt wird. Die Cohnheim'sche Theorie stützt sich besonders auf die Embryome und Teratome. Viele Autoren wollen bei Embryomen, besonders der Genitalien [Thiersch ${ }^{1}$ ), Waldeyer ${ }^{2}$ ), Tauffer ${ }^{3}$ ), Yamagiva ${ }^{4}$ ), Kruckenberg ${ }^{5}$ ), Jores ${ }^{6}$ ), Pinders ${ }^{7}$ ), Biermann ${ }^{8}$ )] den Uebergang in Carcinom sicher beobachtet haben. Zunächst muss man aber hier hervorheben, dass traumatisch verschleppte Epithelien, falls sie überhaupt anwachsen, epidermoidale Cysten liefern, aber nie ein Carcinom; hierfür liegen zahlreiche Belege von Garrè ${ }^{9}$ ), Franke ${ }^{10}$ ), Blumberg ${ }^{11}$ ), Réverdin ${ }^{12}$ ) und Kaufmann ${ }^{13}$ ) vor; die beiden letztgenannten Autoren haben auch den experimentellen Beweis hierfür geliefert, gleichfalls Ribbert ${ }^{14}$ ). Und dann bedenke man die Histogenese der Embryome! Sie entstehen ja sicher aus dislocirten Blastomeren, welche sich später differenzirten und die einzelnen Gewebe des Mischtumors aufbauten, und da halte ich wohl es für sehr leicht möglich, dass gleichzeitig oder auch erst später, gerade so gut wie ein grösserer Complex von Qualitäten der Eizelle in dem Blastomer ausgeschaltet wurde, auch schon fertig oder fast fertig ausgebildete, d. h. differenzirte Epithelien aus dem normalen Zellverbande gesondert wurden, welche sich dann später frejer und in atypischer Richtung und formellen Abweichungen rom Mutterboden entwickelten. So entstand die Aufhebung der gemeinsamen Function mit dem Bindegewebe und eine atypisehe Wachsthumsrichtung, worin Klebs ${ }^{15}$ ) einen Ausdruck der allgemeinen Holoblastose erblickte. Er nahm ja bekanntlich an, dass Hyperplasie und Geschwulstbildung gleichartige Processe seien;

1) Thiersch, Münch. medic. Wochenschrift. 1886.

2) Waldeyer, Virch. Archiv. Bd. 41, 55 .

3) Tauffer, Virch. Archiv. Bd. 142.

4) Yamagiva, Virch. Archiv. Bd. 147.

5) Kruckenberg, Arch. f. Gynäkologie. Bd. 30.

6) Jores, Virch. Arch. Bd. 133.

7) Pinders, Dissertation. Bonn 1887.

8) Biermann, Prager med. Wochenschrift. 1885.

9) Garrè, Bruns' Beiträge z. klin. Chirurgie. Bd. II.

10) Franke, Deutsche Zeitschrift f. Chirurgie. Bd. 40. Arch. f. klin. Chirurgie. Bd. 34. Virch. Arch. Bd. 121.

11) Blumberg, Deutsche Zeitschr. f. Chirurgie. Bd. 38.

12) Reverdin, Revue de chirurgie 14.

13) Ka u fmann, Vireh. Arch. Bd. 97.

14) Ribbert, Das pathologische Wachsthum. Bonn 1897.

15) Klebs, Deutsche Medicin. 1890. 
372 Offergeld, Ueber die Histologie der Adenocarcinome im Uterusfundus.

jeder Tumor entsteht durch eine allgemeine Hyperplasie der ortsangehörigen Gewebe; aus dieser Holoblastose entstehen durch Ueberwuchern einer oder mehrerer Gewebsarten die Geschwulst. Diese Holoblastose ist aber, wie Lubarsch ${ }^{1}$ ) richtig ausführt, nur für die Hyperplasie für richtig $\mathrm{zu}$ halten, da sie viel eher zu einer Trennung als zu einer Gleichstellung von Hyperplasie und autonomer Geschwulstbildung führt.

Da man also ohne Weiteres die Keimausschaltung für sich allein nicht für die Entstehung eines Carcinoms verantwortlich machen kann, so suchte man nach anderen Ursachen. Hs sollten jetzt die Krebszellen entstehen aus normalen Epithelzellen durch "natürliche Variation", also eine Aenderung ihrer biologischen Eigenschaften, oder sie seien von Hause aus in ihrer Entwickelung. und Zusammensetzung fehlerhaft angelegt. Es führt das auf das vorhin über die Metaplasie Gesagte hinaus. Hansemann ${ }^{2}$ ) wie Benecke ${ }^{3}$ ) sprechen eine Aplasie als Ursache an, also eine Aenderung des Zellcharakters, ähnlich wie $\mathrm{Hana} \mathrm{u}^{4}$ ) und Hauser ${ }^{5}$ ). $\mathrm{Da}$ wir uns aber nicht leicht vorstellen können, wie worher normale Zellen sich so eingreifend zu ändern vermögen, so liegt die Vermuthung sehr nahe, dass dio Geschwulstzellen ron Anfang an andere, uns unbekannte biologische Eigenschaften besitzen. Während Ribbert ${ }^{6}$ ) als Grundlage ein Selbstständigwerden von Gewebskeimen dem gesammten Organismus gegenüber hervorhebt, wobei die Entdifferenzirung und Anaplasie nur das Wachsen begünstige, hat Borst ${ }^{7}$ ) sehr interessante Mittheilungen veröffentlicht.

Folgen wir seinen Ausführungen, so kominen zwei Arten von Wachsthumsstörungen in Frage. Zunächst grobe Forruen von Missbildungen an Ort und Stelle, Keimausschaltung aus dem normalen Zellverbande und Bildung überflüssiger Keime. Weiterhin aber auch feinste, uns bisher noch unbekannte Störungen der Entwicklung der Gewebe und Zellen, die die Grundlage eines Carcinoms abgeben können, etwa so, dass die Zellen und Zellcomplexe

1) Lubarsch, Ergebnisse der allgemein. Pathol. Bd. I-VI,

2) Hansemann, Die mikroskopische Diagnostik bösartiger Geschwülste. Berlin 1897/1902.

3) Benecke, Deutsches Arch. f. klin. Medicin, Bd. 64.

4) Hanau, Fortschritte der Medicin. 1889.

5) Hauser, Biologisches Centralblatt. Bd. 15. Virch. Arch. 138/141.

6) Ribbert, Lehrbuch d. allgem. Pathol. Leipzig 1901.

7) Borst, Die Lehre ron den Gesohwülsten. Wiesbaden 1902. 
hinsichtlich ihrer Lage und Beziehungen zur Nachbarschaft normale Verhältnisse aufweisen, aber in ihrer specifischen Differenzirung, in ihren idioblastischen Eigenschaften Spuren von Abweichungen vom Normalen darbieten. Bei irgend einer Gelegenheitsursache würden dann die pathologisch veranlagten Zellen sich ganz anders verhalten als die normalen. Unter physiologischen Bedingungen würden sie sich, da sie sich gut in das Gefüge eingepasst haben, genau so verhalten wie die anderen Zellen auch und zu Sonderheiten keine Veranlassung geben, erst wenn durch pathologische Zustände die normale Hemmung von Seiten der gesunden Zellen wegfiele, träte ihre krankhafte Richtung in die Erscheinung. Es handelt sich daher nach Borst ${ }^{1}$ ) um locale Entwicklungsstörungen, deren Produkte gelegentlich mit Macht hervortraten und ihre abnormen Qualitäten zeigten. An den verschiedensten Orten tritt ja für gewöhnlich bei der Einwirkung gleicher, äusserer Schädlichkeiten kein Carcinom auf, nur in Ausnahmen entsteht bei der gleichen Noxe eine atypische Epithelwucherung; das eben beweist, dass das Wesentliche das primär veränderte Gewebe sein muss, das Trauma ist nur nebensächlich. Zwar ist die von v. Rindfleisch ${ }^{2}$ ) betonte Möglichkeit, dass vom Nervensystem getrennte Zellcomp?exe eine abnorme Entwicklung durchmachen, nicht direct zu bestreiten, so dass es immerhin als wahrscheinlich angesehen werden darf, dass auch hierin ein Grund für das Entstehen der Carcinome mitgegeben ist. Also darf man wohl daran festhalten, dass das Carcinom durch eine primär vorhandene, örtlich noch unbekannte Disposition entsteht, und vielleicht eine allgemeine Disposition.

Der schwache Punkt der Cohnheim'schen Theorie ist ohne Zweifel darin zu suchen, dass wenigstens die Carcinome für gewöhnlich in 4-5 Jahrzehnten nach dem embryonalen Leben, in welchem ihr Fundament gelegt sein soll, erst in die Erscheinung treten, dass ferner nach den ersten bemerkbaren Symptomen der Tumor sehr schnell wächst unter gleichzeitigem Verfall seiner selbst und des Organismus. Man muss daher die Frage zu beantworten suchen, weshalb die dislocirten embryonalen Keime so lange latent bleiben und erst im höhern Alter wachsen. Scheinbar bietet ja die fötale Luebensperiode und die ersten Jahre des extra-

1) 1. c.

2) v. Rindfleisch, Elemente der Pathologie. Leipzig 1886. Lehrbuch der path. Gewebelehre. Leipzig 1886. 
374 Offergeld, Ueber die Histologie der Adenocarcinome im Uterusfundus.

uterinen Lebens dio besten Aussichten für die Entwicklung des ausgeschalteten Zellcomplexes. Durch die normale Wachsthumshyperämie wird dem gesammten Organismus sehr viel Nährmaterial zugeführt, die Gewebe sind locker und weich, der Widerstand ist nach allen Seiten ein sehr schwieriger und der Stoffwechsel, ganz besonders der des Eiweisses, ein ungemein reger, so dass für die dislocirten Zellen Nährmaterial stets im Ceberfiuss zur Verfügung ist, - aber die klinische Erfahrung lehrt, dass in diesem Alter das Carcinom eine sehr grosse Seltenheit ist, ferner anch, wenn es einmal vorkommt, einen sehr raschen Verlauf nimut, so dass es als höchst maligner Tumor um so eher angesprochen werden darf, als meist die Hülfe zu spät kommt. Wie lassen diese Thatsachen sich erklären?

Die zu irgend einer Zeit aus dem normalen Zellverbande ausw geschiedenen Blastomere oder ectodermalen Bestandiheile oder auch schon ganz oder fast vollständig differenzirten Epithelien sind in letzter Linie auf die Eizelle zurückzuführen und gelangen irgend wohin in das Gewebe hinein, welches sich schon weiter differenzirt hat, also nicht mehr eine Summe von Qualitäten besitzt, sondern nor mehr einige wenige in höherer Ausbildung. Sie werden dort, da sie selbst der Eizelle in ihrem Gesammtoharakter um so näher stehen, je mehr Qualitäten wie z. B. Sekretion, Verhornung, Fähigkeit zur Bildung nervöser Organe sie in sich beherbergen, während die anderen Gewebe schon ihre definitive Gewebsausbildung erreicht haben, als artfremde Zellen wirken, welche zuerst einen Reiz und später eine toxische Wirkung ausüben. Dieser Reiz genügt in den schon differenzirten Zellen, welche in ihrem Plasma schon hoch ausgebildete Functionen aufweisen, wahrseheinlich zuerst in den Epithelien; aus welchen Drüsengewabe entsteht, einen sekretorisehen Vorgang hervorzurufen, dessen Produkt insofern deletär auf die ausgeschiedenen Blastomere oder Epithelien einwirkt, dass nur ihre momentane Weiterentwicklung gehemmt wird, die dislocirten Eibestandtheile aber nicht etwa ganz vernichtet und später resorbirt werden, weil sie mit dem übrigen Gewebe nicht vollständig gleichartig sind. Dass in der oben geschilderten Weise albuminoide, auf bestimmte Zellarten direct toxisch wirkende Körper - Oytolysine - entstehen, ist bekannt; ich erwähne nur das hämolytische und nephrolytische Serum, sodass es nicht direct ausgeschlossen erscheinen dürte, dass es auch andere, won anderen Organen oder Zellen erzengte Eiweisskörper geben wird, welche 
auf abnorm einverleibte Zellen toxisch einwirken; es ist doch höchst merkwürdig, dass abnorm verlagerte Epithelien nach der übereinstimmenden Ansicht aller Autoren entweder zu Grunde gehen oder epidermoidale Cysten bilden, also auch ein abnormes Product entsteht, während doch im Allgemeinen die Transplantation anderer Organe im gleichen Thier sich mit Leichtigkeit bewerkstelligen lässt, ohne dass der Haushalt des Thieres in irgend einer Weise Schaden nimmt. Es würden dann die dislocirten Blastomere oder Epithelien zwar dauernd im Gewebe liegen bleiben aber unschädlich sein, weil sie durch den schädigenden, sekretorischen Einfluss der Gewebe darnieder gehalten werden. Es ist das vielleicht der gleiche Gedanke, den Weigert in dem Ausdruck „normale Gewebsspannung" ausdrückte. Erst dann, wenn durch einen anomalen, vielleicht schon direct pathologischen Vorgang dauernd oder wenigstens für längere Zeit die Antitoxinproduction der Gewebe aufhört, wird die ungestörte Weiterentwicklung der letzten Reste des embryonalen Lebens vor sich gehen können. Diese haben aber dann noch den niederen Typus der polyqualitativen Zellen beibehalten und werden unter den hoch differenzirten sicherlich eine Sonderstellung insofern einnehmen, als sie für diese Lebensperiode abnorme specifische Differenzirungen und idioblastische Eigenschaften des Plasma aufweisen, so dass sie also Sonderheiten genug darbieten. Dass wir zur Erklärung der inneren Ursachen der Gesehwülste gezwungen sind auf uns zwar noch ganz unbekannte, aber wohl in ihren ersten Anfängen schon geahnte biologisch-chemische Reactionen im Zellleben zurückgreifen zu müssen, habe $\mathrm{ich}^{1}$ ) an anderer Stelle schon einmal dargelegt. Den Anstoss zur Sistirung der Antitoxinbildung können nun manche Momente abgeben, wohl in erster Linie die, welche man als gewöhnliche Gelegenheitsursachen für die Entstehung der Carcinome annimmt. Dann, dass Entzündungen, besonders langdauernde interstitielle Processe, directe Traumen, mechanische, chemische, thermische Reize, zumal bei längerer Dauer von selbst nicht besonders hervorragender Stärke, weniger die schnell vorübergehenden, wenn sie auch stärker sind und eingreifender einwirken, den Stoffwechsel der befallenen Gewebe in ganz bedeutender Weise zu beeinflussen vermögen, sodass die Toxin- oder Antitoxinbildung aufhört, liegt auf der Hand, und die tägliche Er-

1) Offergeld, Organanlage in den Ovarialembryonen. Arch. f. Gynäk. Bd. 75 . 
376 Offergeld, Ueber die Histologie der Adenocarcinome im Uterusfundus.

fahrung lehrt uns Infectionskrankheiten gegenüber das Gleiche, da oft genug die Infection nur dann erfolgt, wenn gleichzeitig das ortsangehörige Gewebe geschädigt ist. Diese Auseinandersetzungen dürften wohl eine Ergänzung und Erklärung der von Borsty) behaupteten, "feinsten Störungen in der Entwicklung der Gewebe und Zellen" abgeben. Nun wird es auch ganz selbstverständlich sein, dass durch allgemeine krankhafte Processe erst recht die Antitoxinbildung geschädigt wird; es passt dieses auf jene Fälle, wo das Carcinom nach Angabe der Kranken im Anschluss an eine andere Erkrankung entstanden sein soll; es erklärt uns auch das progregiente Fortschreiten aller Carcinome des Körpers während der Gravidität und Laktationsperiode, da hier ja auch ganz andere biologische Vorgänge im Gesammtorganismus sich abspielen als zu andern Lebensperioden, wenn ja auch hier, wenigstens für die weiblichen Genitalien, noch die Hyperämie and Erweiterung der Lymphbahnen hinzukommt.

Man wird daher wohl wieder mit grösserer Zuversicht die alte Cohnheim'sche Theorie ron der embryonalen Keimausschaltung nicht allein für die teratoiden Neubildangen und echten Teratome zu Recht bestehen lassen, sondern ihr auch in der Histogenese der Carcinome den gebührenden ersten Platz anweisen dürfen, da sich alle anderen Theorien überlebt haben oder einer kritischen Durchmusterung nicht haben Stand haiten können, wäbrend gerade zu allen Zeiten immer wieder Autoren zu jener ihre Zuflucht nehmen. Und erst recht wird man sie heute als heiss umstrittenen Faroriten ansprechen dürfen, da die eben bezeichnete Lücke sich in einer einfachen, ungezwungenen Weise ausfüllen lässt, ohne Zuhülfenahme vager Voraussetzungen, sondern allein durch die Annahme feinster Stoffwechselvorgänge, wie sie uns in überraschender Weise in den letaten Jahren die physiologische Chemie ron anderen Organen hat ersehen lassen, und deren Kenntriss sich stetig viermebrt und gleichzeitig vertieft.

Warum nun so häufig etwa in 10 pCt. aller Carcinome das Uteruscarcinom auftritt, ist auch durch die Cohnheim'sche Theorie sehr leicht rerständlich. Wenn wir eine abnorme Keimaussehaltung als die erste Ursache des Krebses ansprechen wollen, so wissen

1) Borst, Die Lehre von den Geschwülsten. Wiesbaden 1902. 
wir durch die sinnreichen Experimente von Keibl und Roux ${ }^{1}$ ), dass mechanische, chemische, thermische, elektrische und, wie ich glaube, ganz besonders biologische Momente ein in Theilung begriffenes $\mathrm{Ei}$ veranlassen können, sich in anormaler Richtung zu furchen; $\operatorname{Roux}^{2}$ ) hat dann weiter gezeigt, dass, wenn überhaupt eine Weiterentwicklung der abgesprengten Blastomere erfolgt, diese in pathologischen Bahnen vor sich geht, so dass Missbildungen entstehen. Diese dislocirte Blastomere, oder im späteren Stadium schon differencirte Epithelien werden natürlich in die Organe am leichtesten gelangen, welche im Embryo ein grosses räumliches Gebiet einnehmen, wie das ja vom Urogenitalsystem bekannt ist; Bonnet ${ }^{3}$ ) hat das schon für die Häufigkeit der genitalen Embryome hervorgehoben. Jedenfalls müssen sie schon im frühen Embryonalleben in die Keimblätter eingelagert werden, von wo sie zuerst in die Primitiv- und später in die Dauerorgane gelangen; es würden also in die Uniere verlagerte Epithelien zunächst in die Geschlechtsleisten und von da zu den bleibenden Genitalien, also Uterus und Ovarium, vor Allem beim Weibe verlagert werden. Dort würden sie latent liegen bleiben, in ihrer Entwicklung gehemmt durch die Sekretionsproducte der normalen Gewebe, bis durch irgendwelchen Reiz diese Sekretion in Wegfall kommt, so dass nun ihrer Weiterentwicklung nichts mehr im Wege steht. Diese geht aber nicht. in den normalen Bahnen vor sich, sondern statt sich zu differenziren und die ihnen noch möglichen Gewebe oder Organe zu bilden, verharren sie auf der niedrigen embryonalen Stufe und machen insofern nur den Gang der Eizelle durch, als sie sich stets weiter theilen und immer wieder ein unfertiges Product mit niedriger Differenzirung aus ihnen entsteht.

Wenn wir also die embryonale Keimausschaltung als die Grundbedingung für das Zustandekommen des Carcinoms ansehen, ein Vorgang, der an und für sich ganz belanglos für die Zukunft des Individuums ist, so wäre das Primäre eine Aenderung der normalen Sekretion und des Stoffwechsels der Gewebe, also ein krankhafter Zustand, welcher der Degeneration der Zellen auf das Nächste verwandt ist. Um nicht falsch verstanden $z$ u werden, meine ich damit nicht die Degeneration der Epithelzellen zu carcinomatösen,

1) Keibl-Roux, Verhandl. a. deutsch. Naturforscher- u. Aerzte-Versamml. Wien 1894.

2) Fioux, Centralbl. f. Pathologie. Bd. 5.

3) Bonnet, Monatsschr. f. Geburtsh. u. Gynäkol. Bd. 13. 
378 Offergeld, Ueber die Histologie der Adenocarcinome im Uterasfundus.

sondern den Fortfall der normalen Gewebssekretion, also die krankhaften Vorgänge in den Geweben, in welche die abgesprengten Zellen hineingelangt sind. Erst secundär würden diese Epithelien, da die normale chemische Hemmung zu ihrem Wachsthum in Wegfall gerathen ist, sich weiter entwickeln und nicht höher differenziren, oder auch nur auf der gleichen Stufe stehen bleiben, sondern durch eine fortgesetzte Theilung bald in ein atypisches Wuchern gerathen. Die enorme Proliferationsenergie ist ihnen, als nur wenig von der befruchteten Eizelle verschieden, durchaus eigen; ihre Plasmafähigkeiten stimmen mit denen des Eies sehr überein, daher ist das schrankenlose Weiterwachsen nur eine von der Eizelle ererbte Fähigkeit, bedingt dadurch, dass die fertig differenzirte Nachbarschaft den nur wenig differenzirten embryonalen Epithelien nicht mehr alle die Momente gewähren kann, deren ein Gewebe zu seiner morphologischen und physiologischen Ausbildung und Stellung unumgänglich bedarf. Es ist ihnen also ihre nachträgliche Differenzirung unmöglich gemacht. Daher werden wir also, da das Primäre eine Art Degeneration versehiedener Gewebe oder auch des ganzen Organismus ist, die Proliferation aber nur als secundärer Vorgang angesprochen werden darf, das Carcinom nicht mehr zu den progressiven Ernährungsstörungen zu rechnen haben, sondern es in die grosse Kategorie der regressiven Vorgänge, zu denen ja die verschiedenen Formen der Degeneration auch gehören, zu rechnen haben.

Ob die anderen Theorien, welche eine Ana- oder Kataplasie vorher normaler, wenigstens histologisch nicht nachweisbar veränderter Epithelien, annehmen, nun in keinem Falle zutreffen, lässt sich sehr schwer entscheiden. Viele Thatsachen, welche scheinbar für diese sprechen, z. B. die maligne Degeneration einer vorher benignen Geschwulst im Sinne der Kliniker, liessen sich auch durch die erweiterte Cohnheim'sche Theorie erklären. Aber es ist immerhin möglich, dass sie für einzelne Falle zutreffen werden, wenn die totale biologische Aenderung des Zellcharakters auch schwer verständlich ist. Wir würden dann mehrere Ursachen für die Entstehung der Carcinome anzusprechen haben, von welchen allen, wie schon erwähnt, die embryonale Keimausschaltung wobl die häufigste sein dürfte.

Wir haben, wie schon früher auseinandergesetzt wurde, dann eine maligne Neubildung im Uteruscavum zu diagnosticiren, wenn bei einem entsprechenden klinischen Verlaufe die Drüsenwucherung 
Offergel d, Uebor die Histologie der Adenocarcinome im Uterusfundus. 379

so excessiv geworden ist, dass das interglanduläre Stromagewebe ganz zurürktritt; selbst dann, wenn die ersten Schnitte rein adenomatösen Bau zeigen, haben wir doch ein Carcinom vor uns, da erfahrungsgemäss sich stets Stellen vorfinden, wo das Epithel Mehrschichtigkeit aufweist. Das Hauptaugenmerk ist aber zu richten auf das Verhältniss der einzelnen Zellen zu einander hinsiehtlich Lage, Grösse, Gestalt und Differenzirungsvermögen den specifischen Plasmafarbstoffen gegenüber, sodann auf die Proportionalität von Zelle und Kern und dessen Verhalten, insbesondere seine karyokinetischen Vorgänge; das Verhalten der Drüsenmembran ist sehr wechselvoll und weniger eindeutig. Ganz besonders ist für gewöhnlich bei den secernirenden malignen Tumoren die kleinzellige Infiltration unendlich viel zahlreicher als bei der glandulären Endometritis, während auch verschiedene Riesenzellen im Gewebe zu erkennen sind. Da aber das Adenocarcinom sehr häufig mit der Endometritis gepaart sich findet, so ist zur Diagnose bei einem Probecurettement stets eine Reihe verschiedener Schnitte, welche aus allen Theilen der Uteruswand entnommen sein müssen, das unbedingte Erforderniss, unter Umständen sogar die Wiederholung dieses Eingriffes, bei vorhandenem sichtbaren Tumor also arn exstirpirten Uterus die Untersuchung verschiedener Stellen auf Serienschnitten.

Es erübrigt, zum Schlusse noch einige Worte über die Metastasenbildung zu sagen. Wenn es einmal den verschleppten Zellen gelungen ist, in den Nachbarorganen festen Fuss zu fassen, so ist das histologische Verhalten der Tochterzellen höchst interessant. Einmal können sie denen des Mutterbodens durchaus gleichen, ein anderes Mal aber auch sehr weitgehende Unterschiede aufweisen. Es ist ja bekannt, dass bisweilen ein centrales Knochensarkom einen secundären Lungenherd von osteosarkomatösem Typus hervorbringt, gerade so, wie bei einem Drüsencarcinom des Magendarmkanales die Knochenmetastasen den Typus eines Adenocarcinoms aufweisen [Hansemann $\left.\left.{ }^{1}\right)\right]$. Es ist jedoch, aus uns noch durchaus unbekannten Gründen auch die Möglichkeit vorhanden, dass in den metastatischen Tumoren die Zellen noch nachträglich eine höhere Differenzirung durchmachen, sie sich also viel freier entwickeln als die des Primärtumors, wie man ja bekanntlich bei einem ein-

1) Hansemann, Die mikroskopische Diagnostik bösartiger Geschwüıste. Berlin 1897/1902. 
380 Offergeld, Ueber die Histologie der Adenocarcinome im Uterusfundus.

fach alveolären Mammacarcinom in den Metastasen neben den typischen Nestern auch vereinzelte freiere Drüsenimitationen antreffen kann. Hansemann ${ }^{1}$ ) hat diese Vorgänge direct als Anaplasie gedeutet, welche er dann weiter für die Aetiologie der Geschwülste verantwortlich machte; diese Ansicht ist die herrschende geblieben, bis Borst2) in überzeugender Weise darlegte, dass man in diesem Vorgang auch ungezwungen die Anpassungsfähigkeit der Geschwulstzellen an veränderte Bedingungen erblicken kann, wie sie ja zweifelsohne ihnen gestellt werden, wenn der Körper schon von einem Carcinom ergriffen ist.

Vergleichen wir nun Tafel V, Fig. 5. Zunächst fällt hier die enorme Proliferation des Epithels auf, welches nicht einfach von der Unterlage abgehoben ist, sondern selbst in das Bindegewebe hineingewuchert ist. Dieses Epithelverhalten ist in der Metastase viel deutlicher ausgeprägt, als im primären Funduscarcinom. Im Allgemeinen zeigen die Zellen der Metastase auch das Bestreben, Drüsenimitationen zu bilden, die im Grossen und Ganzen denen des Primärtumors ähneln; der Uebergang der verschiedenen Epithe]arten in das polymorphe findet ganz unvermittelt statt. Dort, wo der Drüsentypus noch unverfälscht ist, fndet sich die typische Rückenstellung der benachbarten Epithelien, angelehnt an die letzten Reste des interglandulären Stromagewebes; aweh hinsichtich der Existenz von Riesenzellen stimmen beide Tumoren überein.

Und dennoch sind sie in ihrem innersten Wesen sehr unterschieden. Dass der Uebergang des Drüsenkrebses in den gewöhnlichen in der Metastase plötzlich vor sich geht ohne nachweisbare Uebergänge, ist zwar schon auffällig, von viel einschneidenderer Bedeutung aber ist die Aenderung des gesammten Zellcharakters. Während das Funduscarcinom so gut wie gar keine secretorischen Vorgänge erkennen lässt, müssen wir bei dem Ovarialcarcinom diese Fähigkeit des adenocarcnomatösen Epithels in den Vordergrund stellen, zugleich aber auch betonen, dass diesen Secreten eine anormale Kraft innewohnen muss, sie daher dinrect als pathologisch gedeutet werden müssen. Was uns dio Berechtigung verleiht zu dieser Annahme, ist die ungemein zablreiche und gleichmässig durch das ganze Gewebe vertheilte kleinzellige Infiltration, welche für einen entzündlichen Process viel zu reichbaltig ist. Es

1) Hansemann, Virchow's Arch. Bd. 119, 123, 129, 143.

2) Borst, Die Lehre von den Geschwülsten: Wiesbaden 1902. 
würden sich dann in den verschleppten Careinomzellen zwei direct einander entgegengesetzte Vorgänge abgespielt haben. Ein Theil der Zellen hat sich, vielleicht weil gerade im Ovar mit seinem regen Stoffwechsel die Bedingungen hierzu besonders günstig waren, höher differenzirt, als die Cylinderepithelien des primären Uteruscarcinoms, so dass durch eine nachträgliche höhere Ausbildung des Plasmas aus ihm die specifischen Producte eines krankhaften Zelilebens zur Ausscheidung gelangten. Ein anderer dagegen, vielleicht auch die höher differenzirten nach einer gewissen Ausscheidungsperiode, haben nicht nur den Charakter und die Eigenschaften ihres Mutterbodens gewahrt, sondern sind auf die nächst niedrige Stufe des polymorphen Epithels zurückgekommen, welchen nicht nur die Secretion abgeht, sondern dessen Plasma auch keine Andeutung eines secernirenden Theiles erkennen lässt. In letzterem Falle hätten wir unzweifelhaft eine Entdifferenzirung vor uns, da die Zellen ihre zuerst erworbene hohe morphologische Differenzirung und ihre physiologische Arbeitstheilung preisgaben und nach Verlust beider Eigenschaften auf einen niedrigeren Ausgangstypus zurückfielen. Die Ursachen für dieses Verbalten sind uns schleierhaft, wenn ich auch geneigt bin, die abnorme Secretion, also die Producte des krankhaften, jedenfalls nicht physiologischen Zelllebens hierfür zu beschuldigen.

Während der Ovarialtumor als regionäre, auf dem Wege der Lymphbahnen entstandene Metastase aus den früher angeführten Gründen wohl wird mit Recht angesprochen werden müssen, ist der an der Vaginalwand in der Cutis vorhandene als echte hämatogene Secundärgeschwulst, zu bezeichnen. Im Allgemeinen ist ja eine Metastasenbildung eines Uteruscarcinoms eine Seltenheit. Die zwar alte, aber dennoch vortreffliche Statistik von Wagner 1) liefert wohl hierfür den besten Beweis, wenigstens hinsichtlich des Collumearcinoms. Was das des Corpus angeht, so schreibt Winter ${ }^{2}$ ): „Metastasen anderer Organe scheinen nach nicht wesentlich anderen Grundsätzen zu erfolgen, als bei dem des Collum." Denn es kann gar keinem Zweifel unterliegen, dass, wie ich ${ }^{3}$ ) es schon einmal am anderen Orte hervorhob, die Aufstellung von

1) Wagner, Deutsche med. Wochenschr. 1886. Bd. 12.

2) Winter, In Veit's Handbuch der Gynäkologie. Wiesbaden 1899.

3) Offergeld, Hirnmetastasen nach Uteruscarcinom. Monatsschr. für Geburth. u. Gynäk. Bd. 22. 
382 Offergeld, Veber die Histologie der Adenocarcinome im Uterusfundus.

Blau ${ }^{1}$ ), der 50 pCt. Metastasen beim Funduscarcinom herausrechnete, durchaus falsch ist aus verschiedenen Gründen.

Fragen wir nach den Ursachen für die Seltenheit der Generalisirung des Processes durch den Blutstrom beim Carcinom, so ist Borst ${ }^{2}$ ) geneigt, hierfür auf physikalisch-chemische Verhältnisse zurückzugreifen. Die Carcinomzellen als Epithelderivate suchten die dem Blutstrom abgewandte Seite der Ernährungsterritorien auf, da ja auch normaler Weise die Epithelien nie dem Blutstrom direct aufsitzen, im Gegensatz zu den Bindegewebszellen, deren pathologische Abart; die Sarkomzellen, deshalb auch die Blutgefässe zu ihrer Ausbreitung bevorzugten, während die Carcinomzellen in den Lymphbahnen stecken. Letztere durehwachsen das ibnen congeniale Lymphsystem leichter als erstere, da diese einen bindegewebigen Typus aufweisen. Sind nun einmal Carcinomtheile in die Strombahn gelangt, sei es durch den Ductus thoracicus ader directes Einwuchern in die Gefässe, so können die echten Toehtergeschwülste in Nlen Organen entstehen. Die dünne Wand der Capillaren wird sehr schnell durchwachsen und so gelangen die Zellen in die Vene; selten wird sie direct $\nabla$ on aussen durch das Epithel perforirt [Hedinger $\left.{ }^{3}\right)$ ]; um so häufiger aber fndet der Transport durch die nutritiven Gefässehen der Wand statt. Natürlich wird jedes befallene. Gefäss in kurzer Zeit bis zum Abgang der nächsten Collateralbahn thrombosiren in der bekannten Weise; aber noch ehe die Organisation des Thrombus erfolgt ist, haben die carcinomatösen Epithelien Dank des ihnen innewohnenden enormen Proliferationsvermögens das ganze Coagulum durchsetzt; dass auf diese Weise alle Bedingungen zum Losreissen von Partikelchen durch das circulirende Blut gegeben sind, liegt auf der Hand; wir haben also wit der Möglichkeit der Embolie in allen ihren Variationen zu rechnen. Unterstützend wirkt hierbei noch eine Verlangsamung des Stromes, daher die Häufigkeit in Leber, Milz, Knochenmark und Vorengerung der Bahn, wie z. B. in der Niere oder im Gehirn. Und democh, trotzdem die Möglichkeit stets gegeben ist, findet man echte Metastasen beim Funduscarcinom so selten. Dafür kotnmen neben der Grundbedingung, dass die verschleppten Zellen durchaus lebensfrisch und mit

1) Blau, Charité-Annalen. Berlin 1896.

2) Borst, Die Lehre von den Geschwülsten. Wiasbaden 1902.

3) Hedinger, Dissortation. Bern 1900. 
grosser vitaler Energie ausgestattet sein müssen, auch noch andere Momente in Betracht, von welchen zunächst die von Borst I) behaupteten und auch zum Theil durch Experimente bewiesenen Schwankungen des Blutserums hinsichtlich seines Eiweissgebaltes und seiner Fähigkeit, Alexine zu produciren, zu erwähnen sind, welche als eine Art von "Dyskrasie" einmal die Ansiedelung erleichtern, das andere Mal verhindern oder wesentlich erschweren können.

Ferner gehören zu dieser Reihe Wachsthumsstörungen und der in jedem Organe in seiner feinen Abstufung anders geartete Stoffwechsel. Ganz besonders aber muss, wie es Lubarseh ${ }^{2}$ ) überzengend darlegte, die Resorptionsfähigkeit und das Zerstörungsvermögen des ganzen Körpers auf das Eingreifendste geschädigt sein, ehe es zur Metastasirung kommt; denn es ist nicht zu bestreiten, dass trotz Kreisens lebensfähiger Tumorzellen in reicher Anzahl im Blute die Metastasenbildung ausbleibt. Die vornehmste und eingreifendste Schädigung wird weniger durch Krankheiten zu Stande kommen, als hauptsächlich durch die Stoffwechselproducte der carcinomatösen Zellen selbst; diese sind es ja mit an Sicherheit grenzender Wahr-. scheinlichkeit, welchen auch das Hauptwerk an dem Symptomencomplex der Kachexie zufällt. Denn dass die jungen Zellen sehr wenig resistent sind, liegt auf der Hand und wird durch das histologische Bild aufs Eindeutigste gezeigt; sie neigen sehr zu Zerfall und setzen daher die abnormen Eiweisskörper ihres Plasmas in Freibeit, welche von den Leukocyten resorbirt dem gesammten Organismus übermittelt werden, in welchem sie durch Schädigung der Zellen und künstliche Steigerung des Eiweissverbrauches direct giftig wirken. Man sieht also, dass eine Bildung von Tochtergeschwülsten nur erfolgen kann, wenn verschiedene Voraussetzungen und Bedingungen erfüllt sind.

Es sind bisher nur sehr wenige Metastasen beim Adenocarcinom des Fundus beschrieben worden. Gebhard ${ }^{3}$ ) beschreibt einen böchst interessanten Tumor des subperitonealen Fettgewebes an der vorderen Bauchwand bei einem primären Drüsenkrebs im Uteruskörper; die Tochtergesehwulst hatte den Bau des Primär-

1) Borst, Zur Lehre von den Geschwülsten. Wiesbaden. 1902.

2) Lubarsoh, Ergebnisse der allgemeinen und speciellen Pathologie. Bd. I- VI.

3) Gebhard, Pathologische Anatomie der weiblichen Sexualorgane. Leipzig 1899. 
384 Offergeld, Jeber die Histologie der Adenocarcinome im Uterusfundus.

tumors mejsterhaft nachgeahmt auch hinsichtlich der sekretorischen Verhältnisse; daneben waren in der Umgebung zahlreiche Drüsen mit normalem einschichtigen Cylinderepithel, deren Lumen leer war, so dass also in der Metastase neben dem Typus des primären Adenocarcinoms auch der des gesunden Mutterbodens, aus welchem der Krebs hervorgegangen war, anzutreffen gewesen sei. Ob diese Deutung richtig ist, sei dahingestellt. Ich kann mir nicht versagen, nach der Beschreibung des Präparates es als Adenocarcinom anzusprechen mit stellenweise überwiegend einschichtigem Epithel, also fast von adenomatösem Bau, wenn ja auch die Deutung ohne Bilder sehr schwierig ist. Gebhard ist ja, wie schon Eingangs erwähnt, noch Anhänger der alten Fintheilung; welche eine scharfe Trennung zwischen den ein- und mehrschichtiges Epithel führenden Tumoren macht; es ist aber wie gesagt die Möglichkeit vorhanden, dass einzelne Zellen sich freier entwickelten als im primären Tumor und so der Unterschied im Bau sich unschwer erklären lässt, denn es ist nicht recht verständlich, wie sich normale Uterusdrüsen in der Umgebung gefunden haben soltten. Jedenfalls können die doch unmöglich auf metastatischem Wege entstanden sein, weil es unklar bjeibt, wie sie sich haben losreissen könen, und erst recht, warum sif an der fremden Stellen festen Fuss fassten und sich vermehrten.

Getrennt sind hiervon die Metastasen in den distalen Theilen des Genitaltractus zu behandeln, welche man früher als echte Impfmetastasen betrachtete, die aber, um das gleich vorwegzunehmen, nicht durch Spontanimpfung bedingt sind, sondern als regionäre auf lymphogenem oder als echte auf dem Blutwege entstandene Tochtergeschwülste angesprochen. werden müssen. So haben

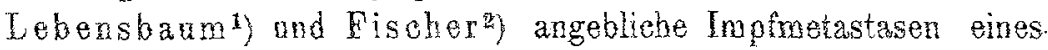
Corpuscarcinoms in der hinteren Vaginalwand beschrieben und Hesse ${ }^{3}$ ) bei einem Drüsenkrebs im Uterusgrunde einen gleich gebauten Tumor am Introitus aul die hintere Scheidenwand übergreifend, genau mitgetheilt. Die genanuten Autoren nehmen hinsichtlich der Entstehung die zuerst von flofmeiers) und Pfannenstiel $^{5}$ geäusserte Ansicht an, welche bekanntlich darauf hinausläuft,

1) Tebeasbaum, Centralbl. f. Gyn, 1893.

2) Fischer, Zeitschr. f. Geburtsh, u. Gyn. Bd. 21.

3) Hesse, Inang.-Diss. Jena 1886.

4) Hoimeier, Münch. med. Wochenschr. 1890.

5) Pranenstiel, Centralbl. f. Gyn. 1893. 
dass durch die Pyometra einzelne Carcinompartikelchen losgerissen und fortgeschwemmt werden, welche sich dann an der hinteren Vaginalwand, wo das eitrige Sekret in Tropfen herunterrinnt und am Introitus, wo eine geringe Stagnation sich stets vorfindet, in dem hyperämischen und succulenten Gewebe festsetzen oder gar direct durch das zähe pyometrische Sekret dort festgeklebt werden soller. Zuerst ist meines Wissens diese etwas gekünstelte Annahme von Kaufmann ${ }^{1}$ ) und später Borst2) stark in Zweifel gezogen worden. Was den vorliegenden Fall angeht, so ist bezüglich der Histologie nichts Neues zu sagen; die Metastase hat den gleichen Bau wie der primäre Herd auch hinsichtlich der sekretorischen Verhältnisse; gerade der charakteristische Schwund des gesammten elastischen Gewebes in der Cutis und Subcutis, besonders in den Wänden der Gefässe weist mit bestimmter Sicherheit auf eine abnorme Production chemischer Natur der adenocarcinomatösen Zellen hin, da wir einen so vollständigen Schwund nur antreffen bei hochgradigen Aenderungen im Chemismus der benachbarten Gewebe; erst recht kann gar keine Rede davon sein, dass er durch das Oedem bei der Verbrennung bewirkt sei; denn in allen Präparaten ist das elastische Element wie ausgelöscht, während doch das collagene Bindegewebe noch als vollkommen unverletzt zu erkennen ist; wir werden daher schon aus diesem Verhalten auf eine ganz abnorme Production zu schliessen haben, die so anders gestaltet ist als das normale Sekret, dass das zwar schon auf geringe Schwankungen im Chemismus empfindlich reagirende elastische Gewebe vollständig dahingeht und unter dem Bilde einer Auflösung zerfällt, bis seine letzte Spur vernichtet ist.

Am interessantesten ist der Befund an einzelnen Stellen in der Gefässwand selbst. Die grösste Mehrzahl der perivasculären Lymphspalten stecken voll von carcinomatösen Zellen, welche sich grösstentheils um ein centrales Lumen gruppirt haben und deutlich ihre sekretorischen Fähigkeiten erkennen lassen, welche der Hauptsache nach in der Production von Schleim besteht. Man erkennt also auch hier wieder das Bestreben der embolisch verschleppten Carcinomzellen, die Eigenschaften der Zellen des primären Herdes in jeder Weise nachzuahmen. Sodann sind aber auch in verschiedenen Vasa vasorum, die sofort auf den ersten Blick durch die

1) Kaufmann, Lebrbuch der spec. pathol. Anatomie. Berlin 1896.

2) Borst; Die Lehre von den Geschwülsten. Wiesbaden 1902. 
386 Offergeld, Ueber die Histologie der Adenocarcinome im Uterusfundus.

Stärke ihrer Wandung sich von den Lymphbahnen unterscheiden, die gleichen Gebilde mit gleichen sekretorischen Eigenthümlichkeiten zu erkennen. Die einzelnen Herde von Carcinom finden sich in allen diesen Präparaten nur in der allerunmittelbarsten Nähe der Gefässe und theilweise in diesen selbst oder auch zwischen den einzelnen das Gefäss bildenden Schichten. Es fragt sich nun, ob diese Befunde sich verwerthen lassen zur Lösung der Frage nach der Entstehungsweise der Tochtergeschwülste in den distalen Partien des Genitaltraktus, wenn in den mehr oben gelegenen Theilen ein Carcinom sitzt. Ganz abgesehen davon, dass die Vorstellung schwer fällt, wie gerade Zellen im Sekret der Pyometra verschleppt noch die Fähigkeiten besitzen sollen, welche ihnen die Localisation im Gewebe and ibre Vermehrung daselbst ermöglichen, wachsen doch für gewöhnlich diese Trmoren aus dem Gewebe heraus nach der freien Oberfläche zu and nicht von ihr in das Gewebe hinein. Ich glaube vielmehr hierin einen weiteren Beweis zu erblicken für die zuerst von Milner ${ }^{1}$ ) für die Metastasirung der Mammacarcinome aufgestellte Behauptung, dass alle diese Hautmetastasen als auf hämatogenem Wege entstanden aufzufassen sind. Für die Entstehung der vaginalen und vulvären Tochtergeschwïlste hat $A m a n n^{2}$ ) auch schon einmal gelegentlich einer Discussion diese Möglichkeit als die wahrscheinlichere hingestellt und die $\mathrm{H}$ ofmeierPfannenstiel'sche Ansicht als zum mindest nicht erwiesen und auch direct unwahrscheinlich bezeichnet.

Nach allen diesen Thatsachen werden wir daher heute mit vollem Recht dio Geschwälste, welche sich bei einem primären Uteruscarcinom in den distalen Partien des uropoetischen Systems vorfinden, als Wetastasen ansprechen dürfen, die sicher theils auf dem Wege der Lymphbahnen als regionäre entstanden sind, zum andern Theil ihren Ursprung yerdanken der Perforation oder Arrosion eines Gefässes durch das Carcinom oder der Verschleppung der Zellen ans dem Lymph- in das Blutgefässsystem; welche daher als echte oder hämatogene aufzufassen sind. Dann, dass wohl in jedem dieser. Fälle im Blute lebensfäbige Carcinomzellen mit enormem Proliferationsvermögen kreisen, geht "am besten daraus hervor, dass gerade die nutritiven Gefässchen in der Wand grösserer

1) Milner, Arch. f. klin. Chirurgie. Bd. 68.

2) Amann, Discussionsbemerkungen zu Klein-Leusewitz. Münoh. gyn. Gesellsch. November 1904. 
oder stärkerer Arterien oder Venen die gleichen Epithelien führen, wie sie sonst in der Metastase vorkommen; diese beziehen aber ihr Blut wieder aus grösseren Gefässen, müssen daher aus diesem auch das embolische Carcinommaterial erhalten. Ob nun die Ansicht von der Spontanimpfung durch das pyometrische Sekret in keinem Falle zutrifft oder vielleicht unterstützend wirkt, ist sehr schwer zu bestimmen; die Möglichkeit lässt sich auch nicht ganz strikte abstreiten, dagegen werden wir als Hauptursache für die Entstehung der secundären carcinomatösen Tumoren der distalen Theilen des weiblichen Genitaltraktus bei bestehendem Uteruscarcinom zu beschuldigen haben neben dem Fortschreiten der Geschwulstzellen auf dem Wege der perivasculären und intramuśculären Lymphbahnen das Kreisen virulenter, proliferationsfähiger Oarcinomepithelien in dem Blutgefässsystem, welches, wenn die früher erwähnten lokalen und allgemeinen Stoffwechselstörungen hinzukommen, die Embolie der Geschwulstblastomere in allen ihren Abstufungen und ihrer Weiterentwicklung in den geschädigten Geweben zur Folge haben wird.

Es würde sich noch erübrigen das Ergebniss dieser Abhandlung in ein paar Sätzen darzulegen. Für das klinische Interesse kommt Folgendes in Betracht.

1. Weder ist in der Häufigkeit und der raschen Aufeinanderfolge von Geburten eine absolute Prädisposition für das Carcinom gegeben, noch schützen entzündliche Veränderungen der Genitalien oder gynäkologische Behandlung sicher vor seinem Entstehen.

2. Auch das Corpuscarcinom ist, wenn eben möglich, durch Laparotomie zu entfernen, da er sehr bäufig schon recht frühzeitig regionäre Drüsenmetastasen oder Carcinomdepots im Ovarium sich finden.

3. Hinsichtlich des klinischen Begriffes der Malignität sind alle Spielarten des Corpuscarcinoms vollständig einander gleich.

Die histologischen Folgerungen fasse ich in Folgendem zusammen:

4. Da auch das "maligne Adenom". an einzelnen Stellen stets mehrschichtiges Epithel aufweist, und sich bei Adenocarcinom auch die Bilder des grossalveolären Carcinoms finden lassen, so können wir bei den Drüsenkrebsen des Uterus wohl von verschiedenen Spielarten reden, aber nicht von eigenen Species innerhalb dieser Gattung. 
388 Offergeld, Ueber die Histologie der Adenocarcinome im Uterusfundus.

5. Auch das Adenocarcinom geht in die Muscularis hinein, wenn auch nicht so tief wie das Carcinoma glandulare simplex.

6. Durch Degenerationsprocesse innerhalb der Nester können sowohl sarkomartige Bilder wie eine pseudoacinöse Zeichnung vorgetäuscht werden.

7. Sehon sehr frühzeitig treten beim Drüsencarcinom Veränderungen im Gewebe auf, welche eine Sonderstellung der Zellen beweisen. Diese sind

a) Degeneration und Tinktionsverlust der Membrana propria, sodann ihr definitiver Schwund.

b) Aenderungen im Epithel:

a) Gräbern in der Formation des Epithels;

$\beta)$ feinste hinsichtlich Färbung und Differenzirung im Plasma. und Kern der Zellen.

c) Abnorm reicher Gehalt an Mitosen mit Ueberwiegen der pathologischen Formen und Riesenzellen.

8. Die Regeneration des carcinomatösen Epithels verläuft insofern irregulär, als selten echte Restitutio ad integrum erfolgt, desto häufiger aber unter Aenderung des gesammten Charakters ein Uebergang in das alveoläre.

9. Eine echte Metaplasie findet unter keinen Umständen statt; ob die rom Deckepithel ausgehenden Carcinome aus metaplasirten Epithelien entstanden sind, ist zweifelhaft.

10. Die maligne Degeneration eines klinisch benignen epithelialen Tumors in ein Carcinom ist nicht nur nicht bewiesen, sondern wegen der Specifität der Zellen auch direct unwahrscheinlich; diese klinisch beobachteten Uebergänge lassen sich auch dureh Annabme zeitlich oder räumlich getrennter Verhältnisse erklären.

11. Die Sekretion der Adenocarcinome erstreckt sich sicher auf Fibrin und Schleim und ist eine sehr rege; mit grösster Wahrscheinlichkeit secernirt es aber auch eine fibrinogene Substanz und albuminoide Körper, welche direct toxisch wirken auf das Gewebe, besonders das elastische Element, die Drüsenkapsel und den Gesammtorganismus (Kachexie).

12. Zur genauen histologischen Diagnose ist stets der ganze Tumor zu untersuchen, oder beim Probecurettement viele Stücke, da sich oft eine gewöhnliche glanduläre Endometritis mit einem 
Offergeld, Ueber die Histologie der Adenocarcinome im Uterusfundus. 389

beginnenden Carcinom der Drüsen paart; unter Umständen ist letztere Operation mehrmals zu wiederholen.

13. Die bei einem primären Corpuscarcinom auftretenden Tochtergeschwülste in den distalen Partien des uropoetischen Systems und Dammes sind als regionäre lymphogene oder echte hämatogene Metastasen zu betrachten, da für die Contact- oder Spontanimpfung der Beweis fehlt.

14. Als Aetiologie kommt die embryonale Keimausschaltung (Cohnheim'sche Theorie) um so eher in Betracht, als die Gewebe wohl im Stande sind, Antitoxine zu produciren, welche abnorm einverleibte Zellen am Weiterwachsen zu hindern vermögen. Wenn durch gewisse Schädlichkeiten, nämlich die gewöhnlich beschuldigten Gelegenheitsursachen, die Alexinbildung vorübergehend oder dauernd aufgehoben wird, können sich die embryonalen Reste weiter entwickeln, müssen es aber in anormaler Richtung besorgen, da die voll differenzirten Gewebe ihnen nicht mehr alle die Faktoren gewähren können, deren Zellen zu ihrer morphologischen und physiologischen Ausbildung bedürfen. Eine Verlagerung von Blastomeren und Zellen ist durch verschiedene Ursachen (Keibl-Roux) sehr leicht möglich; gerade die räumlich grosse Anlage des Urogenitalsystems beim Embryo (Bonnet'sche Theorie) lässt die grosse Häufigkeit des Uteruscarcinoms (10 pCt. aller Carcinome) erklären. Dass auch andere Theorien für die Aetiologie der Carcinome Geltung haben, ist zuzugeben.

15. Demnach wäre das Wesen des Carcinoms ein Vorgang regressiver Art in den Nachbargeweben, vielleicht schon zur Gruppe der Degeneration gehörig, die Proliferation der Zellen nur als Ausdruck ihrer zur Eizelle nächster Verwandtschaft anzusehen, also etwas Secundäres.

Am Schlusse meiner Arbeit ist es mir ein dringendes Bedürfniss, aufrichtigen Dank auszusprechen meinem stets hochverehrten Chef Herrn Geheimrath Prof. Dr. Ritter Franz v. Winkel für die grosse Liebenswürdigkeit, mit welcher er diese Abhandlung vor ihrem Erscheinen durchgelesen hat, und das grosse Interesse, welches er alle Zeit ihr und mir entgegenbrachte. Gleichfalls danke ich verbindlichst Herrn Prof. Dr. Dürck, der sich der mühevollen Arbeit unterzog, meine Präparate kritisch zu durchmustem und mit seinem Rath mich manchmal in Fragen der pathologischen Histologie angelegentlichst unterstützte. 


\section{Erklärung der Abbildungen anf Tafel V.}

Figur I. Wucherung der Drüsenneubildungen gegen das Bindegewebe: Mau sieht oine Menge sternförmiger, stark rameficirter Drüsen, welche in ein noch ziemlich reichhaltiges Stromagewebe mit verhältnissmässig reicher kleinzelliger Infiltration vorgedrungen sind. Es wechselt der invertirende (a) Typus und der evertirende (b) ab. Die Epithelion haben ihre Cylinderform gewaht und sind wahrscheinlich in nur einer Schicht angeordnet. Die Entscheidung ist wegen der Feinheit der Zellen sehr schwierig. Gezeichnet mit Objectiv 3.

Figur II. Psoudoacinöse Zeichnung: In dem deatlich erhaltenen, fibrillären Bindegewebe (a) mit ganz geringer kleinzelliger Infiltration (b) liegen scheinbar 3 Drüsenlumina mit mehrschichtigem Epithel and Seliretionsproducten. Es handolt sich jedoch sicher um Zerfall eines Carcinoma glandalare simplex, am regellose Anhäufung der fipithelien um eine centrale Vacuole. Es fehlt die Membrana propria, die Epithelien sind sebr schlecht tingirt, die Kerne kaum erkennbar. In der mittleren Drüse liegen bei c im Epithelsaum auch 2 lileine Lumina, welche im Begriffe sind, sich zum Centrum eines pseudoacinösen Gebildes zu entwickeln. Gezeichnet mit Objectiy 7. Năheres siehe Fall II im Text.

Figur III. Rundzellensarkomäbnliche Bilder: In Degeneration begriflene Stellen sines. Carcinom erlitten darch den Härtungsprocess eingreifende Veränderungen. Die Alveolen ordnen sioh mascbenartig an, die erkranliten Epithelien, besonders ihre Kerne ähneln sehr denen des Rundzellensarkoms; die Zwischensubstanz diferenzirt sich und tritt doutliob hervor. Gezeichnet mit Objectiv 7. Besebrieben genau im Text unter Fall II:

Sigur IY. Aendarung Im Epithelcharakter in Aer Drise: Das bindegewebige Stroma (a) ist wohl enhalten und hat nur geringe kleinzellige Infiltration (b). Die Membrana propria um die Drüse fehlt. Das hohe, einschichtige Cylinderepitbel verliert bel c znerst seine Pallisadenstellang, die Zellen orduen sich nuregelmässig, so eben, wie der Raum es gestattet; die Kerne werden grósser, und es tritt Mehrzeilung auf bei d. Diese geht im nächsten Stadium in mohrschichtiges Fpithel aber (e). Aber bald daraf trit wieder oine Aenderung im Zellcharalter auf, das Epithel wird oin mehtsohichtiges polymorphes (f); auch die Kerne baben die. Umwandlung mitgemacht, statt der längliohen Form haben sie die runde angenommen. Gezeichnet mit objectiy 7 . Ausführliche Beschreibung im Text bei Fall V.

Figur $\mathrm{Y}$. Ovarialmetastase zu den letaten Fall: In dem bindegewebigen Stroma des Orarium ist stellenweise eine beträohtliche klemuellige Infiztration (a) und in Nestern zusammenliggend nergebildeta Drüsen (0) forn Typus des primären Tumor, Das Innere jst grösstentheils leer, in nur wenigen ist etwas Schleim (o) vorhanden. Das Epithel is polymorph odex cylindrisch mit Uebergängen. In einzeinen grossen Nestern ist neben Carcinombildung auch eine hyaline Hasse (d) zil sehen, Gezeichnet mit Objectiv 3 . Eingehend bei Fall V im Text beschribben.

Figur Y. Mehrzeilige Anordnung der Cylinderepithelien: In einer neugebildeten Drüse ist das hohe Oylinderepithel (a) pallisadenartig angeordnet, and die Kerne sind länglioh und liegen alle peripher in einer Höbe. Bei b 
sind schon einige Kerne höher hinaufgerückt, bei $\mathrm{c}$ ist die Pallisadenform ganz verloren gegangen, die Zellen lagern sich so, wie der Raum es gestattet, die Kerne sind in verschiedener Höhe, sowohl central wie peripher gelagert, aber es tehlt die Mehrschichtigkeit, es stehen keine zwei Zellen aufeinander. Im Bindegewebe etwas stärkere kleinzellige Infiltration (d). Gezeichnet mit Objectiv 7. Weiteres im Text bei Fall VII.

Figur VII. Sekretionsvorgang im Adenocarcinom: Durch nur ganz geringes Zwischengewebe mit Leukocyteninfiltration getrennt (a), liegt Drüse an Drüse, theilweise, wie auch das interglanduläre Stroma etwas Blut (b) durch das Curettement enthaltend. Oben im Bilde ist ein Drüsenausführungsgang angeschnitten, welcher, wohl durch Hypersekretion bedingt, ganz niederes, plattes Epithel (c) führt. Im Lumen ist Schleim (d) in reichlicher Menge vor$\mathrm{h}$ anden, welcher durch den Härtungsprocess geschrumpft ist und so künstljch den Hohlraum (e) bildet. Ueber das Ganze hinweg zieht ein Saum von Plattenepithel (f). Gezeichnet mit Objectiv 7. Beschrieben im Text beim XII. Fall.

Figur VIIIa. Aenderung im Epithelcharakter nach einer Abrasio: Anstossend an ein bindegewebiges Stroma (a), liegen Nester (b), getrennt durch etwas Zwischensubstanz, welche sich als die Reste der Drüsen erweisen. Das Cylinderepithel ist vollkommen geschwunden, die Regenerationsvorgänge in diesen Schnitten nicht deutlich zu erkennen. Der Epithelbelag ist jetzt ein wirr durcheinander gelagertes, polymorphes Epithel, dessen Kerne zwar allenfalls noch zu erlennen sind, dessen Plasma sich aber gar nicht mehr differenzirt hat, und wo die Zellgrenzen selbst nur sehr schlecht noch zu erkennen sind. Das Lumen der Drüsen ist leer, die Zwischensubstanz an einzelnen Stellen (-c) stark gewuchert. Färbung in abnormer Weise mit Karmin. Gezeichnet mit Objectiv 7. Ausführlich sind diese Verbältnisse in Fall XII beschrieben; es stellt ein weiteres Stadium der letzten Zeichnung dar.

Figur VIIIb. Regenerationsvorgänge: Das Gewebe hat weniger gelitten, das Bindegewebe hat nicht die Ergänzung des Defectes besorgt, sondern der Epitheldefect ist durch gleichartige Zellen gedeckt. Das Epithel ist polymorph, ganz aus der Reihe gewichen (a), theils finden sich abnorm grosse, blasse Zellen (b), theils ganz kleine polyedrische, welche als solider Strang in das Innere wuchern (c). Mitosen durchweg pathologisch auf diesem Bilde (d). Die Zellkerne sind noch deutlich erkennbar. Die Regeneration ist hier vollendet, aber der ganze Zellcharakter hat sich geändert; abnormer Weise sind die Zellen mit Karmin gefärbt. Gezeichnet mit Vergrösserung 7. Genauer beschrieben bei Fall XII.

Figur IX. Orientirungsbild: Durch nur spärliches Bindegewebe mit etwas kleinzelliger Infiltration getrennt (a), liegt Drüse an Drüse. Diese haben eine durchaus polymorphe Gestalt (b); das Epithel ist ein niedriges, einschichtiges Cylinderepithel, welches da, wo zwei Drüsen aneinander stossen, die typische dos à dos-Stellung aufweist (c). Das Lumen ist leer, nur künstlich sind einige Drüsen mit Blut angefüllt (d). In der Hauptsache ist es ein Adenom. Gezeichnet mit Objectiv 3. Genaueres im Text bei Fall XIII.

Figur X. Pathologische Mitosen: Durch ganz spärliches interglanduläres Bindegewebe mit typischen fixen Zellen (a) und weissen Blutkörperchen (b), welche eingewandert sind, getrennt, stossen zwei Drüsen aneinander. Der 
392 Offergeld, Ueber die Histologie der Adenocarcinome im Uterusfundus.

Epithelbelag ist durchgehends ein zweischichtiges, ziemlich hohes Cylinderopithel (c) mit gut ausgebildeten ovalen, gut tingirten Kernen, welche auch angedeutet die Rücken an Rücken-Stellung aufweisen (d). Plötzlich geht boi e das Cylinderepithel in mehrschichtiges, polymorphes mit rundlichen Zellen über. Das zweischichtige Gylinderepithel weist eine unipolare (f) und zwei multipolare (g) Mitosen auf. Gezeichnet mit Leitz: Oelimmersion 1/12* Ausführliche Beschreibung im Text bei Fall XIII.

Figur XI. Vorgang bei der Metastasenbildung: In der ganzen Peripherie des schräggeschnittenen Blutgefässes sind die perivasculären Lymphbahnen (a) und theils auch die nutritiven Gefässchen (b) der Arterienwand angefüllt mit Carcinomzellen (c), welche an einzelnen Stellen durch Gruppirung um ein centrales Lumen (d) und Sekretion ron Schleim (e) den adenomatösen Typus imitiren. Das Gefäss selbst ist abliterirt, die freien Vasa vasorum strotzend mit Blat gefüllt (f). Gezeichnet mit Fergrösserung $\bar{\gamma}$. Beschrieben genauer im XV. Foll bei der Metastasenbildung. 